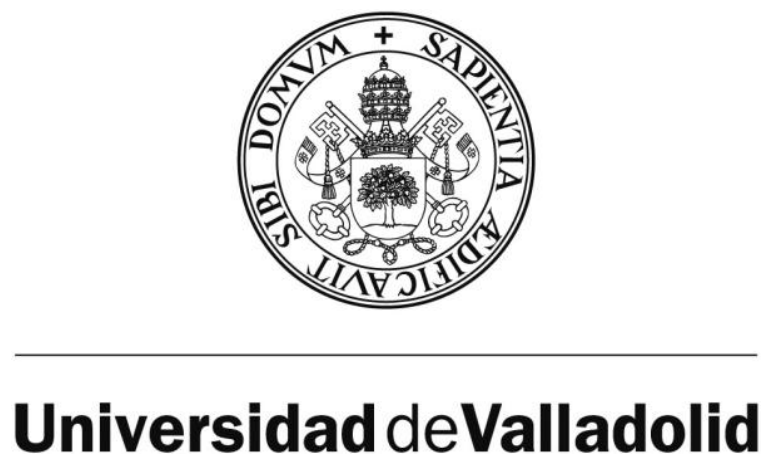

\author{
Facultad de Medicina \\ Departamento de Biología Celular, Histología y \\ Farmacología
}

Rasgos de personalidad e impulsividad en pacientes con migraña episódica y crónica. Influencia en la gravedad y respuesta al tratamiento

Presentada por Irene Muñoz León para optar al grado de

Doctora por la Universidad de Valladolid

Dirigida por:

Vicente Molina Rodríguez

Ma Luz Cuadrado Pérez 
A mis padres y a Goyo 
No podemos prescindir de las personas que se atreven a pensar cosas nuevas antes de ser capaces de demostrarlas SIGMUND FREUD 


\section{AGRADECIMIENTOS}

Al Dr. Ángel Luis Guerrero Peral, por ser mi mentor, mi guía y sobre todo mi amigo.

Al Dr. Vicente Molina Rodríguez, por todos los conocimientos que me ha transmitido y por el apoyo que siempre me ha brindado. Por su rigor científico y su profesionalidad. Sin él esta tesis no hubiera sido posible.

Al Dr. Fernando Uribe Ladrón de Cegama, que corrigió mi primer resumen y otros que siguieron, por todo el tiempo que me dedicó durante mi residencia y por la confianza que depositó en mí en el inicio de mi etapa profesional.

A la Dra. M M $^{a}$ Luz Cuadrado Pérez, por haber estado dispuesta a ayudarme en las dificultades que se me han presentado en la realización de este trabajo y por la relación tan especial que ha surgido con esta tesis doctoral.

A la Dra. Ma Nieves López Fernández, que siempre ha sabido aconsejarme y ha estado a mi lado para lo que pudiera necesitar.

A la Dra. Françoise Gorog, que me tendió la mano para trabajar en París y que nunca la retiró. Por recibirme en el Hospital Sainte-Anne de París y enseñarme otra forma de hacer clínica.

A los coautores por haber dedicado parte de su tiempo a este proyecto, en especial a Helena y Marta por haber consolidado el equipo de investigación al que pertenecemos y sobre todo por su comprensión, cariño y amistad.

Al equipo de Hospital de Día, por apoyarme en mi primera etapa de Médico Adjunto. Por su ilusión, compañerismo y profesionalidad. 
A mi grupo de teatro, por todos los momentos que hemos compartido, las risas, los nervios, los planes a última hora y los bolos en Toro.

A mis amigos, en especial a Marian D., Mariate G., Sofía C., Sonia R., Isabel A., Elvira R., Sandra C. y Patricia M., por su apoyo incondicional desde siempre y para siempre.

A mis residentes mayores, Isabel L. Saracho y Daniel G. Pizarro, que me enseñaron la psicopatología. Gracias por ese curso de Rorschach en Madrid que, a pesar del esfuerzo, completamos satisfactoriamente. Siempre recordaré Berlín.

Gracias al equipo del Lado Oeste, Ana N, Sergio G, José Q, Alicia A, Isabel R., por las carcajadas y los abrazos, en especial a mi gallega Beatriz F., gran profesional y amiga.

A mis padres. A ellos les debo todo, desde mi primera tabla de multiplicar hasta la última línea de esta tesis. Me dieron su tiempo, me llenaron de sueños y estuvieron a mi lado para que yo los pudiera conseguir.

A Goyo, mi compañero de viaje. Ni siquiera la geografía pudo separarnos. El amor todo lo puede. Gracias por verme con los ojos con los que me miras y estar siempre ahí. 


\section{ORGANIZACIÓN DE LA TESIS}

De acuerdo con el R.D. 1393/2007, de 29 de octubre, por el que se regulan las enseñanzas oficiales de doctorado, la Comisión de Doctorado y Posgrado de la Universidad de Valladolid establece como posible formato de presentación de Tesis Doctoral, la modalidad de Tesis por Compendio de Artículos/Publicaciones. La presente Tesis Doctoral se presenta en Esta modalidad.

Las publicaciones incluidas en este compendio son:

1. RASGOS DE PERSONALIDAD EN PACIENTES MIGRAÑOSOS: ESTUDIO MULTICÉNTRICO UTILIZANDO EL CUESTIONARIO DE CRIBADO SALAMANCA.

I Muñoz ${ }^{1}$, E Toribio ${ }^{2}$, FJ Carod-Artal ${ }^{3}$, ML Peñas $^{4}$, L Ruiz $^{5}$, E Domínguez ${ }^{1}$, MI Pedraza $^{6}$, V Molina ${ }^{1}$, AL Guerrero ${ }^{6}$, F Uribe ${ }^{1}$. Revista de Neurología. 2013. 57(12):529-34.

1. Servicio de Psiquiatría. Hospital Clínico Universitario de Valladolid

2. Servicio de Neurologia. Hospital Universitario del Henares, Coslada, Madrid

3. Servicio de Neurología, Hospital de Raigmore, Inverness, Reino Unido

4. Sección de Neurología. Hospital Virgen de la Concha, Zamora

5. Servicio de Neurología. Hospital de Parapléjicos de Toledo

6. Servicio de Neurología. Hospital Clínico Universitario de Valladolid

2. IMPULSIVIDAD EN PACIENTES MIGRAÑOSOS: ESTUDIO EN UNA SERIE DE 155 CASOS.

I Muñoz ${ }^{1}$, MS Hernández ${ }^{1}$, MI Pedraza ${ }^{2}$, E Domínguez ${ }^{1}$, M Ruiz $^{2}$, G Isidro ${ }^{1}$, E Mayor $^{1}$, EM Sotelo ${ }^{1}$, V Molina ${ }^{1}$, AL Guerrero ${ }^{1}$, F Uribe ${ }^{1}$. Neurología. 2014. DOI: 10.1016/j.nrl.2014.10.006.

1. Servicio de Psiquiatría. Hospital Clínico Universitario de Valladolid

2. Servicio de Neurología. Hospital Clínico Universitario de Valladolid 
3. RASGOS DE PERSONALIDAD EN MIGRAÑA CRÓNICA: ESTUDIO CATEGORIAL Y DIMENSIONAL EN UNA SERIE DE 30 PACIENTES.

I Muñoz ${ }^{1}$ E Domínguez ${ }^{1}$, MS Hernández ${ }^{1}$, M Ruiz $^{2}$, G Isidro ${ }^{1}$, E Mayor ${ }^{1}$, EM Sotelo ${ }^{1}$, V Molina ${ }^{1}$, F Uribe $^{1}$, AL Guerrero ${ }^{2}$. Revista de Neurología (en prensa).

1. Servicio de Psiquiatría. Hospital Clínico Universitario de Valladolid

2. Servicio de Neurología. Hospital Clínico Universitario de Valladolid 


\section{ABREVIATURAS}

CIC Clasificación Internacional de las Cefaleas

CIC-II Clasificación Internacional de las Cefaleas, segunda edición

CIC-IIR Clasificación Internacional de las Cefaleas, segunda edición, revisada

CIC-3 beta Clasificación Internacional de las Cefaleas, tercera edición, versión beta

CIE-10 Clasificación Internacional de Enfermedades, décima versión

DE Desviación estándar

DSM-IV Diagnostic and Statistical Manual of Mental Disorders, fourth edition

IC Intervalo de confianza

IHS International Headache Society

HADS Escala Hospitalaria de Ansiedad y Depresión

HIT-6 Headache Impact Test-6

MC Migraña crónica

ME Migraña episódica

MMPI-2 Minnesota Multiphasic Personality Inventory-2

NS No significativo

OMS Organización Mundial de la Salud

OR Odds ratio

SPSS Statistical Package of the Social Sciences

TCI Temperament and Character Inventory

UEM Uso excesivo de medicación 


\section{ÍN DICE}

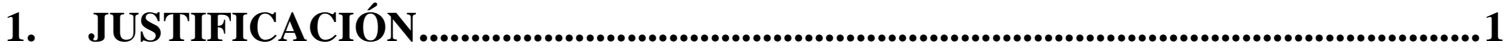

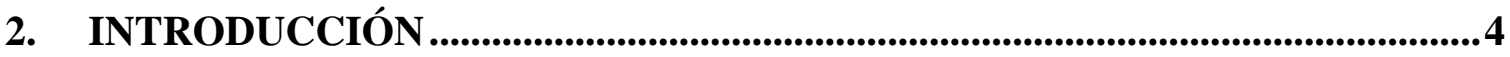

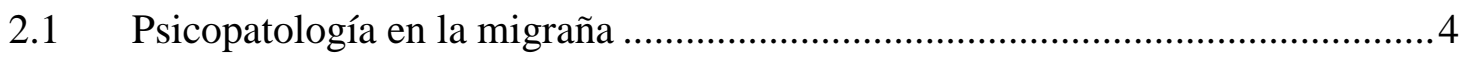

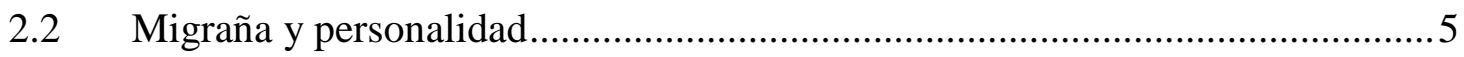

2.2.1 Evaluación dimensional de la personalidad en la migraña..........................6

2.2.2 Evaluación categorial de la personalidad en la migraña................................ 7

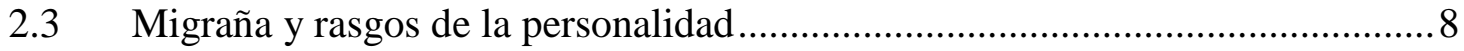

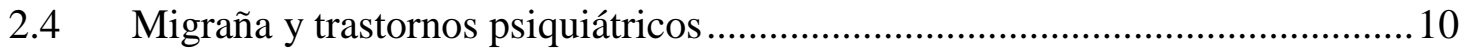

2.4.1 Migraña y trastorno depresivo ............................................................... 10

2.4.2 Migraña y trastorno de ansiedad............................................................ 10

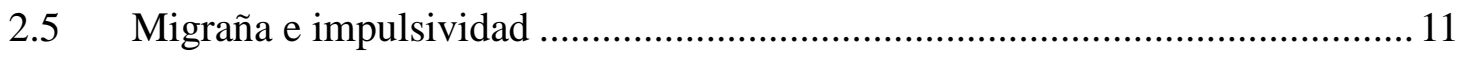

2.6 Influencia de los rasgos de personalidad e impulsividad en el tratamiento

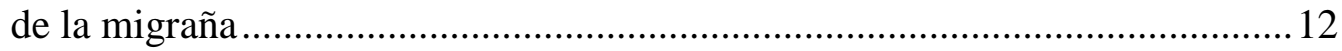

2.7 Limitaciones metodológicas del análisis de la personalidad en la migraña

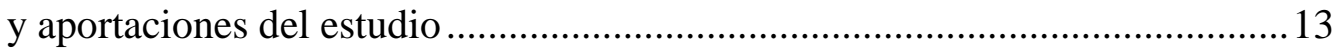

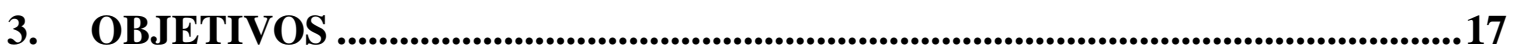

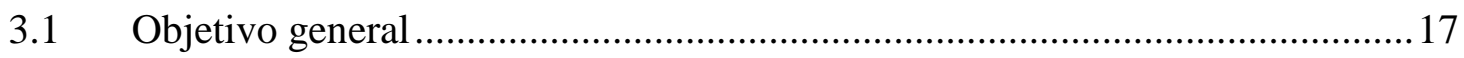

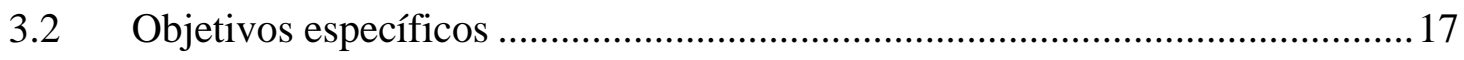

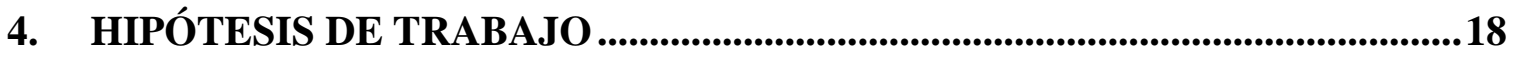

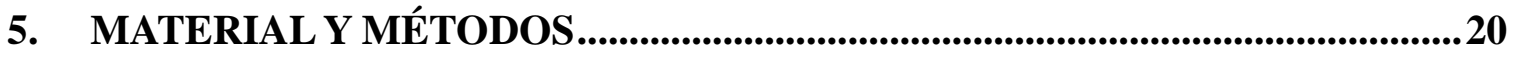

5.1 Primera fase del proyecto: Estudio de rasgos de personalidad en pacientes

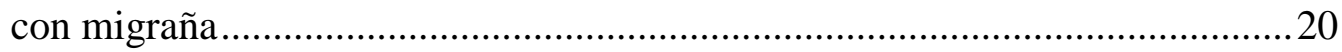

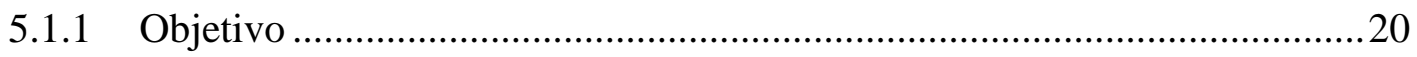

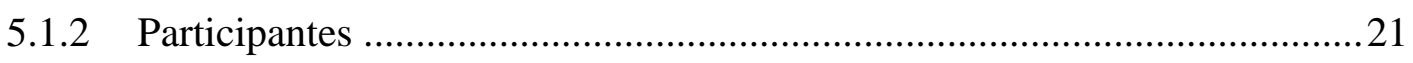

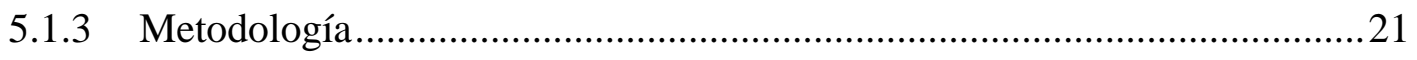

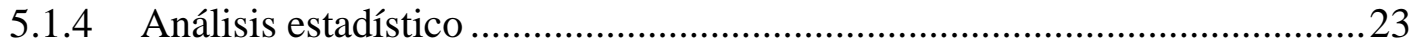

5.2 Segunda fase del proyecto: Estudio de impulsividad en pacientes con

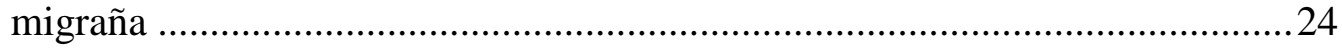

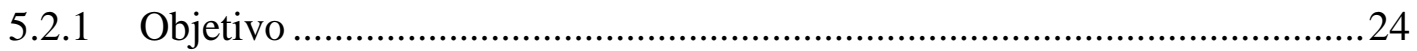




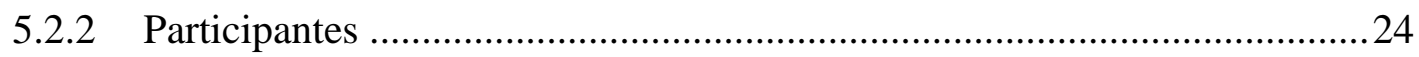

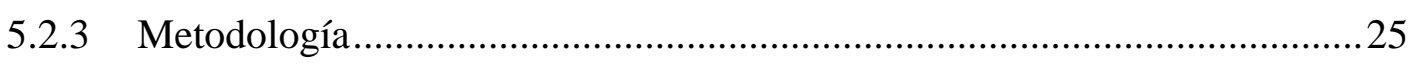

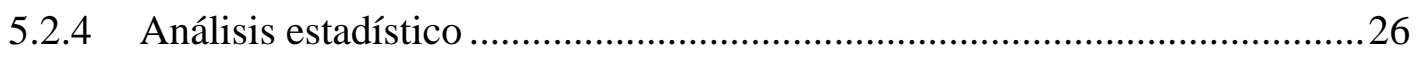

5.3 Tercera fase del proyecto: Evaluación categorial y dimensional de la personalidad en pacientes con migraña crónica.............................................26

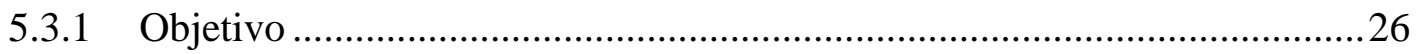

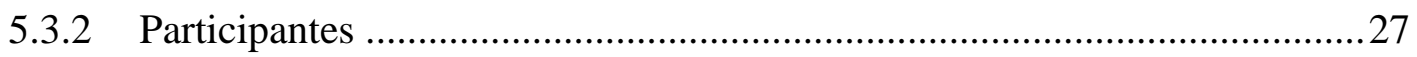

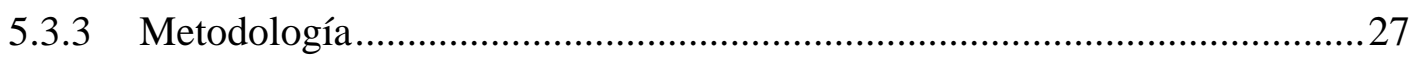

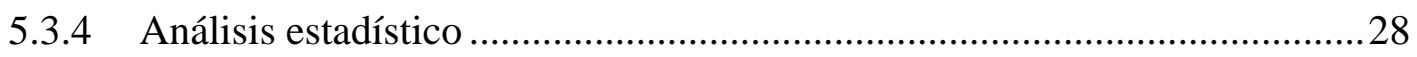

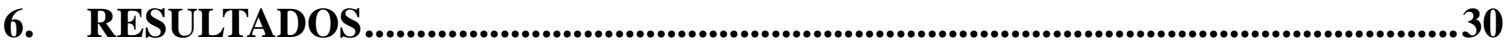

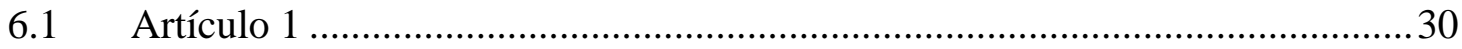

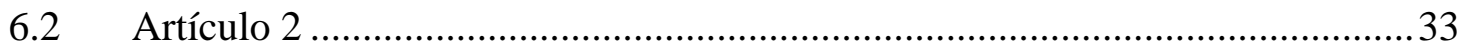

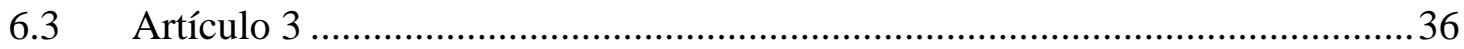

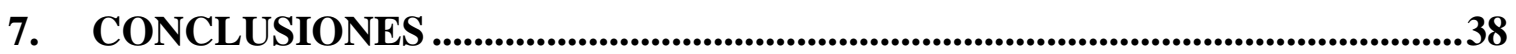

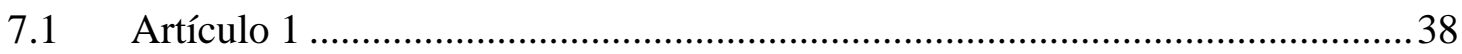

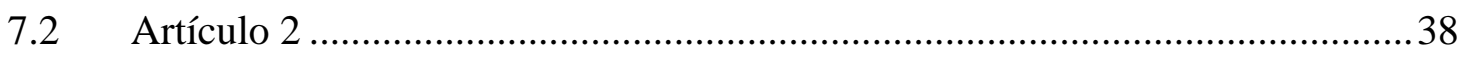

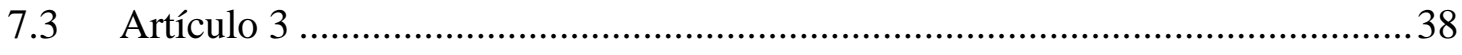

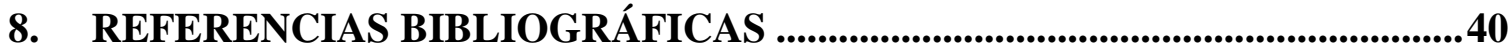

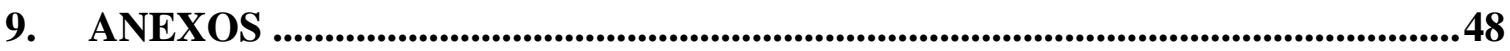

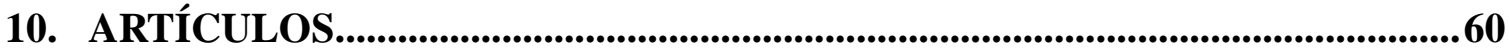




\section{JUSTIFICACIÓN}

La Organización Mundial de la Salud (OMS) ha identificado la migraña como un problema mayor de Salud Pública dada su alta prevalencia (Jette et al, 2008). Afecta, de acuerdo con la práctica totalidad de estudios llevados a cabo, a más del $10 \%$ de la población (alrededor del 7\% en varones y el 16\% en mujeres) (Manzoni y Stovner, 2011). Además de ser una causa importante de discapacidad, la migraña tiene gran impacto socioeconómico (Lipton et al, 2001; Berg y Stovner, 2005). En España la prevalencia de migraña en adultos oscila entre el 11 y el 13\% (Fernández de Las Peñas et al, 2010; Matías-Guiu et al, 2011).

Desde mediados del siglo XX ha habido un interés creciente por el análisis de las características de personalidad en los pacientes con migraña, y se ha observado que estas características pueden influir en el curso clínico de la enfermedad (Rasmussen et al, 1992). Se ha demostrado que los pacientes con migraña presentan un estilo de afrontamiento al dolor específico, que se observa de manera repetida, así como una mayor vulnerabilidad al estrés y una mayor tendencia a la somatización que los sujetos no migrañosos. Además se ha observado que estos rasgos de la personalidad pueden repercutir en la respuesta al tratamiento (Di Piero et al, 2001).

Estas conclusiones se han extraído, en la mayor parte de los casos, de los resultados obtenidos de evaluaciones dimensionales de la personalidad. Por ejemplo el Eysenk Personality Questionnaire mostró que los pacientes migrañosos poseen un alto grado de neuroticismo e introversión (Cao et al, 2002).

El Minnesota Multiphasic Personality Inventory-2 (MMPI-2) es un cuestionario capaz de evaluar el grado de neuroticismo en individuos mediante tres de sus diez escalas (hipocondría, depresión e histeria). Estas tres escalas configuran la triada neurótica, y aparecen sistemáticamente elevadas en los pacientes con migraña (Mongini et al, 2000). 
También se ha descrito a los pacientes con migraña como personas con escasa tolerancia a la frustración. Tres estudios que utilizaron el Temperament and Character Inventory, que hace referencia al modelo desarrollado por Cloninger para evaluar personalidad en pacientes con migraña, encontraron puntuaciones superiores en la dimensión "Evitación del daño" en los pacientes migrañosos que en un grupo control (Abbate-Daga et al, 2007; Mongini et al, 2005; Sánchez-Román et al, 2007; Cloninger et al, 1993). La dimensión psicológica "Evitación del daño" se caracteriza por inhibición conductual, excesivo miedo/preocupación, pesimismo e introversión, y estas características muestran ciertas similitudes con el neuroticismo.

El paciente con migraña que presenta puntuaciones más altas en los rasgos ansiosos u obsesivos de la personalidad (Mongini et al, 2003) y que algunos autores han denominado "el paciente con migraña y personalidad difícil" no suele responder al tratamiento preventivo o sintomático estándar de forma satisfactoria (Bigal et al, 2003). En este tipo de pacientes se ha denominado pain panic al miedo exacerbado a las crisis de migraña asociado a la búsqueda anticipada y compulsiva de medicación infravalorando sus consecuencias (Curone et al, 2011).

En lo que respecta a la dosis de medicación analgésica, los pacientes con migraña y rasgo obsesivo-compulsivo de la personalidad son pacientes que en la mayor parte de los casos no mejoran con la dosis pautada por el neurólogo, lo que desemboca en un consumo de dosis de medicación mayor a la dosis prescrita (Curone et al, 2011). De este consumo excesivo y anticipado de medicación suele derivarse una refractariedad al tratamiento habitual y una cronificación de la migraña (Curone et al, 2012). Por ello algunos autores afirman que los pacientes con migraña y este tipo de rasgos de personalidad representan un importante porcentaje de migrañas refractarias al tratamiento convencional (Saper et al, 2006; Hedborg et al, 2011).

Por tanto, podemos proponer que los pacientes con migraña y personalidad premórbida con importantes características neuróticas, entendida como una personalidad con importante inestabilidad emocional y altos niveles de ansiedad y preocupación, suelen 
presentar un mal manejo del dolor (Mongini et al, 2000; Bigal et al, 2003). Esto puede repercutir en la eficacia del tratamiento antimigrañoso habitual y, por consiguiente, influir en el pronóstico de la migraña, por ejemplo cronificándola (Bigal et al, 2008). Proponemos, además, que la evaluación de la personalidad de los pacientes con migraña es una estrategia útil y necesaria para detectar a aquellos pacientes en los que existe riesgo de fracaso del tratamiento habitual y en los que se deben plantearse alternativas terapéuticas. 


\section{INTRODUCCIÓN}

\subsection{Psicopatología en la migraña}

El rol de la psicopatología en la génesis, evolución y exacerbación de la migraña ha motivado la puesta en marcha de numerosos estudios en las últimas décadas. En estos trabajos los investigadores y clínicos se han planteado si los factores psicopatológicos son determinantes en el inicio y mantenimiento de la migraña o, por el contrario, son consecuencia de la propia migraña

A comienzos del siglo $\mathrm{XX}$ se realizaron estudios fundamentalmente descriptivos acerca de las características psicológicas más frecuentes en pacientes con migraña. Wolff evaluó durante más de 25 años a pacientes con migraña que no habían recibido tratamiento psiquiátrico. Su objetivo era intentar esclarecer la psicopatología implicada en la aparición y posterior progresión de la migraña. En el año 1937 propuso la definición de una "personalidad migrañosa", caracterizada por un perfil obsesivo y rígido encontrado repetidamente en pacientes con migraña. En palabras del propio Wolff:

"Personality features and reactions dominant in individuals with migraine... feelings of insecurity with tension manifested as inflexibility, conscientiousness, perfectionism, meticulousness and resentment" (Wolff, 1937).

(Características de personalidad y reacciones que predominan en individuos con migraña... sentimientos de inseguridad con tensión que se ponen de manifiesto con inflexibilidad, perfeccionismo, meticulosidad y resentimiento)

Otros autores del siglo XX señalaron cómo estos pacientes a menudo presentaban apatía, falta de energía, ansiedad, depresión y fatiga (Moersch et al,1924). Algunas hipótesis sobre el origen de la migraña apuntaban a que las alteraciones psicopatológicas podían constituir uno de los factores etiológicos de esta enfermedad. 
Así, Liveing y colaboradores sugirieron que las alteraciones emocionales eran la tercera causa de la migraña (Liveing et al, 1978). Argumentaron a favor de posibles desencadenantes como la excitación, el placer excesivo, las preocupaciones o la fatiga. Además, hicieron referencia a su mayor prevalencia en el sexo femenino, puntualizando que los hombres que la padecían eran delicados o vulnerables.

\subsection{Migraña y personalidad}

Actualmente algunos de los estudios que analizan psicopatología en la migraña persiguen definir perfiles de personalidad de los pacientes migrañosos mediante una evaluación dimensional que no sólo sirva para caracterizar a estos pacientes, sino que los diferencie de otros individuos que no tengan dolor o que presenten otro tipo de cefalea (Hedborg et al, 2011; Huber y Henrich, 2003). Las características de personalidad de los pacientes con migraña pueden complicar su manejo y dificultar el tratamiento de los trastornos afectivos y de ansiedad en caso de que se presenten, lo que es frecuente en estos pacientes (Radat et al, 2004; Saper y Lake, 2002). En otras palabras, las características de la personalidad contribuyen en buena medida a la refractariedad de la migraña al tratamiento (Rothrock et al, 2007).

Abbate-Daga y colaboradores analizaron la personalidad de 105 pacientes con migraña mediante el Temperament and Character Inventory (TCI) y la compararon con un grupo control de 79 sujetos. El TCI mostró perfiles de personalidad en el grupo de los pacientes diferentes a los del grupo control. Los pacientes con migraña presentaban rasgos ansiosos y obsesivos, tendían a comportarse de una forma insegura y eran más vulnerables ante el estrés (Abbate-Daga et al, 2007). También se ha observado la asociación de la migraña con determinadas características de la personalidad, como la tendencia al hipercontrol, la evitación, la rigidez y la obsesividad (Mateos et al, 2011).

La personalidad puede ser evaluada con sistemas de medida tanto dimensionales como categóricos. 


\subsubsection{Evaluación dimensional de la personalidad en la migraña}

El modelo dimensional define un continuum de los rasgos de la personalidad desde la "normalidad" a sus expresiones claramente patológicas (desadaptativas) en el que se pueden ordenar los individuos (Henry et al, 2000). La característica principal del modelo dimensional es que todas las variantes de la personalidad, tanto "normales" como desadaptativas, se imbrican imperceptiblemente (López-Ibor et al, 2002). Es decir, que se trata de un modelo donde todas las posibles combinaciones son tenidas en cuenta y que, por tanto, puede considerarse un modelo muy completo a la hora de evaluar la personalidad.

La evaluación dimensional de la personalidad puede realizarse con instrumentos de medida en forma de cuestionarios. Cada cuestionario identifica unas dimensiones fundamentales de la personalidad, que son puntuadas en función de unos criterios designados. La valoración de la personalidad tiene en cuenta los antecedentes étnicos, culturales y sociales del individuo. Los criterios son debidamente diferenciados por sexos y baremados mediante tablas de puntuaciones típicas normalizadas. En función de la puntuación recogida el test detecta, en el caso de existir, una desviación de la normalidad en cada una de estas dimensiones de la personalidad respecto a la base normativa establecida.

La mayor parte de los trabajos que han investigado la personalidad de los pacientes con migraña mediante cuestionarios de análisis dimensional de la personalidad ampliamente aceptados, como el Temperament and Character Inventory (TCI), han señalado una mayor presentación de síntomas somáticos en respuesta a la ansiedad (Abbate-Daga et al, 2007; Mongini et al, 2005; Sánchez-Román et al, 2007). Por otra parte, la aplicación del Zuckerman-Khulman's o Eysenk Personality Questionnaire ha demostrado que los pacientes migrañosos poseen un alto grado de neuroticismo e introversión (Cao et al, 2002). Del mismo modo, los trabajos que han empleado el Minnesota Multiphasic Personality Inventory, 2 (MMPI-2) como instrumento de medida han demostrado que los pacientes con migraña presentan puntuaciones elevadas en las escalas Hipocondría, 
Depresión e Histeria de conversión, que conforman la triada neurótica (Mongini et al, 2003; Bigal et al, 2003). También se ha descrito una configuración típica "conversiva V" -con elevación en las puntuaciones de las escalas Hipocondría e Histeria, siendo inferior la puntuación de la escala Depresión en las mujeres con migraña (Mongini et al, 2009).

Un estudio prospectivo de pacientes con migraña crónica demostró que las puntuaciones mayores en las escalas que conforman la triada neurótica al inicio del registro se asociaban a un pronóstico desfavorable de la migraña, independientemente del grado de discapacidad, la gravedad, la frecuencia o la duración de los episodios de migraña (Luconi et al, 2007).

\subsubsection{Evaluación categorial de la personalidad en la migraña}

Como ya hemos mencionado, la evaluación de la personalidad también puede llevarse a cabo mediante un enfoque categorial. La evaluación de la personalidad desde un punto de vista categorial persigue el diagnóstico de los diferentes trastornos de personalidad tal y como se recogen en las clasificaciones DSM-IV (Diagnostic and Statistical Manual of Mental Disorders, cuarta edición) y CIE-10 (Clasificación Internacional de Enfermedades, décima versión).

Como ocurre con la evaluación dimensional, la evaluación categorial de la personalidad puede ser realizada mediante cuestionarios. Los cuestionarios de cribado permiten en un primer momento detectar desviaciones de la normalidad en determinados rasgos de personalidad, que orientan al clínico, siendo éste quien determina finalmente si existe o no un trastorno de la personalidad.

Las clasificaciones DSM-IV y CIE-10 consideran los rasgos de personalidad como patrones persistentes de formas de percibir, relacionarse y pensar sobre el entorno y sobre uno mismo (López-Ibor et al, 2002). Sólo constituyen trastornos de personalidad cuando se vuelven inflexibles y desadaptativos o cuando causan deterioro funcional 
significativo o malestar subjetivo. Sin embargo, también permiten clasificar los rasgos de personalidad desadaptativos específicos que no llegan a traspasar el umbral para algún trastorno de personalidad (López-Ibor et al, 2002). Estos son los rasgos o características de personalidad que nos interesa detectar y analizar en los pacientes con migraña. Aun sin representar verdaderos trastornos de la personalidad, estos rasgos diferenciales pueden constituir desviaciones de la normalidad con repercusión en el curso clínico de la migraña.

\subsection{Migraña y rasgos de la personalidad}

Existen rasgos o características de personalidad relacionados con patrones de afrontamiento al dolor que parecen complicar el manejo de la migraña. Se encuentran en pacientes con mayor susceptibilidad al estrés, en los cuales el tratamiento preventivo estándar de la migraña suele resultar infructuoso.

Por ejemplo, se ha relacionado el rasgo obsesivo-compulsivo o anancástico con el riesgo de presentar migraña crónica. Radat y colaboradores demostraron que los pacientes con migraña y rasgo obsesivo-compulsivo o anancástico de la personalidad solían presentar comportamientos compulsivos de toma de fármacos, y que este sobreuso de medicación se asociaba con una cronificación de la migraña (Radat et al, 2005).

Existen diferentes estudios que apoyan este razonamiento. Así, por ejemplo, Curone y colaboradores (2012) explican que el rasgo anancástico de la personalidad en pacientes con migraña se asocia al sobreuso de medicación, que a su vez representa un factor de refractariedad al tratamiento preventivo en la migraña. Por tanto, este rasgo de personalidad supone un riesgo de transformación de la migraña episódica en crónica (Curone et al, 2012; Lipton et al, 2009). En otros dos estudios se concluye que una conducta compulsiva en la toma de medicación, es decir un consumo rápido y escalonado, representa un riesgo mayor de sobreuso de medicación en pacientes con migraña. Estos trabajos demuestran que el rasgo obsesivo-compulsivo o anancástico de 
la personalidad puede promover este tipo de conductas compulsivas, interfiriendo en la respuesta a los tratamientos preventivos de la migraña (Curone et al, 2011; Cupini et al, 2009).

En uno de sus últimos y más interesantes estudios, Curone y colaboradores han analizado la influencia del rasgo obsesivo-compulsivo de la personalidad en pacientes con migraña en el tratamiento de depresión comórbida, confirmándose los hallazgos de estudios previos. Este trabajo muestra que tanto la frecuencia de ataques de migraña como el sobreuso de medicación disminuyen en los pacientes con migraña crónica y depresión cuando se trata la depresión comórbida con un antidepresivo (duloxetina). Sin embargo, los pacientes en los cuales coexisten rasgos obsesivo-compulsivos de personalidad no ven reducida la frecuencia de sus ataques de migraña ni limitado su sobreuso de medicación (Curone et al, 2013). De este estudio puede deducirse que el rasgo obsesivo-compulsivo influye directamente en la respuesta al tratamiento de la depresión comórbida en pacientes con sobreuso de medicación y migraña crónica. De lo expuesto, podemos deducir que el uso excesivo de medicación sintomática asociado a dichas características de la personalidad influye en la respuesta a los tratamientos preventivos y, por ende, en el curso clínico de la migraña, desembocando en muchas ocasiones en la cronificación de la misma.

Por tanto, hay al menos dos razones por las que las características de la personalidad susceptibles de influir en la migraña deben ser detectadas y, si es posible, abordadas. En primer lugar, para que no interfieran en la respuesta a la medicación preventiva o sintomática. En segundo lugar, para que no alteren la respuesta al tratamiento de trastornos psiquiátricos comórbidos, como la depresión. Precisamente, los trastornos psiquiátricos son los trastornos comórbidos más frecuentes en los pacientes con migraña (Sheftell et al., 2002; Hamelsky y Lipton, 2006). 


\subsection{Migraña y trastornos psiquiátricos}

La comorbilidad psiquiátrica en migraña es frecuente (Jette et al, 2008; Antonaci et al, 2011) y se encuentra cada vez mejor documentada, especialmente en lo que se refiere al trastorno de depresión mayor y al espectro de los trastornos de ansiedad (Merikangas et al, 1993). Estos trastornos se han relacionado con una peor respuesta al tratamiento farmacológico estándar, uso excesivo de medicación y cronificación de la migraña (Breslau et al, 2003).

\subsubsection{Migraña y trastorno depresivo}

Se ha demostrado que la comorbilidad entre depresión y migraña actúa de manera bidireccional (Breslau et al, 2000; Breslau et al, 2003). Destacan dos artículos de revisión publicados recientemente.

Uno de los artículos muestra un metaanálisis de 12 estudios diferentes. En él se expresa el riesgo estimado de padecer depresión en personas con migraña respecto de los que no presentan migraña, hallado mediante las odds ratio (OR) de cada uno de los 12 estudios, con una OR de 2,2 y con un intervalo de confianza del 95\% de 2,0-2,3 (Antonaci et al, 2011).

En el otro artículo, se revisan estudios epidemiológicos de cohortes prospectivos de poblaciones no seleccionadas con el objetivo de hallar una inferencia causal mayor. La conclusión es que los pacientes con migraña presentan 2,2 a 4 veces más riesgo de presentar una depresión (Hamelsky y Lipton, 2006).

\subsubsection{Migraña y trastorno de ansiedad}

La comorbilidad entre trastornos de ansiedad y migraña también actúa de forma bidireccional (Breslau et al, 2003). La asociación hallada entre migraña y trastornos de ansiedad es aún mayor que entre la depresión y la migraña (Zwart et al, 2003). 
En el artículo de revisión ya citado en el epígrafe anterior se analiza también esta comorbilidad, siendo la OR entre migraña y trastorno de ansiedad generalizada de 3,5 a 5,3 (Hamelsky y Lipton, 2006).

De acuerdo con otro estudio prospectivo poblacional reciente, los sujetos con migraña presentan más frecuentemente trastornos de ansiedad que la población control (OR: 3,8 95\%; IC: 2,5-6). Según este trabajo el 9\% de los pacientes con migraña tienen trastornos de ansiedad (McWilliams et al, 2004). En la mayor parte de las ocasiones se manifiesta mediante fobia social, pero también son frecuentes los trastornos de ansiedad generalizada y los trastornos de pánico (Stewart et al, 1994).

\subsection{Migraña e impulsividad}

Como hemos expuesto, existen características de la personalidad que deben evaluarse en pacientes con migraña, ya que pueden promover una tendencia al uso excesivo de medicación sintomática y, a su vez, disminuir la respuesta a la medicación preventiva (Zwart et al, 2004). Nos preguntamos si la personalidad impulsiva, que se expresa en forma de conductas rápidas provocadas por un bajo umbral de paso a la acción donde se subestiman las consecuencias, puede representar un riesgo de sobreuso de medicación (Bigal y Lipton, 2006).

La impulsividad es una dimensión psicológica no estudiada en profundidad en pacientes con migraña. Se han formulado diferentes teorías acerca de la naturaleza de la impulsividad, pero hay varias coincidencias entre los distintos autores, que se detallan a continuación. Un comportamiento impulsivo responde casi siempre a tres mecanismos subyacentes: la alta sensibilidad a las recompensas, la actuación inmediata sin planificación, y el comportamiento compulsivo en busca de alivio ante la tensión o el estrés (Billieux et al, 2010; Smith et al, 2007; Lipton et al, 2009). En un paciente con migraña, la impulsividad podría ser el origen de una anticipación ansiosa del dolor en sí mismo y de una pérdida de control sobre el consumo de fármacos, lo que llevaría a un uso excesivo de medicación sintomática por parte del paciente. 
Si el sobreuso de medicación supone uno de los riesgos principales para la cronificación de la migraña y la impulsividad cognitiva representa un riesgo para el sobreuso de medicación, entonces la impulsividad podría suponer un riesgo para la cronificación de la migraña. La impulsividad cognitiva debería, en ese caso, ser detectada y tratada ya que puede complicar el tratamiento y pronóstico de la migraña. El despistaje de rasgos impulsivos puede proporcionar al clínico información que le permita elegir entre diferentes opciones de tratamiento en cada uno de sus pacientes. Este es uno de los objetivos específicos de este trabajo.

\subsection{Influencia de los rasgos de personalidad e impulsividad en el tratamiento de la migraña}

El objetivo del estudio de la personalidad en pacientes con migraña es determinar si existen rasgos o características de la personalidad que puedan influir en la respuesta al tratamiento habitual de la migraña y de qué manera, lo que permitirá diseñar estrategias de tratamiento.

El primer punto a destacar es que la existencia de determinadas características de la personalidad susceptibles de influir en la migraña no depende de la gravedad ni de la frecuencia de la misma (Luconi et al, 2007). Este punto confirma que existen características de la personalidad que pueden alterar el curso clínico de la migraña y que actúan como componentes fundamentales de la misma. Luconi y colaboradores demostraron que el grado en el que estas características de la personalidad se desvía de la normalidad, a pesar de no ser patológicas por definición, afecta proporcionalmente la respuesta al tratamiento. A pesar de que el rol patogénico de la personalidad en la migraña aún no ha sido definido, puede afirmarse que determinadas características de la personalidad pueden influir en el curso clínico de la migraña y empeorar el pronóstico de la misma (Luconi et al, 2007).

Por ejemplo, como ya se ha constatado, el rasgo obsesivo-compulsivo de la personalidad se ha relacionado con un miedo desmesurado a sufrir nuevos episodios 
dolorosos, que se traduce en un consumo anticipado y excesivo de medicación sintomática. Dependiendo de que el uso excesivo de medicación sintomática por parte del paciente con migraña responda a la necesidad del alivio de un dolor progresivamente creciente, o a acompañantes comportamentales, el tratamiento debería ser diferente. Así, en el primer caso valdría con la búsqueda del fármaco preventivo más eficaz para cada paciente, mientras que la eficacia de estos fármacos probablemente sería menor en el segundo grupo, haciéndose necesario un abordaje multidisciplinar que incluyera la actuación psicológica sobre estos determinantes. Esta distinción permitiría un triage de estos pacientes y el desarrollo de estrategias de tratamiento más efectivas.

Por tanto, la evaluación psicológica puede proporcionar información privilegiada que permita al clínico escoger entre diferentes opciones de tratamiento en función de la presencia o ausencia de determinadas características de personalidad. La personalidad debería evaluarse de forma sistemática en los pacientes con migraña o, al menos, en los pacientes más refractarios.

\subsection{Limitaciones metodológicas del análisis de la personalidad en la migraña y aportaciones del estudio}

La investigación de la personalidad en la migraña supone analizar la influencia de variables heterogéneas y difícilmente cuantificables. Detallamos a continuación diferentes limitaciones metodológicas que han podido dificultar el diseño de protocolos y la obtención de resultados concluyentes. El artículo de revisión que publicaron Silberstein, Lipton y Breslau en 1995 ilustra las dificultades que presentaron los estudios del siglo XX.

En primer lugar, muchos de los estudios se llevaron a cabo en centros especializados. La muestra no representaba a aquellos que, estando diagnosticados, no acudieron a este tipo de centros ni a aquellos que no fueron diagnosticados porque no llegaron a acudir a ningún otro médico. Podríamos por tanto presumir que sólo se evaluaron los pacientes 
con mayor preocupación por su estado de salud y con mayores niveles de ansiedad en relación con el manejo de su enfermedad, lo que supone un sesgo de selección.

Otro problema de muchos estudios que se han centrado en analizar la personalidad de los pacientes con migraña es que no recogían dentro de sus protocolos de investigación la detección de trastornos psiquiátricos comórbidos a la migraña. Por consiguiente, estos estudios no pueden discriminar si las características de personalidad halladas estaban asociadas a la migraña o a la psicopatología acompañante, en particular al trastorno de depresión mayor o de ansiedad, muy prevalentes en este tipo de pacientes.

Por otro lado, ni la migraña ni los trastornos psiquiátricos tienen marcadores diagnósticos definitivos. El diagnóstico de estas entidades se basa en los criterios clínicos admitidos y recogidos en las clasificaciones oficiales: la Clasificación Internacional de las Cefaleas (CIC) en el caso de la migraña y el DSM en el caso de los trastornos psiquiátricos. Estas dos clasificaciones incluyen series de criterios politéticos, en las cuales sólo se necesita presentar unos pocos síntomas de la amplia lista general. Esto supone que las personas con un mismo trastorno son heterogéneas porque cada una de ellas puede presentar síntomas diferentes dentro de la lista proporcionada por la clasificación. Es esperable, por tanto, que los casos de migraña o de trastorno psiquiátrico sean heterogéneos de un estudio a otro.

Tampoco podemos olvidar que los criterios diagnósticos reseñados han sido modificados a lo largo de los años. Por ejemplo, la primera versión de los criterios de la International Headache Society (IHS), en uso hasta 2004, no incluía dentro de la clasificación la definición de ciertas formas de migraña, como la migraña crónica (Lipton et al, 2009).

Si nos centramos en los instrumentos de medida utilizados para la evaluación de la personalidad en pacientes con migraña, la principal dificultad deriva de que las características de personalidad pueden ser evaluadas con sistemas de medida tanto dimensionales como categoriales. No existe acuerdo acerca del abordaje más adecuado. 
El análisis dimensional de la personalidad ha sido el más usado a lo largo de los años, ya que es capaz de detectar de una forma más precisa diferencias entre individuos. A pesar de ello presenta no pocos inconvenientes. Uno de los inconvenientes del análisis dimensional de la personalidad en pacientes con migraña es que, incluso cuando los protocolos de investigación de los diferentes estudios utilizan el mismo instrumento de medida, los resultados son difícilmente comparables entre sí debido a su heterogeneidad.

Por otro lado, las versiones de los manuales diagnósticos en psiquiatría y psicología utilizadas en nuestro estudio, DSM-IV y CIE-10, que fueron concebidas para aumentar la fiabilidad entre profesionales en la práctica diagnóstica, usan criterios categóricos. De ello deriva la dificultad para correlacionar los resultados de las escalas dimensionales con los rasgos desadaptativos específicos de la personalidad, tal y como se recogen en los manuales DSM-IV y CIE-10, lo que representa otra de las limitaciones del análisis dimensional de la personalidad. Además, los instrumentos de medida dimensionales de la personalidad consumen una gran cantidad de tiempo y son difíciles de interpretar sin entrenamiento previo. Esto no ocurre con los instrumentos de medida categoriales, que son más fáciles de utilizar y que se pueden aplicar en un corto periodo de tiempo.

El enfoque categorial permite detectar rasgos desadaptativos específicos de personalidad sin detenerse en descripciones de la personalidad, adecuándose a los criterios recogidos en los manuales diagnósticos de los trastornos mentales. Este tipo de sistema permite una recogida de datos breve y de interpretación sencilla. Por otro lado, su adecuación a los criterios recogidos en manuales diagnósticos facilita un trabajo colaborativo entre neurólogo y psiquiatra. Pretendemos demostrar que este sistema de medida no sólo es adecuado sino que es preferible para evaluar la personalidad en pacientes con migraña en una consulta de neurología.

No obstante, y a pesar de que prevemos que utilizar un instrumento de medida categorial optimizará la recogida e interpretación de los datos, no podemos olvidar que los sistemas de medida dimensionales han sido los más utilizados para analizar la 
personalidad de pacientes con migraña y esto dificultará la comparación con estudios previos. En la literatura no existen trabajos que hayan comparado ambos sistemas de medida en una misma muestra de pacientes con migraña, de modo que no podemos saber si existe correlación entre las escalas de los instrumentos categoriales y dimensionales.

Contar con estos dos enfoques complementarios en el análisis de la personalidad en una misma muestra de pacientes con migraña ofrece varias ventajas. En primer lugar, permitirá validar los resultados obtenidos con el instrumento de medida categorial gracias al otro instrumento de medida dimensional, de modo que en investigaciones sucesivas podamos comparar los resultados obtenidos con los de este estudio, ya validados. En segundo lugar supondrá un análisis de la personalidad más completo, que permita a la vez describir la personalidad de una forma más detallada, gracias al instrumento de medida dimensional, y a la vez clasificarla en categorías, gracias al instrumento de medida categorial. Evaluar la personalidad mediante dos instrumentos de medida categorial y dimensional y comparar los resultados obtenidos en una misma muestra de pacientes con migraña constituye otro de los objetivos principales de este trabajo. 


\section{OBJETIVOS}

\subsection{Objetivo general}

Evaluar rasgos de personalidad e impulsividad cognitiva en pacientes con migraña y determinar si existe relación entre su presencia y una mayor tendencia al uso excesivo de medicación o la existencia de migraña crónica. Validar los resultados obtenidos comparando características de personalidad a la vez de forma dimensional y categorial en una misma muestra de pacientes con migraña crónica.

\subsection{Objetivos específicos}

1. Evaluar la presencia de diferentes rasgos de personalidad en pacientes con migraña, utilizando para ello el Cuestionario Salamanca de trastornos de personalidad. Estudiar la relación entre estos rasgos de personalidad y la existencia de migraña crónica con y sin abuso de medicación.

2. Evaluar la impulsividad en diferentes situaciones clínicas de migraña y determinar si existe relación entre la presencia de esta dimensión de la personalidad y una mayor tendencia al uso excesivo de medicación sintomática o la evolución a una migraña crónica.

3. Comparar la personalidad de pacientes con migraña crónica mediante dos test diferentes: uno de tipo categorial, de nuevo el test de cribado Salamanca, y otro de tipo dimensional, el MMPI-2. Validar los resultados obtenidos con estudios previos en este campo que utilicen los mismos sistemas de medida y analizar si los resultados obtenidos mediante estos dos sistemas de medida diferentes pueden correlacionarse. 


\section{HIPÓTESIS DE TRABAJO}

1. Se detectarán rasgos de personalidad alterados en pacientes con migraña.

a. Los rasgos de personalidad encontrados serán comparables a los resultados obtenidos en estudios previos llevados a cabo en este campo.

b. La presentación de rasgo obsesivo-compulsivo o anancástico de la personalidad supondrá un riesgo superior de migraña crónica.

2. Los pacientes con migraña presentarán criterios de impulsividad en una proporción importante.

a. Existirá asociación entre impulsividad y migraña crónica.

b. Existirá asociación entre impulsividad y uso excesivo de medicación sintomática.

3. Existirá una fuerte asociación entre los trastornos del estado del ánimo y de ansiedad, por un lado, y la migraña de tipo crónico y el uso excesivo de medicación sintomática, por otro.

4. Los pacientes con migraña crónica presentarán un tipo de personalidad característica.

a. La evaluación dimensional de la personalidad pondrá de manifiesto un alto grado de neuroticismo. El MMPI-2 señalará un perfil de personalidad caracterizado por puntuaciones elevadas en las escalas de Hipocondría (Hs), Depresión (D) e Histeria (Hy), que conforman la triada neurótica.

b. La medida de la personalidad de forma categorial detectará una mayor frecuencia de los rasgos de personalidad recogidos dentro del grupo C. El rasgo 
de personalidad más prevalente será el rasgo obsesivo-compulsivo de personalidad.

c. Las características de personalidad evaluadas mediante sistema dimensional y los rasgos de personalidad evaluados mediante sistema categorial serán comparables. El cuestionario Salamanca de personalidad será capaz de detectar alteraciones en la personalidad de los pacientes migrañosos similares a las que detecta el MMPI-2.

d. Las características de personalidad evaluadas mediante el sistema dimensional y los rasgos de personalidad evaluados mediante el sistema categorial serán congruentes con los resultados de estudios previos. 


\section{MATERIAL Y MÉTODOS}

\subsection{Primera fase del proyecto: Estudio de rasgos de personalidad en pacientes con migraña}

\subsubsection{Objetivo}

El objetivo inicial de este proyecto es definir características de personalidad en términos operativos que permitan llevar a cabo un trabajo colaborativo entre neurólogo y psiquiatra. Por ello consideramos clínicamente más relevante estudiar rasgos de personalidad cualitativamente distintos. Este enfoque categorial permite detectar perfiles de personalidad anormales sin detenerse en descripciones de la personalidad desde un punto de vista dimensional.

Los rasgos de personalidad están clasificados en tres grupos diferentes: A, "extraños o extravagantes" (paranoide, esquizoide, esquizotípico); B, "inmaduros" (histriónico, antisocial, narcisista, trastorno de la inestabilidad emocional con sus dos subtipos) y C, "temerosos" (anancástico, ansioso y dependiente).

Pretendemos identificar rasgos de personalidad en pacientes migrañosos y relacionarlos con las características clínicas de la migraña. Utilizaremos para ello el Cuestionario Salamanca de Trastornos de Personalidad, un test de screening diseñado para el cribado de 11 trastornos de la personalidad, agrupados en 3 grupos, mediante 22 sencillas preguntas (según nomenclatura DSM-IV-TR: paranoide, esquizoide, esquizotípico, histriónico, antisocial, narcisista y dependiente; según nomenclatura CIE-10: trastorno de inestabilidad emocional subtipo impulsivo, trastorno de inestabilidad emocional subtipo límite, anancástico y ansioso). 


\subsubsection{Participantes}

Se reclutaron pacientes atendidos consecutivamente por migraña en las consultas ambulatorias de cinco centros hospitalarios diferentes. En cuatro de ellos (Coslada, Cuenca, Toledo y Zamora), en consultas generales de neurología, y en uno (Valladolid), en una consulta monográfica de cefaleas. La migraña se diagnosticó de acuerdo con los criterios de la Clasificación Internacional de Cefaleas, segunda edición (CIC-II, 2004, Anexo I). El diagnóstico de migraña crónica (Anexo II) y sobreuso de medicación (Anexo III) se llevó a cabo de acuerdo con los criterios revisados de la CIC-II del 2006 (CIC-IIR). Se obtuvo consentimiento informado previo a la inclusión de los pacientes en el estudio. La investigación fue aprobada por el Comité Ético de Investigación Clínica de cada centro. Se excluyeron aquellos pacientes con alteraciones físicas o psicológicas que pudieran limitar su capacidad para responder el cuestionario. Ninguno de los pacientes fue evaluado durante un episodio agudo de migraña. Se recogieron las características demográficas (edad y sexo) de cada caso.

\subsubsection{Metodología}

En todos los pacientes se aplicaron las siguientes escalas y cuestionarios: el Headache Impact Test-6 (HIT-6), la Escala de Ansiedad y Depresión Hospitalaria (HADS) y el Cuestionario de Salamanca.

\section{Headache Impact Test-6 (HIT-6, Anexo VI)}

Permite evaluar el grado de discapacidad producido por la migraña (Kosinski et al, 2003; Yang et al, 2011). Es un test específico, breve y autoaplicado. Establece cuatro categorías de discapacidad en función de la puntuación: grave ( $\geq 60$ ), moderada (56-59), leve (50-55) y ausente $(\leq 49)$. 


\section{Cuestionario de Salamanca (Anexo VII)}

Es un test de screening validado que permite una detección precoz de rasgos de personalidad. Esto es fundamental en la evaluación de rasgos de personalidad. Determinados perfiles de personalidad poseen características muy sutiles que pasan desapercibidas si no se exploran de manera directa y exhaustiva. El cuestionario de Salamanca detecta rasgos de personalidad con una alta sensibilidad. Clasifica los rasgos de personalidad desde un punto de vista categorial. Este cuestionario es autoaplicado, de corta duración (< 10 minutos) y fácil interpretación.

Fue validado en 2007 y se correlacionó con el International Personality Disorder Examination, considerándose un adecuado test de cribado, con una sensibilidad del 100\% y una especificidad del 76,3\% (Caldero-Alonso A, 2009). Clasifica los rasgos de personalidad desde un punto de vista categorial y los define según la nomenclatura del DSM-IV, texto revisado (paranoide, esquizoide, esquizotípico, histriónico, antisocial, narcisista y dependiente) o según la nomenclatura de la Clasificación Internacional de Enfermedades, décima revisión (CIE-10) (inestabilidad emocional subtipo impulsivo, inestabilidad emocional subtipo límite, anancástico y ansioso). Los 11 rasgos se agrupan en tres grupos diferentes (Tabla 1). El Cuestionario Salamanca consta de 22 preguntas; cada uno de los 11 rasgos de personalidad se evalúa utilizando dos preguntas. Cada pregunta tiene cuatro posibilidades de respuesta, que puntúan de 0 a 3 . La suma de las dos preguntas tiene como valor máximo 6 puntos, y se establece la puntuación de corte para rasgo de personalidad en 3.

Escala hospitalaria de Ansiedad y Depresión (HADS, Anexo VIII)

Se trata de un instrumento de cribado que permite la detección de trastornos depresivos y ansiosos (Zigmond y Snaith, 1983). En el caso de hallarse una puntuación positiva en el test, el diagnóstico definitivo deberá ser realizado por el clínico. Es un test autoaplicado. El marco de referencia temporal es la semana previa. Está adaptada y validada al español. Se compone de 14 ítems agrupados en dos subescalas: de ansiedad 
y depresión. El punto de corte establecido para cada una de las subescalas es de 10. El HADS es especialmente útil para pacientes migrañosos, ya que ninguno de los 14 ítems hace referencia a síntomas somáticos, lo que elimina el riesgo de realizar una sobreestimación de psicopatología derivada de la interpretación de síntomas físicos relacionados con la migraña como secundarios a ansiedad o depresión.

Tabla 1. Rasgos de personalidad evaluados en el Cuestionario Salamanca

\begin{tabular}{|l|l|l|}
\hline $\begin{array}{l}\text { GRUPO A } \\
\text { Extraños, extravagantes }\end{array}$ & $\begin{array}{l}\text { GRUPO B } \\
\text { Inmaduros }\end{array}$ & $\begin{array}{l}\text { GRUPO C } \\
\text { Temerosos }\end{array}$ \\
\hline Paranoide & Antisocial & Anancástico \\
Esquizoide & Narcisista & Dependiente \\
Esquizotípico & Histriónico & Ansioso \\
& $\begin{array}{l}\text { Inestabilidad emocional } \\
\text { subtipo Límite } \\
\text { Inestabilidad emocional } \\
\text { subtipo Impulsivo }\end{array}$ & \\
\hline
\end{tabular}

\subsubsection{Análisis estadístico}

Las variables cuantitativas se presentan con su media y desviación estándar (DE) y las variables cualitativas se muestran como porcentajes. La distribución normal de los datos se verificó mediante la prueba de Kolmogorov-Smirnov. Se utilizó la prueba t de Student para analizar las diferencias de las variables cuantitativas. Por otro lado, se empleó el test de $\chi^{2}$ para analizar las diferencias de distribución de las variables cualitativas entre los pacientes con presencia o ausencia de cada uno de los rasgos de personalidad evaluados. Las variables cualitativas se presentan con sus porcentajes y las variables cuantitativas se expresan con su media y su DE. Se rechazaron las hipótesis 
nulas planteadas con un error alfa menor al permitido (establecido en 0,05). Todos los cálculos se llevaron a cabo con la versión 15.0 del programa estadístico SPSS.

\subsection{Segunda fase del proyecto: Estudio de impulsividad en pacientes con migraña}

\subsubsection{Objetivo}

Pretendemos evaluar la impulsividad en diferentes situaciones clínicas de migraña (episódica y crónica) y determinar si existe relación entre la presencia de esta dimensión de la personalidad y una mayor tendencia al abuso de medicación sintomática o la evolución a una migraña crónica. De ser así, la impulsividad podría actuar como factor predictivo de refractariedad al tratamiento en la migraña crónica, ya que representa un riesgo para el sobreuso de medicación.

\subsubsection{Participantes}

La población a estudio se reclutó entre los pacientes que acudieron consecutivamente a una unidad de cefalea de un hospital terciario con migraña y migraña crónica a lo largo de 15 meses. El diagnóstico de migraña y migraña crónica fue realizado de acuerdo a los criterios diagnósticos de la Clasificación Internacional de Cefaleas, tercera edición, versión beta (CIC-3 beta, Anexo I y IV respectivamente). Se obtuvo consentimiento informado previo a la inclusión de los pacientes en el estudio. La investigación fue aprobada por el Comité Ético de Investigación Clínica de nuestro centro. Se excluyeron aquellos pacientes con algún trastorno médico o psiquiátrico, no incluido dentro de los trastornos del estado del ánimo o de ansiedad, o bien un déficit intelectual que pudiera limitar su capacidad para entender o contestar a las preguntas de los cuestionarios. También se excluyeron a los pacientes que acudieron con un episodio de migraña agudo. 
Se recogieron prospectivamente las características sociodemográficas y el tiempo transcurrido en años desde el inicio de la migraña. Asimismo, registramos el número de días de cefalea durante el mes previo.

Se registraron los antecedentes psiquiátricos, los hábitos tóxicos, el uso excesivo de medicación y el uso durante los meses previos de medicación psiquiátrica o profilaxis antimigrañosa. El uso excesivo de medicación sintomática se diagnosticado de acuerdo con los criterios de la CIC-3 beta (Anexo V).

\subsubsection{Metodología}

El instrumento utilizado para la evaluación de las conductas impulsivas fue la Escala de Impulsividad de Plutchik (Plutchik Impulsivity Scale, PIS). Se aplicaron también el Headache Impact Test-6 (HIT-6) y la e Escala hospitalaria de Ansiedad y Depresión (HADS).

\section{Escala de Impulsividad de Plutchik (Anexo IX)}

Es un test autoaplicado, diseñado para evaluar conductas impulsivas (Rubio et al, 1998). Se trata de una herramienta de cribado validada al español, de fácil interpretación y corta duración (entre 2 y 5 minutos). Consta de 15 ítems que se refieren a la tendencia del paciente a "hacer cosas sin pensar" o de forma impulsiva. Todos ellos se relacionan con una posible falta de control sobre determinadas conductas englobadas en la capacidad para planificar (3 ítems), control de los estados emocionales (3 ítems), control de las conductas de comer, gastar dinero o mantener relaciones sexuales (3 ítems) y control de otras conductas (6 ítems). Las respuestas se recogen en una escala de frecuencia que se puntúa de 0 a 3 (nunca, a veces, a menudo, casi siempre). Los ítems 4, 6, 11 y 15 se puntúan en sentido inverso. La puntación total se obtiene sumando todos los ítems y oscila entre 0 y 45 . En la versión española los autores proponen un punto de corte de 20, con una sensibilidad del 60\% y una especificidad del 74\%. La consistencia interna de la escala de acuerdo al coeficiente de fiabilidad alfa de Cronbach fue 0,9 y la fiabilidad test-pretest por el coeficiente de correlación de Pearson 0,91. 


\subsubsection{Análisis estadístico}

Las variables cualitativas se presentan como porcentajes y las variables cuantitativas se resumen con su media y su DE. Se compararon las características demográficas, clínicas, así como los valores de las diferentes escalas, o la existencia según ellas de depresión, ansiedad o impulsividad entre los grupos de migraña episódica y crónica. Posteriormente se llevó a cabo esta comparación dentro de los pacientes con migraña crónica, clasificando a aquellos con y sin uso excesivo de medicación. Para analizar las diferencias entre grupos, se utilizó la prueba t de Student en el caso de variables cuantitativas y el test de $\chi^{2}$ para las variables cualitativas. La distribución normal de los datos se verificó mediante la prueba de Kolmogorov-Smirnov. En todos los contrastes de hipótesis se rechazó la hipótesis nula con un error de tipo I o error a menor que 0,05. El paquete estadístico utilizado para el análisis fue SPSS para Windows versión 22.0.

\subsection{Tercera fase del proyecto: Evaluación categorial y dimensional de la personalidad en pacientes con migraña crónica}

\subsubsection{Objetivo}

En esta fase nos proponemos ampliar el estudio más allá de un test de screening, utilizando para ello un test de diagnóstico: el Inventario Multifásico de Personalidad de Minnesotta-2 (MMPI-2). Pretendemos obtener una descripción más detallada de la personalidad de los pacientes migrañosos de nuestra población desde el punto de vista dimensional. El MMPI-II garantiza este objetivo, ya que aporta gran riqueza de información sobre la estructura de la personalidad y sus posibles trastornos, proporcionando hasta 3 escalas de validez, 10 escalas básicas y 15 escalas de contenido. Esto nos permitirá, por un lado, validar los resultados obtenidos en la primera fase de nuestro estudio y, por otro, compararlos directamente con los resultados de otros estudios de este campo. 
El MMPI-2 cuenta con más de 50 años de investigación y es uno de los instrumentos más empleados hasta la fecha en el estudio de la personalidad en diferentes contextos clínicos. Destaca también en la evaluación de la personalidad de pacientes migrañosos.

\subsubsection{Participantes}

Se incluyeron pacientes con migraña crónica atendidos consecutivamente en una consulta monográfica de cefaleas en un hospital terciario. El diagnóstico de migraña crónica fue realizado de acuerdo con los criterios de la Clasificación Internacional de Cefaleas, tercera edición, versión beta (CIC-3 beta, Anexo IV).

Seleccionamos pacientes con edades comprendidas entre 19 y 65 años, excluyendo aquellos con algún trastorno médico o psiquiátrico o bien un déficit intelectual que pudiera limitar su capacidad para entender o contestar a las preguntas de los cuestionarios. Se obtuvo consentimiento informado previo a la inclusión de los pacientes en el estudio. La investigación fue aprobada por el Comité Ético de Investigación Clínica de nuestro centro. Ninguno de los pacientes fue evaluado durante un episodio de migraña agudo.

Se recogieron prospectivamente sus características demográficas, el tiempo en años desde el inicio de la migraña, los meses transcurridos desde el inicio de la migraña crónica, y el número de días con cefalea durante el mes previo a su evaluación. Se determinó si el paciente presentaba uso excesivo de medicación sintomática de acuerdo con los criterios de la CIC-3 beta (Anexo V).

\subsubsection{Metodología}

Se aplicaron la escala hospitalaria de ansiedad y depresión (HADS), el Headache Impact Test-6 (HIT-6), y el cuestionario de personalidad Salamanca. Por último se evaluó la personalidad con el MMPI-2 
Inventario Multifásico de Personalidad de Minnesota (MMPI-II)

Es una de las pruebas de personalidad más usadas en salud mental y permite una evaluación psicológica multidimensional. En este caso nos interesa su capacidad para identificar diferentes perfiles de personalidad. Se trata de un test complicado de aplicar e interpretar, pero resulta especialmente útil por su fiabilidad y validez (Butcher et al, 2001). La versión de la escala validada al español es la adaptación de Ávila-Espada y Jiménez-Gómez (Ávila-Espada y Jiménez-Gómez, 1996). Es un test autoaplicado, que tarda en realizarse entre 60 y 90 minutos. Está compuesto por 567 ítems. Dependiendo de las respuestas (verdadero-falso) la puntuación se reparte en 3 escalas de validez (L: Mentira, F: Incoherencia o validez, K: Corrección o defensa) y 10 escalas clínicas (Hs: Hipocondría, D: Depresión, Hy: Histeria de conversión, Pd: Desviación psicopática, Mf: Masculinidad-Feminidad, Ps: Paranoia, Pt: Psicastenia, Sc: Esquizofrenia, Ma: Hipomanía y Si: Introversión social). Existen además otras 15 escalas de contenido. Las escalas se encuentran debidamente diferenciadas por sexos y baremadas mediante unas tablas de puntuaciones típicas normalizadas. Las puntuaciones brutas o puntuaciones directas son transformadas en una medida estandarizada conocida como puntuaciones $\mathrm{T}$ (media 50, desviación típica 10), haciendo su interpretación más sencilla. En cada una de las escalas una puntuación $\mathrm{T}$ de 65 indica que se ha alcanzado un nivel de significación clínica correspondiente al percentil 95. El MMPI-2 posee una estabilidad temporal (fiabilidad test-pretest) entre 0,58 y 0,92 en las escalas clínicas, entre 0,78 y 0,91 en las escalas de contenido y entre 0,34 y 0,91 en las suplementarias. La fiabilidad de la consistencia interna (coeficiente alfa) en los mismos grupos de escalas anteriormente mencionados va, respectivamente, de 0,33 a 0,84, de 0,68 a 0,86 y de 0,24 a 0,91 .

\subsubsection{Análisis estadístico}

Se analizaron las características demográficas y clínicas de los pacientes según las puntuaciones de todos los test utilizados y según la presencia de cada uno de los rasgos de personalidad de acuerdo con los puntos de corte mencionados. Se utilizó la prueba t 
de Student para analizar las diferencias de las variables cuantitativas en el caso de las puntuaciones de las diferentes escalas clínicas del MMPI-2 en los pacientes de la muestra. Las diferencias de distribución de las variables cualitativas entre los pacientes con presencia o ausencia de cada uno de los rasgos de personalidad evaluados se analizaron mediante el test de $\chi^{2}$. La distribución normal de los datos se verificó mediante la prueba de Kolmogorov-Smirnov. Se rechazaron las hipótesis nulas planteadas con un error alfa menor al permitido (establecido en 0,05). Todos los cálculos se llevaron a cabo con la versión 20.0 del programa estadístico SPSS. 


\section{RESULTADOS}

\subsection{Artículo 1}

Se estudiaron 164 pacientes (134 mujeres, 30 varones). La edad al ser atendidos fue de $36,6 \pm 12,5$ años (rango: 18-78).

Cincuenta y nueve pacientes (36\%) cumplían criterios de migraña crónica en el momento de ser evaluados y 40 de ellos (24,4\% del total) de sobreuso de medicación.

La gravedad medida por HIT-6 fue de 62,7 \pm 7,1 (rango: 42-78). En 114 pacientes (69.5\%) el impacto de la migraña era grave (puntuación HIT-6 superior a 59).

La frecuencia de los 11 rasgos de personalidad evaluados se muestra en el Gráfico 1.

El riesgo de migraña crónica fue superior en pacientes con rasgo anancástico, siendo el riesgo relativo de 2,06 (IC 95\%: 1,07-3,94; p = 0,027). No encontramos relación entre la presencia de los diferentes rasgos de personalidad y el resto de variables evaluadas.

La distribución de las principales variables analizadas en función de los rasgos de personalidad del grupo C se muestra en las Tablas 2, 3 y 4. 
Gráfico 1. Porcentaje de pacientes con cada uno de los 11 rasgos de personalidad evaluados

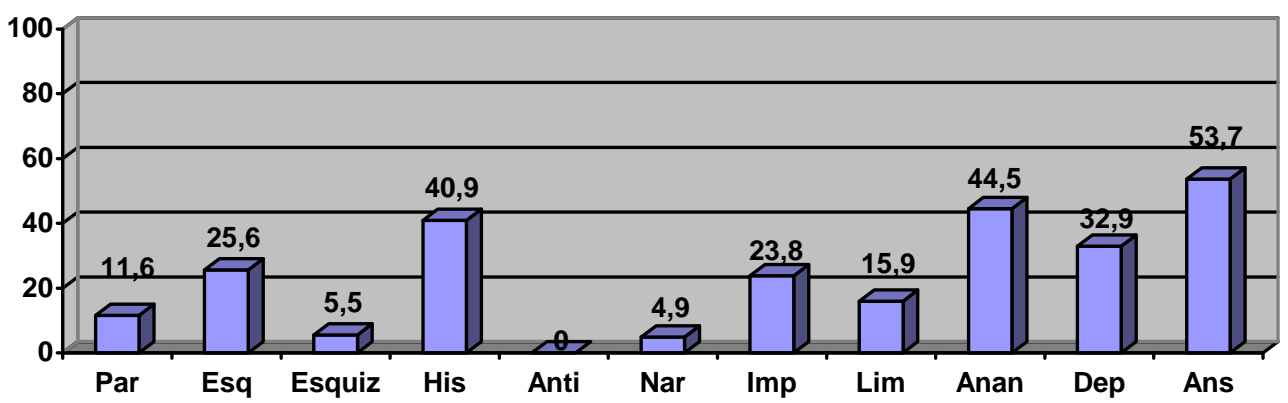

Par: Paranoide, Esq: Esquizoide, Esquiz: Esquizotipico, His: Histriónico, Anti: Antisocial, Nar: Narcisista, Imp: Inestabilidad emocional, subtipo impulsivo, Lim: Inestabilidad emocional, subtipo límite, Anan: Anancástico, Dep: dependiente, Ans: Ansioso

Tabla 2. Distribución de las variables estudiadas en función de la presencia del rasgo ansioso

\begin{tabular}{|l|l|l|l|}
\hline & $\begin{array}{l}\text { ANSIOSO }+ \\
\mathrm{n}=88\end{array}$ & $\begin{array}{l}\text { ANSIOSO - } \\
\mathrm{n}=76\end{array}$ & $\mathrm{P}$ \\
\hline Migraña crónica & $36,3 \%$ & $35,5 \%$ & Ns \\
\hline Abuso medicación & $28,4 \%$ & $19,7 \%$ & Ns \\
\hline HIT-6 & $63,2 \pm 7,2$ & $62,2 \pm 6,9$ & Ns \\
\hline HIT-6 > 59 & $68,1 \%$ & $71 \%$ & Ns \\
\hline Evolución migraña (años) & $18,2 \pm 13,1$ & $15,4 \pm 12,4$ & Ns \\
\hline Días de dolor /mes & $10,5 \pm 9,6$ & $10,8 \pm 8,3$ & Ns \\
\hline
\end{tabular}

HIT-6: Headache Impact Test-6; Ns: no significativo 
Tabla 3. Distribución de las variables estudiadas en función de la presencia del rasgo anancástico

\begin{tabular}{|l|l|l|l|}
\hline & $\begin{array}{l}\text { ANANCÁSTICO }+ \\
\mathrm{n}=73\end{array}$ & $\begin{array}{l}\text { ANANCÁSTICO }- \\
\mathrm{n}=91\end{array}$ & $\mathrm{P}$ \\
\hline Migraña crónica & $45,2 \%$ & $28,5 \%$ & 0,027 \\
\hline Abuso medicación & $19,7 \%$ & $30,1 \%$ & Ns \\
\hline HIT-6 & $63,5 \pm 7,3$ & $62,1 \pm 6,9$ & Ns \\
\hline HIT-6 > 59 & $72,6 \%$ & $67 \%$ & Ns \\
\hline Evolución migraña (años) & $18,7 \pm 13,8$ & $15,4 \pm 11,8$ & Ns \\
\hline Días de dolor /mes & $11,9 \pm 9,5$ & $9,6 \pm 8,6$ & Ns \\
\hline
\end{tabular}

HIT-6: Headache Impact Test-6; Ns: no significativo

Tabla 4. Distribución de las variables estudiadas en función de la presencia del rasgo dependiente

\begin{tabular}{|l|l|l|l|}
\hline & $\begin{array}{l}\text { DEPENDIENTE }+ \\
\mathrm{n}=54\end{array}$ & $\begin{array}{l}\text { DEPENDIENTE }- \\
\mathrm{n}=110\end{array}$ & $\mathrm{P}$ \\
\hline Migraña crónica & $38,8 \%$ & $34,5 \%$ & Ns \\
\hline Abuso medicación & $25,9 \%$ & $23,6 \%$ & Ns \\
\hline HIT 6 & $63,6 \pm 6,2$ & $62,3 \pm 7,5$ & Ns \\
\hline HIT-6 > 59 & $72,2 \%$ & $68,1 \%$ & Ns \\
\hline Evolución migraña (años) & $16,4 \pm 13,8$ & $17,1 \pm 12,3$ & Ns \\
\hline Días de dolor /mes & $11,4 \pm 9,6$ & $10,3 \pm 8,7$ & Ns \\
\hline
\end{tabular}

HIT-6: Headache Impact Test-6; Ns: no significativo 


\subsection{Artículo 2}

Se incluyeron en el estudio 155 pacientes (22 varones, 133 mujeres). La edad en el momento de su inclusión en el estudio fue de 38,2 \pm 11,7 años (rango: 18-70).

Cincuenta y un casos (32,9\%) padecían una migraña episódica y 104 (67,1\%) migraña crónica; dentro de estos últimos, en 74 (71,1\%) pacientes había uso excesivo de medicación

La gravedad de la migraña medida por ła escala HIT-6 fue de 61,3 \pm 6.5 (42-78) y en el 82,8\% de los casos la discapacidad era al menos moderada (HIT-6 > 55).

Las puntuaciones de los 155 pacientes fueron de 7,9 \pm 4,3 (0-17) en la subescala HADS-Ansiedad, 3,6 \pm 3,9 (0-18) en la escala HADS-depresión y 14,1 \pm 6,7 (1-32) en la escala de impulsividad de Plutchik. Aplicando los correspondientes puntos de corte, el 28,4\% de los pacientes cumplía criterios de ansiedad, el 7,1\% de depresión, y el $16,1 \%$ de impulsividad.

Al comparar las poblaciones de migraña crónica y migraña episódica, las puntuaciones en las subescalas HADS-Ansiedad y HADS-Depresión, así como el porcentaje de pacientes que cumplían criterios de ansiedad y de depresión fueron significativamente mayores en el grupo de migraña crónica (Tabla 5).

Dentro de los casos con migraña crónica, las puntuaciones en HADS-Ansiedad y HADS-Depresión y el porcentaje de pacientes con ansiedad fueron más elevados en el grupo de pacientes con uso excesivo de medicación (Tabla 6)

No encontramos relación alguna entre la puntuación absoluta en la escala de Plutchik o el hecho de superar el punto de corte para impulsividad en esta escala y la presencia de migraña crónica o el uso excesivo de medicación. 
Tabla 5. Comparación entre los grupos de migraña episódica y migraña crónica

\begin{tabular}{|l|l|l|l|}
\hline & $\mathrm{MC}(\mathrm{n}=104)$ & $\mathrm{ME}(\mathrm{n}=51)$ & $\mathrm{P}$ \\
\hline Edad (años) & $39,8 \pm 12,3$ & $34,9 \pm 10,1$ & 0,009 \\
\hline Tiempo de evolución (años) & $21,6 \pm 13$ & $14,4 \pm 12,9$ & 0,002 \\
\hline Puntuación HIT-6 & $61,7 \pm 6,2$ & $60,6 \pm 6,9$ & Ns \\
\hline HIT-6 > 55 & $83,1 \%$ & $79,5 \%$ & Ns \\
\hline Puntuación HADS-Ansiedad & $8,5 \pm 4,5$ & $6,4 \pm 3,6$ & 0,003 \\
\hline Criterios de Ansiedad & $33,7 \%$ & $17,6 \%$ & 0,038 \\
\hline Puntuación HADS-Depresión & $4,4 \pm 4,3$ & $1,9 \pm 2,3$ & $<0,001$ \\
\hline Criterios de Depresión & $10,6 \%$ & $0 \%$ & 0,017 \\
\hline Puntuación Plutchik & $14.5 \pm 6.6$ & $13.1 \pm 6.8$ & Ns \\
\hline Criterios de Impulsividad & $16,3 \%$ & $15,7 \%$ & Ns \\
\hline
\end{tabular}

HADS: Escala Hospitalaria de Ansiedad y Depresión; HIT-6: Headache Impact Test-6; MC: Migraña crónica; ME: Migraña Episódica; Ns: no significativo. 
Tabla 6. Comparación entre pacientes con y sin uso excesivo de medicación dentro del grupo de migraña crónica

\begin{tabular}{|l|l|l|l|}
\hline & UEM (n=74) & No UEM (n=30) & p \\
\hline Edad (años) & $42,4 \pm 11,4$ & $33,5 \pm 11,9$ & 0,001 \\
\hline Tiempo de evolución (años) & $24 \pm 12,3$ & $15,6 \pm 13,1$ & 0,004 \\
\hline Puntuación HIT 6 & $62,2 \pm 6,5$ & $60,5 \pm 5.6$ & Ns \\
\hline HIT-6 > 55 & $82,3 \%$ & $85,2 \%$ & Ns \\
\hline Puntuación HADS-Ansiedad & $9,3 \pm 4,4$ & $6,8 \pm 4,3$ & 0,01 \\
\hline Criterios de Ansiedad & $41,9 \%$ & $13,3 \%$ & 0,006 \\
\hline Puntuación HADS-Depresión & $5,1 \pm 4,6$ & $2,7 \pm 2,9$ & 0,002 \\
\hline Criterios de Depresión & $12,2 \%$ & $6,7 \%$ & Ns \\
\hline Puntuación Plutchik & $14,8 \pm 6,3$ & $13,8 \pm 7,3$ & Ns \\
\hline Criterios de Impulsividad & $17,6 \%$ & $13,3 \%$ & Ns \\
\hline
\end{tabular}

HADS: Escala Hospitalaria de Ansiedad y Depresión; HIT-6: Headache Impact Test-6; MC: Migraña crónica; ME: Migraña Episódica; Ns: no significativo. 


\subsection{Artículo 3}

Se incluyeron 30 pacientes (26 mujeres, 4 varones). La edad en el momento de la inclusión era de 40,7 \pm 9,6 años (rango: 23-61).

La puntuación en la escala HIT-6 fue de 62,7 \pm 6,8 (46-76) y 24 pacientes (80 \%) presentaban, según esta escala, una discapacidad grave (HIT-6 $\geq 60$ ).

Las puntuaciones en las subescalas ansiedad y depresión de la HADS fueron, respectivamente, 7,1 \pm 3,9 (0-16) y 2,4 $\pm 2,9$ (0-12). Un paciente (3,3\%) sobrepasaba el punto de corte para depresión y 4 (13,3\%) para ansiedad.

La frecuencia de los 11 rasgos de personalidad evaluados en el Test de Salamanca se muestra en el Gráfico 2.

En cuanto a los resultados obtenidos mediante el MMPI-2, los 30 pacientes mostraron perfiles válidos.

Los tres factores de personalidad medidos en el test que reflejan neuroticismo o tríada neurótica fueron los más que se encontraron con más frecuencia. Así, 16 casos (53,3\%) cumplían criterios de hipocondría, 7 (23,3\%) de depresión y 10 (33,3\%) de histeria. Se objetivó una mayor presencia de hipocondría e histeria, unida a una menor frecuencia en la tríada de la depresión, lo que corresponde a la configuración denominada "conversiva V". En 20 pacientes (66,7\%) había al menos un factor de la triada positivo y en 11 (36,7\%) se objetivaron dos o más escalas positivas de esta tríada. La frecuencia de positividades en cada una de las escalas del MMPI-2 se muestra en el Gráfico 3.

No hallamos ninguna asociación entre las puntuaciones de las escalas de personalidad o la presencia de cada uno de los rasgos evaluados en los dos test aplicados con el tiempo de migraña crónica, la discapacidad medida por HIT-6 o el uso excesivo de medicación sintomática. 
Gráfico 2. Presencia de los 11 rasgos de personalidad determinados mediante el Test "Salamanca"

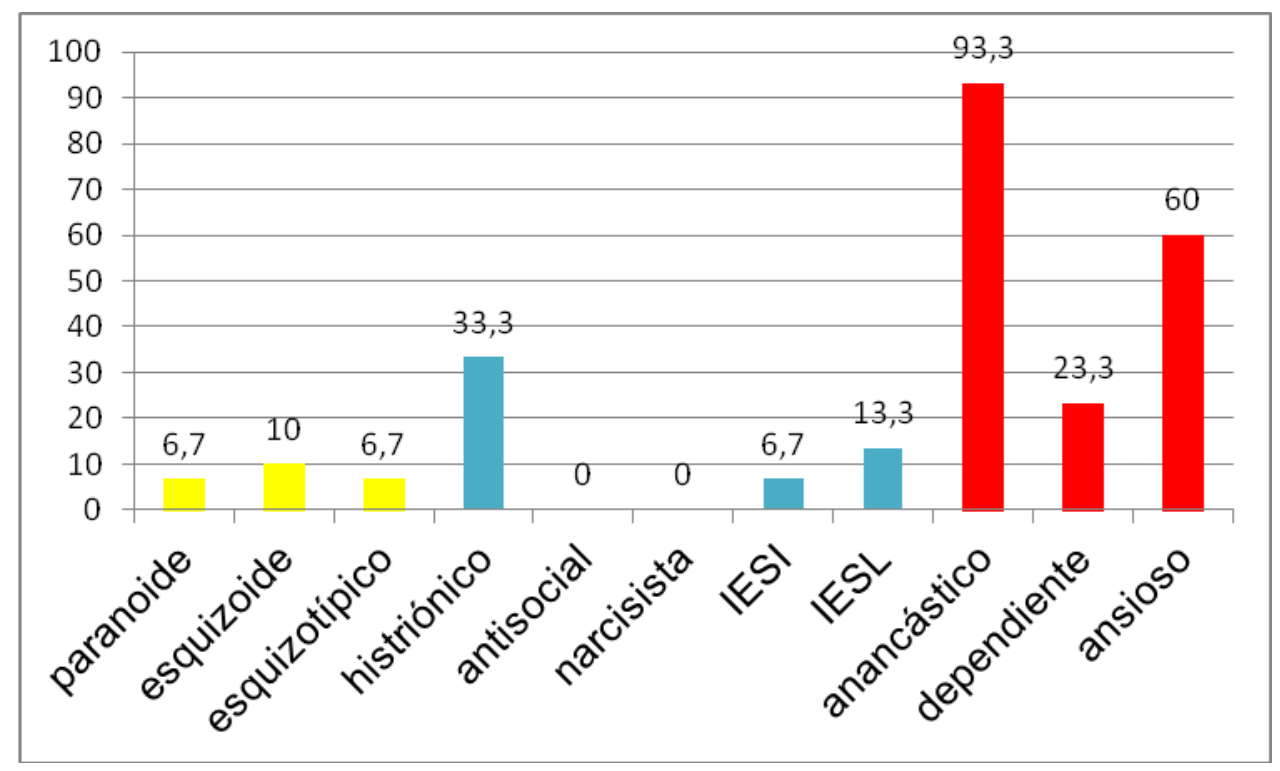

Gráfico 3. Frecuencia de escalas positivas en el MMPI-2 dentro de nuestra muestra.

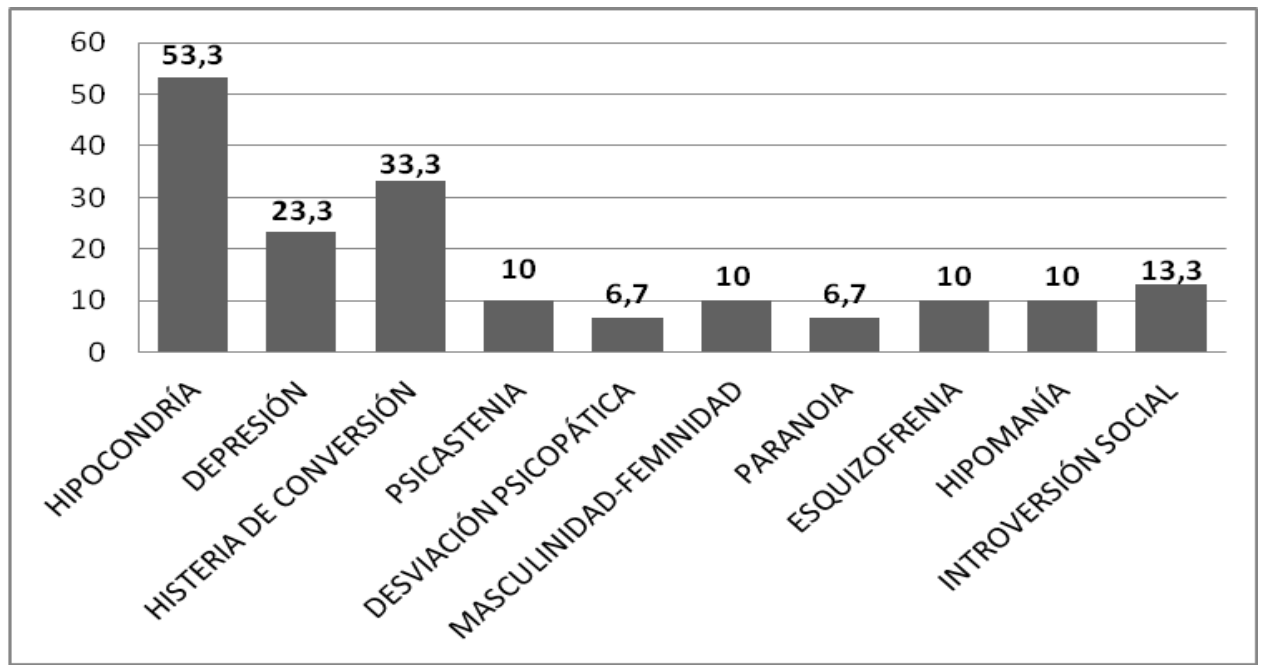




\section{CONCLUSIONES}

\subsection{Artículo 1}

En los pacientes con migraña son frecuentes determinados rasgos de personalidad, en particular aquellos pertenecientes al Grupo C (por orden de frecuencia ansioso, anancástico y dependiente).

Según los resultados de nuestro estudio, no existe asociación entre los rasgos de personalidad y la intensidad de la migraña o el sobreuso de medicación.

Existe un riesgo significativo de presentar migraña crónica en pacientes con rasgo anancástico de la personalidad.

\subsection{Artículo 2}

Los trastornos del estado de ánimo y, sobre todo, de ansiedad son frecuentes en los pacientes con migraña. Existe una fuerte asociación entre los trastornos del estado de ánimo y de ansiedad y la migraña crónica y el uso excesivo de medicación, por lo que sería aconsejable un despistaje sistemático de este tipo de trastornos psiquiátricos.

Los pacientes migrañosos presentan con frecuencia impulsividad. No existe asociación entre la impulsividad y la presencia de migraña crónica o el uso excesivo de medicación. No obstante, su presencia podría constituir un factor determinante en el afrontamiento del dolor y la respuesta de estos pacientes a la medicación preventiva.

\subsection{Artículo 3}

Desde el punto de vista categorial, existe una frecuencia notablemente superior de los rasgos del grupo $\mathrm{C}$ en pacientes con migraña, en particular el rasgo anancástico u obsesivo-compulsivo. 
En la evaluación dimensional de los pacientes con migraña destaca una prevalencia mayor de los rasgos que conforman el neuroticismo.

En base a los resultados obtenidos en esta muestra, las alteraciones de la personalidad no dependen de la gravedad de la migraña ni del tiempo transcurrido desde el inicio de la migraña o de su forma crónica.

Los rasgos anormales de uno y otro test aparecen de forma paralela en ambos. Así, las escalas de personalidad que analizan el neuroticismo en el MMPI-2 se corresponderían con los rasgos de personalidad del grupo C evaluados en el Test de Salamanca.

Los pacientes con migraña crónica presentan rasgos de personalidad bien definidos, para cuya valoración es razonable utilizar cuestionarios categoriales de cribado como el Cuestionario Salamanca. Este cuestionario es un buen instrumento de medida, y podría permitir al neurólogo la detección precoz de rasgos anormales de la personalidad en los pacientes con migraña. 


\section{REFERENCIAS BIBLIOGRÁFICAS}

Abbate-Daga G, Fassino S, Lo Giudice R, Rainero I, Gramaglia C, Marech L et al. Anger, depression and personality dimensions in patients with migraine without aura. Psychoter and Psychosom 2007; 76: 122-128.

Antonaci F, Nappi G, Galli F, Manzoni G C, Calabresi P, Costa A. Migraine and psychiatric comorbidity: a review of clinical findings. J Head Pain 2011; 12: 115-125.

Ávila-Espada A, Jiménez-Gómez F. The castilian version of the MMPI-2 in Spain: development, adaptation, and psychometric properties. International adaptations of the MMPI-2: research and clinical applications, Universidad de Salamanca; 1996, p. 305328.

Banco de Instrumentos básicos para la práctica de la psiquiatría clínica. Garcia-Portilla MP, Bascarán MT, Sáiz PA, Parellada M, Bousoño M y Bobes J . 6 ${ }^{a}$ Edición. Ars Médica. Barcelona 2011.

Berg J, Stovner LJ. Cost of migraine and other headaches in Europe. Eur J Neurol 2005; 12 (Suppl 1): S59-S62.

Bigal ME, Lipton RB. Modifiable risks factors for migraine progression (or for chronic daily headaches)-clinical lessons. Headache 2006; 46: S144-S146.

Bigal ME, Serrano D, Buse D, Scher A, Stewart WF, Lipton RB. Acute migraine medications and evolution from episodic to chronic migraine: a longitudinal populationbased study. Headache 2008; 48: 1157-1168.

Bigal ME, Sheftell FD, Rapaport AM, Tepper SJ, Weeks R, Baskin SM. MMPI personality profiles in patients with primary chronic headache: A case-control study. Neurol Sci 2003; 24: 103-110. 
Billieux J, Gay P, Rochat L, Van Der Linden M. The role of urgency and its underlying psychological mechanisms in problematic behaviours. Behaviour Research and Therapy. 2010; 48: 1085-1096.

Breslau N, Lipton RB, Stewart WF, Schultz LR, Welch KM. Comorbidity of migraine and depression:Investigating potential etiology and prognosis. Neurology 2003; 60: 1308-1312.

Breslau N, Schultz LR, Stewart WF, Lipton RB, Lucia VC, Welch KM. Headache and major depression: Is the association specific to migraine? Neurology 2000; 54: 308-313.

Butcher JN, Dahlstrom WG, Graham JR, Tellengen A, Kaemmer B. MMPI-2 (Minnesota Multiphasic Personality Inventory-2): Manual for Administration and Scoring (Rev. ed.). Minneapolis, MN: University of Minnesota Press; 2001.

Caldero-Alonso A. Estudio de los resultados obtenidos en el cuestionario Salamanca en población normal. Salamanca: Universidad de Salamanca; 2009.

Cao M, Zhang S, Wang K, Wang Y, Wang W. Personality traits in migraine and tension-type headaches: a five-factor model study. Psychopathology 2002; 35: 254-258.

CIE 10. Trastornos mentales y del comportamiento. Madrid: Meditor; 1994.

Cloninger CR, Svrakic DM, Przybeck TR. A psychobiological model of temperament and character. Arch Gen Psychiatry 1993; 50: 975-990.

Cupini LM, De Murtas M, Costa C, Mancini M, Eusebi P, Sarchielli P et al. Obsessivecompulsive trait and migraine with medication-overuse headache. Headache 2009; 49: 1005-1013. 
Curone M, D’Amico D, Bussone G. Obsessive-compulsive aspects as predictors of poor response to treatments in patients with chronic migraine and medication overuse. Neurol Sci 2012; 33 (Suppl1): S211-S213.

Curone M, Tullo V, Mea E, Proietti-Cecchini A, Peccarisi C, Bussone G. Psychopathological profile of patients with chronic migraine and medication overuse: study and findings in 50 cases. Neurol Sci 2011 ; 32(suppl 1): S177- S179.

Curone M, Tullo V, Savino M, Proietti-Cecchini A, Bussone G, D’Amico D. Outcome of patients with chronic migraine with medication overuse and depression after duloxetine: influence of coexisting obsessive compulsive disorder. Neurol Sci 2013; 34 (Suppl 1): S175-S177.

Di Piero V, Bruti G, Venturi P, Talamonti F, Biondi M, Di Legge S et al. Aminergic tone correlates of migraine and tension-type headache: a study using the tridimensional personality questionnaire. Headache 2001; 41: 63-71.

Fernández-de-Las-Peñas C, Hernández-Barrera V, Carrasco-Garrido P, Alonso-Blanco C, Palacios-Ceña D, Jiménez-Sánchez $S$ et al. Population-based study of migraine in Spanish adults: relation to socio-demographic factors, lifestyle and co-morbidity with other conditions. J Headache Pain. 2010; 11: 97-104.

García-Portilla MP, Bascarán MT, Sáiz PA, Parellada M, Bousoño M, Bobes J. Banco de instrumentos básicos para la práctica de la psiquiatría clínica. 6. a ed. Barcelona: Ars Médica; 2011.

Hamelsky SW, Lipton RB. Psychiatric comorbidity of migraine. Headache 2006; 46: 1327-1333.

Headache Classification Committee of the International Headache Society. The International Classification of Headache Disorders, 3rd edition (beta version). Cephalalgia 2013; 33: 629-808. 
Headache Classification Subcommittee of the International Headache Society. The International Classification of Headache Disorders: 2nd edition. Cephalalgia 2004; 24 (Suppl 1): 9-160.

Hedborg K, Anderberg U, Muhr C. Stress in migraine: personality-dependent vulnerability, life events and gender are of significance. Ups J Med Sci 2011; 116: 187199.

Henry P. Is there a "migraine personality"(in french)? Encephale 2000; 26 (spec no 3): 12-15.

Huber D, Henrich G. Personality traits and stress sensitivity in migraine patients. Behav Med 2003; 29: 4-13.

Jette N, Patten S, Williams J, Becker W, Wiebe S. Comorbidity of migraine and psychiatric disorders. A national population-based study. Headache 2008; 48: 501-516.

Kosinski M, Bayliss MS, Bjorner JB, Ware JE Jr, Garber WH, Batenhorst A et al. A six-item short-form survey for measuring headache impact: the HIT-6. Qual Life Res. 2003; 12: 963-974.

Lipton RB, Stewart WF, Scher AL. Epidemiology and economic impact of migraine. Curr Med Res Opin 2001; 17 (Suppl 1): S4-S12.

Lipton RB. Tracing transformation: Chronic migraine: classification, progression and epidemiology. Neurology 2009; 72 (5 Suppl): S3-7.

López-Ibor Aliño JJ, Valdés-Miyar M. Manual diagnóstico y estadístico de los trastornos mentales. Barcelona: Masson; 2002. 
Luconi R, Bartolina M, Taffi R, Vignin A, Mazzanti L, Provinciali L et al. Prognostic Significance of personality profiles in patients with chronic migraine. Headache 2007; 47: 1118-1124.

Manzoni GC, Stovner LJ. Epidemiology of headache. Hadb Clin Neurol 2011; 97: 3-22.

Mateos V, García-Moncó JC, Gómez-Beldarrain M, Armengol-Bertolín S, Larios C. Factores de personalidad, grado de discapacidad y abordaje terapéutico de los pacientes con migraña atendidos en primera consulta en neurología (estudio Psicomig). Rev Neurol (Barc) 2011; 52: 131-138

Matías-Guiu J, Porta-Etessam J, Mateos V, Díaz-Insa S, López-Gil A, Fernández C. One-year prevalence of migraine in Spain: a nationwide population-based survey. Cephalalgia 2011; 31: 463-470.

McWilliams LA, Goodwin RD, Cox BJ. Depression and anxiety associated with three pain conditions. Results from a nationally representative sample. Pain. 2004; 111: 7783.

Merikangas KR, Stevens DE, Angst J. Headache and personality: results of a community sample of young adults. J Psychiatr Res 1993; 27: 187-96.

Mongini F, Fassino S, Rota E, Deregibus A, Levi M, Monticone D et al. The temperament and character inventory in women with migraine. J Headache Pain 2005; 6: 247-249.

Mongini F, Ibertis F, Barbalonga E, Raviola F. MMPI-2 profiles in chronic daily headache and their relationship to anxiety levels and accompanying symptoms. Headache 2000; 40: 466-472. 
Mongini F, Keller R, Deregibus A, Raviola F, Mongini T, Sancarlo M. Personality traits, depression and migraine in women: a longitudinal study. Cephalalgia 2003; 23: 186-192.

Mongini F, Rota E, Evangelista A, Ciccone G, Milani C, Ugolini A et al. Personality profiles and subjective perception of pain in head pain patients. Pain. 2009; 144: 125129.

Mongini F, Rota E, Deregibus A, Mura F, Francia Germani A, Mongini T. A comparative analysis of personality profile and muscle tenderness between chronic migraine and chronic-type headache. Neurol Sci 2005, 26: 203-207.

Olessen J, Bousser MJ, Diener HC, Dodick D, First M, Goadsby PJ et al. Headache Classification Committee. New appendix criteria open for a broader concept of chronic migraine. Cephalalgia 2006; 26: 742-746.

Radat F, Creach C, Swendsen JD, Lafittau M, Irachabal S, Dousset V et al. Psychiatric comorbidity in the evolution from migraine to medication overuse headache. Cephalalgia 2005; 25: 519-522.

Radat F, Swendsen JD. Psychiatric comorbidity in migraine: a review. Cephalalgia 2004; 25: 165-178.

Rasmussen BK. Migraine and tension-type headache in a general population: psychosocial factors. Int J Epidemiol 1992; 21: 1138-1143.

Rothrock J, Lopez I, Zweilfer R, Andress-Rothrock D, Drinkard R, Walters N. Borderline personality disorder and migraine. Headache 2007; 47: 22-26.

Rubio G, Montero I, Jáureguir J, Martínez ML, Álvarez S, Marín JJ et al. Validación de la Escala de Impulsividad de Plutchik en población española. Arch Neurobiol 1999; 61: 223-232. 
Sánchez-Román S, Téllez-Zenteno JF, Zermeño-Phols F, García-Ramos G, Velázquez A, Derry P et al. Personality in patients witn migraine evaluated with the "Temperament and Character Inventory". J Headache Pain 2007; 8: 94-104.

Saper JR, Lake AE. Borderline personality disorder and the chronic headache patient: review and management recommendations. Headache 2002; 42: 663-674.

Saper JR. “Are you talking to me?" Confronting behavioral disturbances in patients with headache. Headache. 2006; 46: S151-S156.

Sheftell FD, Atlas SJ. Migraine and Pshychiatric comorbidity: From theory and hypotheses to clinical Application . Headache 2002; 42: 934-944.

Silberstein SD, Lipton RB, Breslau N. Migraine: association with personality characteristics and psychopathology. Cephalalgia 1995; 15: 358-369.

Smith GT, Fischer S, Cyders MA, Annus AM, Spillane NS, McCarthy DM. On the validity and utility of discriminating among impulsivity-like traits. Assessment. 2007; 14: $155-170$.

Stewart W, Breslau N, Keck PE. Comorbidity of migraine and panic disorder. Neurology 1994; 44 (Suppl 7): S23-S27.

Wolff HG. Personality features and reactions of subjects with migraine. Arch Neurol Psychiatry 1937; 37: 895-921.

Yang M, Rendas-Baum R, Varon SF, Kosinski M. Validation of the Headache Impact Test (HIT-6 ${ }^{\mathrm{TM}}$ ) across episodic and chronic migraine. Cephalalgia 2011; 31: 357-367.

Zigmond AS, Snaith RP. The hospital anxiety and depression scale. Acta Psychiatr Scand 1983; 67: 361-370. 
Zwart JA, Dyb G, Hagen K, Odegard KJ, Dahl AA, Bovim G et al. Depression and anxiety disorders associated with headache frequency. The Nord-Trondelag Study. Eur J Neurol 2003; 10:147-152.

Zwart JA, Dyb G, Hagen K, Svebak S, Stovner LJ, Holmen J. Analgesic overuse among subjects with headache, neck, and low-back pain. Neurology 2004; 62: 1540-1544. 


\section{ANEXOS}

\section{$9.1 \quad$ Anexo I}

Criterios diagnósticos de la migraña sin aura (CIC-II, CIC-3 beta):
A. Al menos 5 ataques de cefalea
B. De 4 a 72 horas de duración
C. $\mathrm{Al}$ menos 2 de las siguientes características:
1. Localización unilateral
2. Pulsátil
3. Dolor moderado o intenso
4. Agravado por la actividad física

D. Durante la cefalea al menos 1 de las siguientes características:

1. Náuseas y/o vómitos

2. Fotofobia y fonofobia

E. No atribuible a otro trastorno o enfermedad

CIC-II: Clasificación Internacional de las Cefaleas, segunda edición

CIC-3 beta: Clasificación Internacional de las Cefaleas, tercera edición, versión beta

Tomado de: Headache Classification Subcommittee of the International Headache Society. The International Classification of Headache Disorders: $2^{\text {nd }}$ edition. Cephalalgia 2004; 24 (Suppl 1): 9-160 y Headache Classification Committee of the International Headache Society. The International Classification of Headache Disorders, 3rd edition (beta version). Cephalalgia 2013; 33: 629-808.

Nota: Los criterios para migraña sin aura no han sido modificados en la tercera edición de la Clasificación de las Cefaleas. 


\subsection{Anexo II}

\section{Criterios diagnósticos revisados de migraña crónica (CIC-IIR):}

A. Cefalea (tensional y/o migraña) $\geq 15$ días/mes en al menos 3 meses

B. $\mathrm{Al}$ menos 5 ataques que reúnen los criterios para Migraña sin aura

C. En $\geq 8$ días/mes en al menos 3 meses la cefalea cumple criterios de dolor y asocia síntomas de migraña sin aura, recogidos en C1 y/o C2

1. Tiene al menos 2 de a-d:

a) Localización unilateral

b) Pulsátil

c) Dolor moderado o intenso

d) Agravado por la actividad física

2. $\mathrm{Y}$ al menos 1 de a-b:

a) Náuseas y/o vómitos

b) Fotofobia y fonofobia

D. No sobreuso de medicación y no atribuible a otro trastorno o enfermedad

CIC-IIR: Clasificación Internacional de las Cefaleas, segunda edición, revisada

Tomado de: Olessen J, Bousser MJ, Diener HC, Dodick D, First M, Goadsby PJ et al. Headache Classification Committee. New appendix criteria open for a broader concept of chronic migraine. Cephalalgia 2006; 26: 742-6. 


\section{3 Anexo III}

Criterios diagnósticos revisados de cefalea por uso excesivo de medicación (CICIIR):

A. Presencia de cefaleas $\geq 15$ días $/$ mes

B. Uso excesivo de medicación durante $>3$ meses de una o varias medicaciones para el tratamiento agudo o sintomatológico de la cefalea

1. Ergotamina, triptanes, opioides, o combinación de medicación analgésica $\geq 10$ días/mes de forma regular durante $>3$ meses.

2. Analgésicos simples o cualquier combinación de ergotamina, triptanes, opiodes $\geq 15$ días/mes de forma regular durante $>3$ meses sin sobreuso de cualquiera de las clases individualmente.

C. La cefalea ha evolucionado o empeorado marcadamente desde el uso excesivo de medicación

CIC-IIR: Clasificación Internacional de las Cefaleas, segunda edición, revisada

Tomado de: Olessen J, Bousser MJ, Diener HC, Dodick D, First M, Goadsby PJ et al. Headache Classification Committee. New appendix criteria open for a broader concept of chronic migraine. Cephalalgia 2006; 26: 742-6. 


\subsection{Anexo IV}

\section{Criterios diagnósticos de migraña crónica (CIC-3 beta):}

A. Cefalea (tensional y/o migraña) $\geq 15$ días/mes durante al menos 3 meses y que cumpla los criterios B y C

B. $\quad \mathrm{Al}$ menos 5 ataques que reúnen los criterios para migraña sin aura o con aura

C. En $\geq 8$ días/mes en al menos 3 meses la migraña sin aura cumple alguno de los siguientes criterios:

1. Criterios C y D de Migraña sin aura (Anexo I)

2. Criterio B y C de Migraña con aura

3. El paciente cree que es migraña desde el inicio del dolor y éste se alivia con un triptán o un derivado de la ergotamina.

D. No se encuentra mejor definido por otro diagnóstico de la CIC-3 beta

CIC-3 beta: Clasificación Internacional de las Cefaleas, tercera edición, versión beta

Tomado de: Headache classification committee of the international headache society. The international classification of headache disorders, 3rd edition (beta version). Cephalalgia 2013; 33: 629-808. 


\section{5 Anexo V}

\section{Criterios diagnósticos para cefalea por sobreuso de medicación (CIC-3 beta):}

A. Presencia de cefaleas $\geq 15$ días/mes en un paciente con diagnóstico de cefalea pre-existente

B. Sobreuso de medicación durante $>3$ meses de una o varias medicaciones que puedan ser usadas en el tratamiento agudo o sintomatológico de la cefalea

C. No se encuentra mejor definido por otro diagnóstico de la CIC-3 beta

CIC-3 beta: Clasificación Internacional de las Cefaleas, tercera edición, versión beta

Tomado de: Headache classification committee of the international headache society.

The international classification of headache disorders, 3rd edition (beta version). Cephalalgia 2013; 33: 629-808. 


\subsection{Anexo VI}

\section{Escala HIT-6 (Headache Impact Test)}

Para cada pregunta, por favor, marque con una cruz la casilla que corresponda a su respuesta.

Cuando usted tiene dolor de cabeza, ¿con qué frecuencia el dolor es intenso?
$\square$
Pocas veces
A veces
Muy a menudo
Siempre

2 i Con qué frecuencia el dolor de cabeza limita su capacidad para realizar actividades diarias habituales como las tareas domésticas, el trabajo, los estudios o actividades sociales?
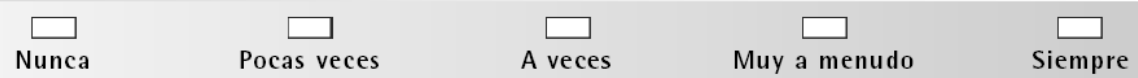

3

Cuando tiene dolor de cabeza, ¿con qué frecuencia desearía poder acostarse?
$\square$
Pocas veces
A veces
Muy a menudo
Siempre

4 En las últimas 4 semanas, ¿con qué frecuencia se ha sentido demasiado cansado/a para trabajar o realizar las actividades diarias debido a su dolor de cabeza?
$\square$
Pocas veces
A veces
Muy a menudo
$\square$ Siempre

5 En las últimas 4 semanas, ¿con qué frecuencia se ha sentido harto/a o irritado/a debido a su dolor de cabeza?

$\square$ Nunca $\quad \square$ Pocas veces $\quad \square \quad$ A veces $\quad \square$ Siempre

En las últimas 4 semanas, ¿con qué frecuencia el dolor de cabeza ha limitado su capacidad para concentrarse en el trabajo o en las actividades diarias?
$\square$

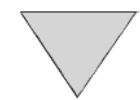

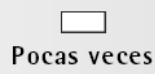
A veces
Muy a menudo
Siempre
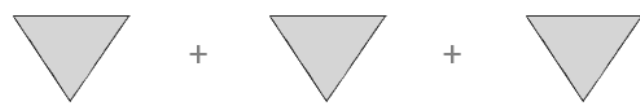
COLUMNA 1
COLUMNA 2
COLUMNA 3
COLUMNA 4
COLUMNA 5
(6 puntos cada respuesta) (8 puntos cada respuesta)
(10 puntos cada respuesta)
(11 puntos cada respuesta)
(13 puntos cada respuesta)
Para calcular el resultado final, sume los
puntos correspondientes a cada columna.
Puntuación total
Por favor, enseñe los resultados de este test (HIT-6) a su médico.

$$
\begin{aligned}
& \text { Cuanto más alta sea la puntuación, } \\
& \text { obtenida, mayores serán los efectos } \\
& \text { del dolor de cabeza en su vida. } \\
& \text { La puntuación va desde } 36 \text { a } 78 .
\end{aligned}
$$

Tomado de: Yang M, Rendas-Baum R, Varon SF, Kosinski M. Validation of the Headache Impact Test $\left(H I T-6^{T M}\right)$ across episodic and chronic migraine. Cephalalgia 2011; 31: 357-367. 


\subsection{Anexo VII}

Cuestionario Salamanca para el screening de trastornos de la personalidad

1. Pienso que más vale no confiar en los demás.

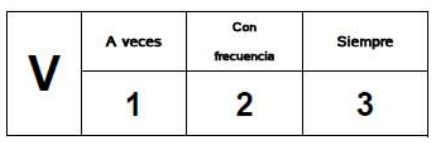

2. Me gustaría dar a la gente su merecido.

\begin{tabular}{|c|c|c|c|}
\hline $\mathbf{V}$ & A veces & $\begin{array}{c}\text { Con } \\
\text { trecuencia }\end{array}$ & Siempre \\
\cline { 2 - 4 } & 1 & 2 & $\mathbf{F}$ \\
\hline
\end{tabular}

3. Prefiero realizar actividades que pueda hacer yo solo.

\begin{tabular}{|c|c|c|c|}
\hline $\mathbf{V}$ & A veces & $\begin{array}{c}\text { Con } \\
\text { trecuencia }\end{array}$ & Siempre \\
\cline { 2 - 4 } & 1 & 2 & $\mathbf{F}$ \\
\hline
\end{tabular}

4. Prefiero estar conmigo mismo.

\begin{tabular}{|c|c|c|c|}
\hline $\mathbf{V}$ & A veces & $\begin{array}{c}\text { Con } \\
\text { trecuencia }\end{array}$ & Siempre \\
\cline { 2 - 4 } & $\mathbf{1}$ & $\mathbf{2}$ & $\mathbf{F}$ \\
\hline
\end{tabular}

5. ¿Piensa la gente que es usted raro o excéntrico?

\begin{tabular}{|c|c|c|c|}
\hline \multirow{2}{*}{ V } & A veces & $\begin{array}{c}\text { Con } \\
\text { trecuencia }\end{array}$ & Siempre \\
\cline { 2 - 4 } & 1 & 2 & 3 \\
\hline
\end{tabular}

\section{$\mathbf{F}$}

\begin{tabular}{|c|c|c|c|}
\hline \multirow{2}{*}{$\mathbf{V}$} & A veces & $\begin{array}{c}\text { Con } \\
\text { trecuencia }\end{array}$ & Siempre \\
\cline { 2 - 4 } & 1 & 2 & $\mathbf{2}$ \\
\hline
\end{tabular}
mayoría de la gente.

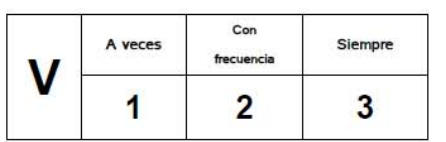

\section{$\mathbf{F}$}

7. Soy demasiado emocional.

\begin{tabular}{|c|c|c|c|}
\hline \multirow{2}{*}{$\mathbf{V}$} & A veces & $\begin{array}{c}\text { Con } \\
\text { trecuencis }\end{array}$ & Siempre \\
\cline { 2 - 4 } & $\mathbf{1}$ & $\mathbf{2}$ & $\mathbf{3}$ \\
\hline
\end{tabular}

8.Doy mucha importancia y atención a mi imagen.

\begin{tabular}{|c|c|c|c|}
\hline \multirow{2}{*}{$\mathbf{V}$} & A veces & $\substack{\text { Con } \\
\text { thecuescis }}$ & Siempre \\
\cline { 2 - 4 } & $\mathbf{1}$ & $\mathbf{2}$ & $\mathbf{3}$ \\
\hline
\end{tabular}

10. Tengo poco respeto por los derechos de los demás.

\begin{tabular}{|c|c|c|c|}
\hline \multirow{2}{*}{$\mathbf{V}$} & A veces & $\substack{\text { con } \\
\text { thecuencis }}$ & Siempre \\
\cline { 2 - 4 } & 1 & 2 & 3 \\
\hline
\end{tabular}


www.seetp.com

11. Soy especial y merezco que me lo reconozcan.

\begin{tabular}{|c|c|c|c|}
\hline \multirow{2}{*}{ V } & A veces & $\begin{array}{c}\text { con } \\
\text { frecuencia }\end{array}$ & Siempre \\
\cline { 2 - 4 } & 1 & 2 & 3 \\
\hline
\end{tabular}

\begin{tabular}{|c|c|c|c|}
\hline \multirow{2}{*}{$\mathbf{V}$} & A veces & $\begin{array}{c}\text { Con } \\
\text { trecuencia }\end{array}$ & Siempre \\
\cline { 2 - 4 } & 1 & 2 & 3 \\
\hline
\end{tabular}

12. Mucha gente me envidia por mi valía.

\begin{tabular}{|c|c|c|c|}
\hline $\mathbf{V}$ & A veces & $\begin{array}{c}\text { Con } \\
\text { frecuencia }\end{array}$ & Siempre \\
\cline { 2 - 4 } & $\mathbf{1}$ & $\mathbf{2}$ & $\mathbf{3}$ \\
\end{tabular}

14. Soy impulsivo.

\begin{tabular}{|c|c|c|c|}
\hline $\mathbf{V}$ & A veces & $\begin{array}{c}\text { Con } \\
\text { trecuencia }\end{array}$ & Siempre \\
\cline { 2 - 4 } & $\mathbf{1}$ & $\mathbf{2}$ & $\mathbf{3}$ \\
\hline
\end{tabular}

15. Me pregunto con frecuencia cuál es mi papel en la vida.

\begin{tabular}{|c|c|c|c|}
\hline \multirow{2}{*}{$\mathbf{V}$} & A veces & $\begin{array}{c}\text { Con } \\
\text { trecuencia }\end{array}$ & Siempre \\
\cline { 2 - 4 } & 1 & 2 & $\mathbf{F}$ \\
\hline
\end{tabular}

16. Me siento aburrido y vacío con facilidad.

\begin{tabular}{|c|c|c|c|}
\hline \multirow{2}{*}{$\mathbf{V}$} & A veces & $\begin{array}{c}\text { Con } \\
\text { trecuencia }\end{array}$ & Siempre \\
\cline { 2 - 4 } & 1 & 2 & 3 \\
\hline
\end{tabular}

$\mathbf{F}$

\begin{tabular}{|c|c|c|c|}
\hline $\mathbf{V}$ & A veces & $\begin{array}{c}\text { Con } \\
\text { trecuencia }\end{array}$ & Siempre \\
\cline { 2 - 4 } & $\mathbf{1}$ & $\mathbf{2}$ & $\mathbf{3}$ \\
\hline
\end{tabular}

17. ¿Le considera la gente demasiado perfeccionista, obstinado o rígido?.

\begin{tabular}{|c|c|c|c|}
\hline $\mathbf{V}$ & A veces & $\begin{array}{c}\text { Con } \\
\text { trecuencia }\end{array}$ & Siempre \\
\cline { 2 - 4 } & $\mathbf{1}$ & $\mathbf{2}$ & $\mathbf{F}$ \\
\hline
\end{tabular}

18. Soy detallista, minucioso y demasiado trabajador.

\begin{tabular}{|c|c|c|c|}
\hline $\mathbf{V}$ & A veces & $\begin{array}{c}\text { Con } \\
\text { trecuencia }\end{array}$ & Siempre \\
\cline { 2 - 4 } & $\mathbf{1}$ & $\mathbf{2}$ & $\mathbf{3}$ \\
\hline
\end{tabular}

20. Me cuesta tomar decisiones por mí mismo.

\begin{tabular}{|c|c|c|c|}
\hline \multirow{2}{*}{$\mathbf{V}$} & A veces & $\begin{array}{c}\text { Con } \\
\text { trecuencia }\end{array}$ & Siempre \\
\cline { 2 - 4 } & 1 & 2 & $\mathbf{F}$ \\
\hline
\end{tabular}

21. Soy nervioso.

\begin{tabular}{|c|c|c|c|}
\hline $\mathbf{V}$ & A veces & $\begin{array}{c}\text { Con } \\
\text { trecuencia }\end{array}$ & Siempre \\
\cline { 2 - 4 } & $\mathbf{1}$ & $\mathbf{2}$ & $\mathbf{3}$ \\
\hline
\end{tabular}

22. Tengo mucho miedo a hacer el ridículo.

\begin{tabular}{|c|c|c|c|c|}
\hline $\mathbf{V}$ & A veces & $\begin{array}{c}\text { Con } \\
\text { trecuencia }\end{array}$ & Siempre & \multirow{2}{*}{$\mathbf{F}$} \\
\cline { 2 - 4 } & $\mathbf{1}$ & $\mathbf{2}$ & $\mathbf{3}$ & \multirow{2}{*}{} \\
\hline
\end{tabular}


Los 11 rasgos se distribuyen en tres grupos diferentes y son evaluados mediante 22 preguntas (2 preguntas por rasgo de personalidad).

Cada pregunta tiene 4 posibilidades de respuesta, que puntúan de 0 a 3. La puntuación de corte para cada rasgo de personalidad se establece en 3.

\begin{tabular}{|c|c|c|}
\hline \multirow{3}{*}{ GRUPO A } & PAR & PARANOIDE (ítems 1 y 2) \\
\hline & ESQ & ESQUIZOIDE (ítems 3 y 4) \\
\hline & EQT & ESQUIZOTÍPICO (ítems 5 y 6) \\
\hline \multirow{5}{*}{ GRUPO B } & HIST & HISTRIÓNICO (ítems 7 y 8) \\
\hline & ANT & ANTISOCIAL (ítems 9 y 10) \\
\hline & NAR & NARCISISTA (ítems 11 y 12) \\
\hline & IE IMP & $\begin{array}{l}\text { Inestabilidad emocional de la personalidad SUBTIPO } \\
\text { IMPULSIVO (ítems } 13 \text { y 14) }\end{array}$ \\
\hline & IE LIM & $\begin{array}{l}\text { Inestabilidad emocional de la personalidad SUBTIPO } \\
\text { LÍMITE (ítems } 15 \text { y 16) }\end{array}$ \\
\hline \multirow{3}{*}{ GRUPO C } & ANAN & ANANCÁSTICO (ítems 17 Y 18) \\
\hline & DEP & DEPENDIENTE (ítems 19 y 20) \\
\hline & ANS & ANSIOSO (ítems 21 y 22) \\
\hline
\end{tabular}

Tomado de: Garcia-Portilla MP, Bascarán MT, Sáiz PA, Parellada M, Bousoño M, Bobes J. Banco de instrumentos básicos para la práctica de la psiquiatría clínica. 6. a ed. Barcelona: Ars Médica; 2011.p. 211. 


\subsection{Anexo VIII}

\section{Escala Hospitalaria de ansiedad y Depresión (HADS)}

A.1. Me siento tenso/a o nervioso/a:

3. Casi todo el día

2. Gran parte del día

1. De vez en cuando

0 . Nunca

D.1. Sigo disfrutando de las cosas como siempre:
0 . Ciertamente, igual que antes
1. No tanto como antes
2. Solamente un poco
3. Ya no disfruto con nada

A.2. Siento una especie de temor como si algo malo fuera a suceder:
3. Sí, y muy intenso
2. Sí, pero no muy intenso
1. Sí, pero no me preocupa
0 . No siento nada de eso

D.2. Soy capaz de reírme y ver el lado gracioso de las cosas:
0 . Igual que siempre
1. Actualmente, algo menos
2. Actualmente, mucho menos
3. Actualmente, en absoluto

A.3. Tengo la cabeza llena de preocupaciones:
3. Casi todo el día
2. Gran parte del día
1. De vez en cuando
0 . Nunca

D.3. Me siento alegre:
3. Nunca
2. Muy pocas veces
1. En algunas ocasiones
0 . Gran parte del día

A.4. Soy capaz de permanecer sentado/a tranquilo/a y relajado/a:
0 . Siempre
1. A menudo
2. Raras veces
3. Nunca

D.4. Me siento lento/a y torpe:
3. Gran parte del día
2. A menudo
1. A veces
0 . Nunca

A.5. Experimento una desagradable sensación de «nervios y hormigueos» en el estómago:

0 . Nunca

1. Sólo en algunas ocasiones

2. A menudo

3. Muy a menudo 
D.5. He perdido el interés por mi aspecto personal:

3. Completamente

2. No me cuido como debería hacerlo

1. Es posible que no me cuide como debiera

0 . Me cuido como siempre lo he hecho

A.6. Me siento inquieto/a como si no pudiera parar de moverme:

3. Realmente mucho

2. Bastante

1. No mucho

0 . En absoluto

D.6. Espero las cosas con ilusión:

0 . Como siempre

1. Algo menos que antes

2. Mucho menos que antes

3. En absoluto

A.7. Experimento de repente sensaciones de gran angustia o temor:
3. Muy a menudo
2. Con cierta frecuencia
1. Raramente
0 . Nunca

D.7. Soy capaz de disfrutar con un buen libro o con un buen programa de radio o televisión:

0 . A menudo

1. Algunas veces

2. Pocas veces

3. Casi nunca

Consta de 14 ítems agrupados en dos subescalas: ansiedad (A) y depresión (D). Cada ítem puntúa de 0 a 3 . El punto de cote establecido para cada una de las subescalas es de 10.

Tomado de: Garcia-Portilla MP, Bascarán MT, Sáiz PA, Parellada M, Bousoño M, Bobes J. Banco de instrumentos básicos para la práctica de la psiquiatría clínica. 6. a ed. Barcelona: Ars Médica; 2011.p. 206 


\subsection{Anexo IX}

\section{Escala de impulsividad de Plutchik}

\begin{tabular}{|l|l|l|l|l|}
\hline & Nunca & $\begin{array}{l}\text { A } \\
\text { veces }\end{array}$ & $\begin{array}{l}\text { A } \\
\text { menudo }\end{array}$ & $\begin{array}{l}\text { Casi } \\
\text { siempre }\end{array}$ \\
\hline 1. ¿Le resulta difícil esperar una cola? & & & & \\
\hline 2. ¿Hace cosas impulsivamente? & & & & \\
\hline 3. ¿Gasta dinero impulsivamente? & & & & \\
\hline 4. ¿Planea cosas con anticipación? & & & & \\
\hline 5. ¿Pierde la paciencia a menudo? & & & & \\
\hline 6. ¿Le resulta fácil concentrarse? & & & & \\
\hline $\begin{array}{l}\text { 7. ¿Le resulta difícil controlar los impulsos } \\
\text { sexuales? }\end{array}$ & & & & \\
\hline $\begin{array}{l}\text { 8. ¿Dice usted lo primero que le viene a la } \\
\text { cabeza? }\end{array}$ & & & & \\
\hline $\begin{array}{l}\text { 9. ¿Acostumbra a comer aun cuando no } \\
\text { tenga hambre? }\end{array}$ & & & & \\
\hline 10. ¿Es usted impulsivo/a? & & & & \\
\hline 11. ¿Termina las cosas que empieza? & & & & \\
\hline $\begin{array}{l}\text { 12. ¿Le resulta difícil controlar las } \\
\text { emociones? }\end{array}$ & & & & \\
\hline 13. ¿Se distrae fácilmente? & & & & \\
\hline 14. ¿Le resulta difícil quedarse quieto? & & & & \\
\hline 15. ¿Es usted cuidadoso o cauteloso? & & & & \\
\hline
\end{tabular}

Las respuestas se recogen en una escala de frecuencia puntuada de 0 a 3 . Los ítems 4, 6, 11 y 15 se puntúan en sentido inverso. La puntuación total se obtiene sumando todos los ítems. El punto de corte propuesto es 20.

Tomado de: Garcia-Portilla MP, Bascarán MT, Sáiz PA, Parellada M, Bousoño M, Bobes J. Banco de instrumentos básicos para la práctica de la psiquiatría clínica. 6. a ed. Barcelona: Ars Médica; 2011.p. 222. 
10. ARTÍCULOS 


\section{Rasgos de personalidad en pacientes migrañosos: estudio multicéntrico utilizando el cuestionario de cribado Salamanca}

Irene Muñoz, M. Elena Toribio-Díaz, Francisco J. Carod-Artal, M. Luz Peñas-Martínez, Lara Ruiz, Elena Domínguez, M. Isabel Pedraza, Vicente Molina, Ángel L. Guerrero-Peral, Fernando Uribe

Introducción. La comorbilidad psiquiátrica en migraña es frecuente, y se ha estudiado más la relacionada con trastornos afectivos y ansiedad que los rasgos de personalidad.

Objetivo. Estudiar la presencia de rasgos de personalidad en personas con migraña y su relación con la presencia de migraña crónica o abuso de medicación.

Pacientes y métodos. Se evalúan pacientes atendidos consecutivamente en cinco centros. Se exploran, mediante las 22 preguntas del cuestionario de cribado Salamanca, 11 rasgos de personalidad agrupados en tres grupos. Se obtuvieron datos referentes a las características demográficas e impacto de la migraña.

Resultados. Se incluyeron en el estudio 164 pacientes (134 mujeres, 30 varones), con una edad media de $36,6 \pm 12,5$ años (rango: 18-78 años). En la mayoría de los pacientes, el impacto de la migraña fue elevado. Los rasgos de personalidad que aparecieron más frecuentemente fueron: ansioso $(53,7 \%)$, anancástico $(44,5 \%)$, histriónico $(40,9 \%)$ y dependiente $(32,9 \%)$. El riesgo de migraña crónica fue superior en pacientes con el rasgo anancástico (riesgo relativo $=2,06$; intervalo de confianza al $95 \%=1,07-3,94 ; p=0,027)$.

Conclusiones. Hay rasgos de personalidad detectables con el cuestionario Salamanca muy frecuentes en pacientes migrañosos. En nuestra serie, el rasgo anancástico se relaciona con la presencia de migraña crónica.

Palabras clave. Abuso de medicación. Cuestionario Salamanca. DSM-IV. Migraña. Migraña crónica. Rasgo de personalidad.

\section{Introducción}

La migraña es uno de los problemas de salud que mayor discapacidad provoca en quienes la padecen $[1,2]$. Afecta, de acuerdo con la práctica totalidad de estudios llevados a cabo, a más del 10\% de la población (alrededor del 7\% en varones y el 16\% en mujeres) [3,4]. En España, dos trabajos recientes muestran que la prevalencia de migraña en adultos oscila entre el $11-13 \%[5,6]$.

La comorbilidad psiquiátrica en migraña es frecuente; los migrañosos tienen entre 2 y 4 veces más riesgo de sufrir depresión que los no migrañosos [7], y entre ambas entidades parece haber una influencia bidireccional. La patología psiquiátrica en migraña se ha relacionado con su cronificación, peor respuesta al tratamiento, sobreuso de medicación, mayor consumo de recursos sanitarios [8-10] y peor percepción de calidad de vida [11]. Muchos trabajos señalan una mayor prevalencia de trastornos afectivos o ansiedad -eje I del Manual diagnóstico y estadístico de los trastornos mentales, cuarta edición (DSM-IV) - [12] en pacientes con migraña crónica que en otros tipos de cefalea [13]. Sin embargo, los estudios centrados en el análisis de las características de personalidad de los pacientes migrañosos son contradictorios y no han conseguido definir sistemáticamente rasgos específicos de personalidad (eje II del DSM-IV) asociados a la migraña [14,15].

Pretendemos evaluar la presencia de diferentes rasgos de personalidad en pacientes migrañosos, utilizando, para ello, el cuestionario Salamanca de trastornos de personalidad [16]. Estudiamos la relación entre estos rasgos de personalidad con la existencia de migraña crónica con o sin abuso de medicación.

\section{Pacientes y métodos}

Incluimos pacientes atendidos consecutivamente como consecuencia de una migraña en las consultas ambulatorias de cinco centros hospitalarios diferentes. En cuatro de ellos (Coslada, Cuenca, Toledo y Zamora), en consultas generales de neurología, y en uno (Valladolid), en una consulta monográfica de cefaleas. El diagnóstico de migraña se realizó de acuerdo con los criterios de la segunda edición de la
Servicio de Neurología; Raigmore Hospital; Inverness, Reino Unido (F.J. Carod-Artal). Servicio de Neurología; Hospital Universitario del Henares; Coslada, Madrid (M.E. Toribio-Díaz). Sección de Neurología; Hospital Virgen de la Concha; Zamora (M.L. Peñas-Martínea). Sevvicio de Neurología; Hospital Nervicio de Neurologia; Hospital Nacional de Parapléjicos; Toledo (L. Ruiz). Servicio de Psiquiatría (I. Muñoz, E. Domínguez, V. Molina, F. Uribe); Servicio de Neurología (M.I. Pedraza, A.L. Guerrero-Peral) Hospital Clínico Universitario de Valladolid; Valladolid, España.

\section{Correspondencia:}

Dr. Ángel tuis Guerrero Peral.

Servicio de Neurología. Hospital Clínico Universitario de Valladolid. Ramón y Cajal, 3. E-47005 Valladolid.

E-mail:

gueneurol@gmail.com

Presentado parcialmente como comunicación oral en el LXIV Congreso de la Sociedad Española de Neurologí; Barcelona, noviembre de 2012

Aceptado tras revisión extema: 17.09.13

Cómo citar este articulo: Muñoz I, Toribio-Díaz ME, CarodArtal FJ, Peñas-Martínez ML, Ruiz L, Domingez $\mathrm{E}$, et al Rast, Dominguez E, et al. Rasgos de migrañosos: estudio multicéntrico migrañosos: estudio multicén
utilizando el cuestionario de utilizando el cuestionario de
cribado Salamanca. Rev Neurol 2013; 57: 529-34.

2013 Revista de Neurologia 
Figura. Porcentaje de pacientes con cada uno de los 11 rasgos de personalidad evaluados. Par: paranoide; Esq: esquizoide; Esquiz: esquizotípico; His: histriónico; Anti: antisocial; Nar: narcisista; Imp: inestabilidad emocional, subtipo impulsivo; Lim: inestabilidad emocional, subtipo límite; Anan: anancástico; Dep: dependiente; Ans: ansioso.

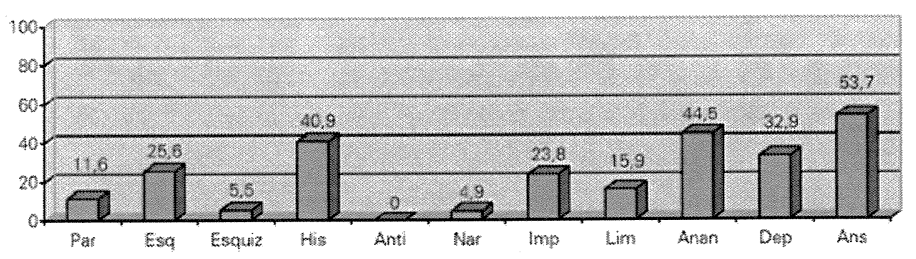

Clasificación Internacional de Cefaleas (CIC-2) [17] y el de migraña crónica y abuso de medicación basándose en los criterios revisados de la CIC-2 de 2006 [18]. Ninguno de los pacientes fue evaluado durante un episodio agudo de migraña.

En estos pacientes consideramos sus características demográficas (edad y sexo) y evaluamos el impacto de la migraña administrando el Headache Impact Test-6 (HIT-6).

A todos ellos se les administró el cuestionario Salamanca. Este cuestionario es autoaplicado, de corta duración (< 10 minutos) y fácil interpretación. Fue validado en 2007 y se correlacionó con el International Personality Disorder Examination, considerándose un adecuado test de cribado, con una sensibilidad del $100 \%$ y una especificidad del $76,3 \%$ [19]. Clasifica los rasgos de personalidad desde un punto de vista categorial y los define según la nomenclatura del DSM-IV, texto revisado [12] (paranoide, esquizoide, esquizotípico, histriónico, antisocial, narcisista y dependiente) o según la nomenclatura de la Clasificación Internacional de Enfermedades, décima revisión (CIE-10) [20] (inestabilidad emocional subtipo impulsivo, inestabilidad emocional subtipo límite, anancástico y ansioso). Los 11 rasgos se agrupan en tres grupos diferentes:

A. Extraños o extravagantes: paranoide, esquizoide y esquizotípico.

B. Inmaduros: histriónico, antisocial, narcisista y trastorno de la inestabilidad emocional, con sus dos subtipos (límite e impulsivo).

C. Temerosos: anancástico, ansioso y dependiente.

El cuestionario Salamanca consta de 22 preguntas; cada uno de los 11 rasgos de personalidad se evalúa utilizando dos preguntas. Cada pregunta tiene cuatro posibilidades de respuesta, que puntúan de 0 a 3 .
La suma de las dos preguntas tiene como valor máximo 6 puntos, y se establece la puntuación de corte para rasgo de personalidad en 3.

Fueron excluidos aquellos pacientes en quienes alteraciones físicas o psicológicas podían limitar su capacidad para responder el cuestionario.

Evaluamos la correlación entre los rasgos de personalidad y el resto de variables consideradas utilizando la $t$ de Student o el test de $\chi^{2}$ según conveniencia, y estableciendo el nivel de significación en 0,05 . Utilizamos para todo ello el programa estadístico SPSS v. 15.0.

\section{Resultados}

Se estudiaron 164 pacientes (134 mujeres, 30 varones). La edad al ser atendidos era de $36,6 \pm 12,5$ años (rango: 18-78 años); la edad referida de inicio de la migraña, 19,6 \pm 9,2 (rango: 5-50 años), y el tiempo de evolución de la migraña, de 10,6 \pm 9,0 años (rango: 0-30 años).

Cincuenta y nueve pacientes (36\%) cumplían al ser evaluados criterios de migraña crónica, y 40 de ellos ( $24,4 \%$ del total), de sobreuso de medicación. La gravedad medida por el HIT-6 fue de 62,7 $\pm 7,1$ puntos (rango: 42-78 puntos), y en 114 pacientes $(69,5 \%)$ el impacto de la migraña era grave (HIT-6 > 59 puntos).

Los rasgos de personalidad que aparecieron más frecuentemente en los pacientes migrañosos fueron los recogidos en el grupo C: ansioso (53,7\%), anancástico $(44,5 \%)$ y dependiente $(32,9 \%)$. Dentro del grupo $\mathrm{B}$, el rasgo histriónico fue el más presente $(40,9 \%)$. La frecuencia de los 11 rasgos de personalidad evaluados se muestra en la figura.

No encontramos diferencias significativas en la presencia de los diferentes rasgos de personalidad estudiados en función del sexo.

El riesgo de migraña crónica fue superior en pacientes con rasgo anancástico, y el riesgo relativo fue de 2,06 (intervalo de confianza al $95 \%=1,07$ $3,94 ; p=0,027)$. No encontramos relación entre la presencia de los diferentes rasgos de personalidad $y$ el resto de variables evaluadas.

La distribución de las principales variables analizadas en función de los rasgos de personalidad del grupo C se muestra en las tablas I, II y III.

\section{Discusión}

Un rasgo de personalidad es un patrón persistente de formas de percibir, relacionarse y pensar sobre el 
entorno y sobre uno mismo [12]. Sólo constituye un trastorno de personalidad cuando se vuelve inflexible y desadaptativo, o cuando causa deterioro funcional significativo o malestar subjetivo. En nuestro caso, hemos seguido un enfoque diagnóstico de los rasgos de personalidad con perspectiva categorial, como el presentado en los manuales DSM-IV y CIE-10, es decir, que consideramos 11 rasgos de personalidad cualitativamente distintos de acuerdo con estas dos clasificaciones. Es importante diferenciar estos rasgos de personalidad de comportamientos reactivos a estresantes situacionales o incluso de estados mentales transitorios. Por ello, su diagnóstico requiere una evaluación específica. En un primer abordaje se utilizan generalmente cuestionarios o tests de cribado, como el Salamanca empleado en este trabajo, que permitan una tipificación. No es extraño que un mismo individuo cumpla criterios para más de un rasgo a la vez, haciéndose constar todos ellos.

La implicación de la psicofisiopatología en la migraña se reconoce desde hace años [21]. Wolff definió la 'personalidad migrañosa' en 1937 [22]. Sin embargo, la relación entre migraña y psicopatología ha sido más discutida que estudiada de forma sistemática [14], y sólo recientemente se está investigando en esa dirección [23-27].

El estudio de la comorbilidad psiquiátrica en la migraña es tarea complicada. Supone añadir variables heterogéneas y difícilmente medibles. El uso de la primera versión de la CIC, hasta 2004, con una falta de reconocimiento de la migraña crónica, ha afectado a los resultados de bastantes estudios [28]. Estas y otras limitaciones metodológicas han podido dificultar el diseño de protocolos y la obtención de resultados concluyentes.

A pesar de ello, existen hallazgos de notable consistencia dentro de este campo. Estudios epidemiológicos y clínicos han mostrado la comorbilidad entre migraña y depresión. Los pacientes migrañosos tienen de 2,2 a 4 veces más riesgo de padecer depresión [7]. Diferentes estudios han confirmado, además de una relación sindrómica, una secuencia temporal [23-25]. Actualmente se apuesta por una influencia bidireccional entre depresión y migraña [29-31]. Del mismo modo, se ha señalado la asociación entre migraña y trastornos de ansiedad. En algunos estudios, la asociación es incluso mayor que entre depresión y migraña, siendo la odds ratio entre migraña y trastorno por ansiedad generalizada de $3,5-5,3$ [7].

Recientemente se ha abordado también un enfoque multidisciplinar, orientado hacia el análisis de las características de personalidad, en tanto que exis-
Tabla I. Distribución de las variables estudiadas en función de la presencia del rasgo ansioso.

\begin{tabular}{lcc}
\hline & $\begin{array}{c}\text { Presencia } \\
(n=88)\end{array}$ & $\begin{array}{c}\text { No presencia } \\
(n=76)\end{array}$ \\
\hline Migraña crónica & $36,3 \%$ & $35,5 \%$ \\
\hline Abuso de medicación & $28,4 \%$ & $19,7 \%$ \\
\hline HIT-6 (puntos) & 63,2 & 62,2 \\
\hline HIT-6 > 59 puntos & $68,1 \%$ & $71 \%$ \\
\hline Evolución de la migraña (años) & 18,2 & 15,4 \\
\hline Días de dolor/mes & 10,5 & 10,8 \\
\hline
\end{tabular}

HIT-6: Headache Impact Test-6.

Tabla II. Distribución de las variables estudiadas en función de la presencia del rasgo anancástico.

\begin{tabular}{lcc}
\hline & $\begin{array}{c}\text { Presencia } \\
(n=73)\end{array}$ & $\begin{array}{c}\text { No presencia } \\
(n=91)\end{array}$ \\
\hline Migraña crónica ${ }^{\text {a }}$ & $45,2 \%$ & $28,5 \%$ \\
\hline Abuso de medicación & $19,7 \%$ & $30,1 \%$ \\
\hline HIT-6 (puntos) & 63,5 & 62,1 \\
\hline HIT-6 > 59 puntos & $72,6 \%$ & $67 \%$ \\
\hline Evolución de la migraña (años) & 18,7 & 15,4 \\
\hline Días de dolor/mes & 11,9 & 9,6 \\
\hline
\end{tabular}

HIT-6: Headache Impact Test $-6 .{ }^{\text {a }} p=0,027$.

Tabla III. Distribución de las variables estudiadas en función de la presencia del rasgo dependiente.

\begin{tabular}{lcc}
\hline & $\begin{array}{c}\text { Presencia } \\
(n=54)\end{array}$ & $\begin{array}{c}\text { No presencia } \\
(n=110)\end{array}$ \\
\hline Migraña crónica & $38,8 \%$ & $34,5 \%$ \\
\hline Abuso de medicación & $25,9 \%$ & $23,6 \%$ \\
\hline HIT-6 (puntos) & 63,6 & 62,6 \\
\hline HIT-6 > 59 puntos & $72,2 \%$ & $68,1 \%$ \\
\hline Evolución de la migraña (años) & 16,4 & 17,1 \\
\hline Días de dolor/mes & 11,4 & 10,3 \\
\hline
\end{tabular}

HIT-6: Headache Impact Test-6. 
ten ciertos perfiles, así como estilos de afrontamiento, que se observan de manera repetida en pacientes migrañosos [27,32]. Éstos tienen mayor vulnerabilidad al estrés, rigidez y tendencia a la somatización que los sujetos no migrañosos [33]. Un perfil psicológico anormal puede tener importantes implicaciones clínicas y terapéuticas [34,35]. El uso del Zuckerman-Khulman's Eysenk Personality Questionnaire ha evidenciado que los pacientes migrañosos poseen un alto grado de neuroticismo e in troversión [36,37]. De manera similar, el Minnesota Multiphasic Personality Inventory (MMPI) ha demostrado una puntuación elevada del rango neurótico (hipocondría, neurosis, depresión e histeria) [38]. Una aproximación novedosa al estudio dimensional de la personalidad es el Temperament and Character Inventory, que hace referencia al modelo desarrollado por Cloninger et al [39]; así, se ha registrado una mayor presentación de síntomas somáticos en respuesta a la ansiedad y una mayor tendencia a la evitación de daños.

El objetivo de nuestro trabajo ha sido definir estas características de personalidad en términos operativos; por ello, hemos considerado clínicamente más relevante estudiar rasgos de personalidad cualitativamente distintos. Este enfoque categorial permite detectar perfiles de personalidad anormales sin detenerse en descripciones de la personalidad desde un punto de vista dimensional.

Los rasgos de la personalidad complican el manejo de la migraña, dificultan el tratamiento de los trastornos afectivos y de ansiedad, y pueden llegar incluso a frustrar al profesional, contribuyendo por todo ello a un peor pronóstico del paciente [40]. Representan posiblemente un elevado porcentaje de migrañas intratables, especialmente en lo referido al trastorno límite de personalidad [41]. Una única entrevista raramente es suficiente para confirmar el diagnóstico, pero sí para establecer una sospecha.

En nuestro estudio se aprecian rasgos de personalidad especialmente frecuentes entre la población de migrañosos, particularmente los pertenecientes al grupo $\mathrm{C}$ (por orden de frecuencia: ansioso, anancástico y dependiente). Estos tres rasgos de personalidad se correlacionan con las dimensiones clásicas de introversión y neuroticismo. Estos resultados son comparables con los de otros estudios en pacientes migrañosos, especialmente aquellos que utilizan como herramienta el MMPI [27,32-39]. Podríamos inferir que existe una alta probabilidad de que los pacientes migrañosos tengan una personalidad más ansiosa y reactiva al estrés. Otra posibilidad sería definirlo en términos de nerviosismo, sensibilidad y propensión a la preocupación. Hablaríamos de pacientes con mayor susceptibilidad al estrés y menor tolerancia a la frustración; podríamos abordar la posibilidad de detectar con este planteamiento al 'paciente migrañoso difícil', en el que un abordaje limitado al tratamiento sintomático o preventivo estándar resultaría infructuoso $[42,43]$.

Aunque no hemos encontrado correlación entre los rasgos de personalidad y la intensidad de la migraña o el sobreuso de medicación como apuntan otros estudios [44], merece la pena destacar el riesgo significativo de migraña crónica en pacientes con el rasgo anancástico. En este sentido, dicho rasgo de personalidad se ha estudiado como posible factor predictivo de pacientes refractarios al tratamiento en la migraña crónica, por su sospechada relación con el sobreuso de medicación [45]. Pretendemos, en un futuro próximo y siguiendo en esta línea de investigación, aumentar el número de pacientes estudiados, incluir el estudio de la impulsividad como posible factor de riesgo de sobreuso de medicación [46], y validar los resultados obtenidos con el test de cribado Salamanca con herramientas más complejas, como el MMPI, en un grupo de pacientes.

Este estudio presenta, sin embargo, algunas limitaciones. La prevalencia de los trastornos de personalidad estudiados en sujetos migrañosos no se comparó con un grupo control de sujetos sanos sin migraña. Por otro lado, la migraña es una enfermedad crónica que cursa con fases de exacerbación, recurrencia y mejora a lo largo de la vida. Ya que se desconoce la sensibilidad al cambio de dicho cuestionario de personalidad, serán necesarios en el futuro estudios de carácter prospectivo que nos permitan evaluar los cambios que de modo dinámico pueden surgir a lo largo del tiempo en los aspectos relacionados con la personalidad en una cohorte poblacional.

\section{Bibliografía}

1. Steiner TJ, Stovner LJ, Birbeck GL. Migraine: the seventh disabler. Headache 2013; 53: 227-9.

2. Vos T, Flaxman AD, Naghavi M, Lozano R, Michaud C, Ezzati M, et al. Years lived with disability (YLD) for 1160 sequelae of 289 diseases and injuries 1990-2010: a systematic analysis for the Global Burden of Disease Study 2010. Lancet 2012; 380: 2163-96.

3. Stovner LJ, Zwart JA, Hagen K, Terwindt GM, Pascual J. Epidemielogy of headache in Europe. Eur J Neurol 2006; 13: $333-45$.

4. Manzoni GC, Stovner LJ. Epidemiology of headache Hadb Clin Neurol 2011; 97: 3-22.

5. Fernández de las Peñas $C$, Hernández-Barrera V, CarrascoGarrido P, Alonso-Blanco C, Palacios-Ceña D, JiménezSánchez S, et al. Population-based study of migraine in Spanish adults: Relation to socio-demographic factors, lifestyle and co-morbidity with other conditions. J Headache Pain 2010; 11: 97-104. 
6. Matías-Guiu J, Porta-Etessam J, Mateos V, Díaz-Insa S, López-Gil A, Fernández C. One-year prevalence of migraine in Spain: a nationwide population-based survey. Cephalalgia 2011; 31: 463-70.

7. Hamelsky SW, Lipton RB. Psychiatric comorbidity of migraine. Headache 2006; 46: 1327-33.

8. Sheftell FD, Atlas SJ. Migraine and psychiatric comorbidity: from theory and hypotheses to clinical application. Headache 2002; 42: 934-44.

9. Leonardi M, Musicco M, Nappi G. Headache as a major public health problem: a current status. Cephalalgia 1998; 18 (Suppl 21): S66-9.

10. Carod-Artal FJ, Irimia P, Ezpeleta D. Migraña crónica: definición, epidemiología, factores de riesgo y tratamiento. Rev Neurol 2012; 54: 629-37.

11. Jette N, Patten S, Williams J, Becker W, Wiebe S. Comorbidity of migraine and psychiatric disorders. A national populationbased study. Headache 2008; 48: 501-16.

12. López-Ibor Aliño JJ, Valdés-Miyar M. Manual diagnóstico y estadístico de los trastornos mentales. Barcelona: Masson; 2002.

13. Antonaci F, Nappi G, Galli F, Manzoni GC, Calabresi P, Costa A. Migraine and psychiatric comorbidity: a review of clinical findings. J Head Pain 2011; 12: 115-25.

14. Silberstein SD, Lipton RB, Breslau N. Migraine: association with personality characteristics and psychopathology. Cephalalgia 1995; 15: 358-69.

15. Mongini F, Keller R, Deregibus A, Raviola F, Mongini T, Sancarlo M. Personality traits, depression and migraine in women: a longitudinal study. Cephalalgia 2003; 23: 186-92

16. García-Portilla MP, Bascarán MT, Saiz PA, Parellada $M$,

Bousoño M, Bobes J. Banco de instrumentos básicos para la práctica de la psiquiatría clínica. 6 ed. Barcelona: Ars Médica; 2011.

17. Headache Classification Subcommittee of the International Headache Society. The international classification of headache disorders: second edition. Cephalalgia 2004; 24 (Suppl 1): S9-160.

18. Olessen J, Bousser MJ, Diener HC, Dodick D, First M, Goadsby PJ, et al; Headache Classification Committee. New appendix criteria open for a broader concept of chronic migraine. Cephalalgia 2006; 26: 742-6.

19. Caldero-Alonso A. Estudio de los resultados obtenidos en el cuestionario Salamanca en población normal. Salamanca: Universidad de Salamanca; 2009.

20. CIE 10. Trastornos mentales y del comportamiento. Madrid: Meditor; 1994.

21. Keck PE Jr, Merikangas KR, McElroy SL, Strakowski SM. Diagnostic and treatment implications of psychiatric comorbidity with migraine. Ann Clin Psychiatry 1994: 6: 165-71.

22. Wolff HG. Personality features and reactions of subjects with migraine. Arch Neurol Psychiatry 1937; 37: 895-921.

23. Merikangas KR, Angst J, Isler $\mathrm{H}$. Migraine and psychopathology: results of the Zurich cohort study of young adults. Arch Gen Psychiatry 1990: 47: 849-53.

24. Merikangas KR, Stevens DE, Angst J. Psychopathology and headache syndromes in the community. Headache 1994; 34: $17-22$.

25. Breslau N, Davis GC, Andreski P. Migraine, psychiatric disorders, and suicide attempts: an epidemiologic study of young adults. Psychiatry Res 1991; 37: 11-23.

26. Breslau N, Davis GC. Migraine, physical health and psychiatric disorder: a prospective epidemiologic study in young adults. J Psychiatr Res 1993; 27: 211-21.

27. Mateos V, García-Moncó JC, Gómez-Beldarrain $M$ Armengol-Bertolín S, Larios C. Factores de personalidad, grado de discapacidad y abordaje terapéutico de los pacientes con migraña atendidos en primera consulta en neurología (estudio Psicomig). Rev Neurol 2011; 52: 131-8.

28. Lipton RB, Tracing transformation: chronic migraine: classification, progression and epidemiology. Neurology 2009; 72 (Suppl 5): S3-7.

29. Breslau N, Davis GC, Schultz LR, Peterson EL. Migraine and major depression: a longitudinal study. Headache 1994; 34: 387-93.

30. Breslau N, Lipton RB, Stewart WF, Schultz LR, Welch KM. Comorbidity of migraine and depression: investigating potential etiology and prognosis. Neurology 2003; 60: 1308-12.

31. Breslau N, Schultz LR, Stewart WF, Lipton RB, Lucia VC, Welch KM. Headache and major depression: is the association specific to migraine? Neurology 2000; 54: 308-13.

32. Di Piero V, Bruti G, Venturi P, Talamonti F, Biondi M, Di Legge $S$, et al. Aminergic tone correlates of migraine and tension-type headache: a study using the tridimensional personality questionnaire. Headache 2001; 41: 63-71.

33. Merikangas KR, Stevens DE, Angst J. Headache and personality: results of a community sample of young adults. J Psychiatry Res 1993; 27: 187-96

34. Sánchez-Román $\mathrm{S}$, Téllez-Zenteno JF, Zermeño-Phols $\mathrm{F}$, García-Ramos G, Velázquez A, Derry P, et al. Personality in patients with migraine evaluated with the "Temperamen and Character Inventory'. J Head Pain 2007; 8: 94-104.

35. Abbate-Daga G, Fassino S, Lo Giudice R, Rainero I, Gramaglia C, Marech L, et al. Anger, depression and personality dimensions in patients with migraine without aura. Psychoter Psychosom 2007; 76: 122-8.

36. Cao M, Zhang S, Wang K, Wang Y, Wang W. Personality traits in migraine and tension-type headaches: a five-facto model study. Psychopathology 2002; 35: 254-8.

37. Rasmussen BK. Migraine and tension-type headache in a general population: psychosocial factors. Int J Epidemiol 1992. 21: 1138-43.

38. Mongini F, Ibertis F, Barbalonga E, Raviola F. MMPI-2 profiles in chronic daily headache and their relationship to anxiety levels and accompanying symptoms. Headache 2000; 40: 466-72

39. Cloninger CR, Svrakic DM, Przybeck TR. A psychobiological model of temperament and character. Arch Gen Psychiatry 1993; 50: 975-90.

40. Saper JR, Lake AE. Borderline personality disorder and the chronic headache patient: review and management recommendations. Headache 2002; 42: 663-74.

41. Rothrock J, Lopez I, Zweilfer R, Andress-Rothrock D, Drinkard R Walters $N$. Borderline personality disorder and migraine. Headache 2007; 47: 22-6.

42. Rausa M, Cevoli S, Sancisi E, Grimaldi D, Pollutri G, Casoria M, et al. Personality traits in chronic daily headache patients with and without psychiatric comorbidity: an observationa study in a tertiary care headache center. J Headache Pain 2013; 14: 22.

43. Davis RE, Smitherman TA, Baskin SM. Personality traits, personality disorders, and migraine: a review. Neurol Sci 2013; 34 (Suppl 1): S7-10.

44. Curone M, Tullo V, Mea E, Proietti-Cecchini A, Peccarisi C Bussone G. Psychopathological profile of patients with chronic migraine and medication overuse: study and findings in 50 cases. Neurol Sci 2011; 32 (Suppl 1): S177-9.

45. Curone M, D'Amico D, Bussone G. Obsessive-compulsiv aspects as predictors of poor response to treatments in patients with chronic migraine and medication overuse. Neurol Sci 2012; 33 (Suppl 1): S211-3.

46. Radat F, Creach C, Swendsen JD, Lafittau M, Irachabal S, Dousset V, et al. Psychiatric comorbidity in the evolution from migraine to medication overuse headache. Cephalalgia 2005; 25: 519-22. 
Personality traits in patients with migraine: a multi-centre study using the Salamanca screening questionnaire

Introduction. Psychiatric comorbidity is frequent in cases of migraine and research has focused more on that related to affective disorders and anxiety than to personality traits.

Aims. To study the presence of personality traits in persons with migraine and how they are related with the presence of chronic migraine or medication abuse.

Patients and methods. Patients attended consecutively in five centres were evaluated. The 22 questions in the Salamanca screening questionnaire were used to explore 11 personality traits classified in three groups. Data were obtained concerning demographic characteristics and the impact of migraine.

Results. The sample used in the study included 164 patients (134 females and 30 males), with a mean age of $36.6 \pm 12.5$ years (range: $18-78$ years). In most patients, the impact of migraine was high. The personality traits that appeared most frequently were: anxious (53.7\%), anankastic (44.5\%), histrionic $(40.9 \%)$ and dependent $(32.9 \%)$. The risk of chronic migraine was higher in patients with the anankastic trait (relative risk $=2.06$; confidence interval at $95 \%=1.07-3.94 ; p=0.027$ ).

Conclusions. Some of the personality traits that can be detected with the Salamanca questionnaire are very common in patients with migraine. In our series, the anankastic trait is related with the presence of chronic migraine.

Key words. Chronic migraine. DSM-IV. Medication abuse. Migraine. Personality trait. Salamanca questionnaire. 
ORIGINAL

\title{
Impulsividad en pacientes migrañosos: estudio en una serie de 155 casos $^{\text {is }}$
}

\author{
I. Muñoz ${ }^{a}$, M.S. Hernández ${ }^{a}, M_{\text {.I. Pedraza }}{ }^{b}$, E. Domínguez ${ }^{a}$, M. Ruiz ${ }^{b}$, G. Isidro ${ }^{a}$, \\ E. Mayor ${ }^{a}$, E.M. Sotelo ${ }^{a}$, V. Molina ${ }^{a}$, A.L. Guerrero ${ }^{b, *}$ y F. Uribe ${ }^{a}$
}

a Servicio de Psiquiatria, Hospital Clínico Universitario de Valladolid, Valladolid, España
b Servicio de Neurologia, Hospital Clínico Universitario de Valladolid, Valladolid, España

Recibido el 2 de abril de 2014; aceptado el 10 de octubre de 2014

\begin{abstract}
PALABRAS CLAVE
Ansiedad;

Depresión;

Escala de Plutchik;

Impulsividad;

Migraña crónica;

Uso excesivo de

medicación

Resumen

Introducción: La impulsividad es una dimensión psicológica no estudiada en profundidad en pacientes con cefalea. Pretendemos evaluar su influencia en la presencia de una migraña crónica (MC) o uso excesivo de medicación (UEM).

Pacientes: Pacientes atendidos consecutivamente en una consulta de cefaleas (enero de 2013marzo de 2014). Diagnosticamos migraña episódica, MC o UEM de acuerdo con la Clasificación Internacional de Cefaleas, versión beta de la III edición (CIC-III). Recogimos prospectivamente características demográficas y clínicas. Evaluamos trastornos del ánimo mediante la Escala de Ansiedad y Depresión Hospitalaria (HADS) y la impulsividad con la Escala de Plutchik.

Resultados: Ciento cincuenta y cinco pacientes (22 varones, 133 mujeres), edad 38,2 $\pm 11,7$ años $(18-70) ; 104(67,1 \%)$ con MC y entre ellos $74(71,1 \%)$ con UEM. El $28,4 \%$ de los 155 pacientes incluidos en la serie cumplía criterios de ansiedad, el 7,1\% de depresión, y el 16,1\% de impulsividad. Las puntuaciones de las subescalas HADS-ansiedad $(8,5 \pm 4,5$ vs. $6.4 \pm 3.6, p: 0.003)$ y HADS-depresión ( $4,4 \pm 4,3$ vs. $1,9 \pm 2,3, p<0,001)$, eran mayores en los casos con MC. Entre los pacientes con MC, HADS-ansiedad $(9,3 \pm 4,4$ vs. $6,8 \pm 4,3$, p: 0,01$)$ y HADS-depression $(5,1 \pm 4,6$ vs. $2,7 \pm 2,9, p: 0,002$ ) eran más altas en aquellos con UEM. No encontramos relación entre la presencia de impulsividad o la puntuación en la Escala de Plutchik y la MC o UEM.

Conclusiones: En nuestra población de migrañosos la impulsividad es frecuente, pero, a diferencia de los estados de ánimo, no se correlaciona con MC O UEM.

(c) 2014 Sociedad Española de Neurología. Publicado por Elsevier España, S.L.U. Todos los derechos reservados.
\end{abstract}

\footnotetext{
Presentado parcialmente como Comunicación Oral en el LXV Congreso de la Sociedad Española de Neurología, Barcelona, Noviembre 2013.

* Autor para correspondencia.

Correo electrónico: gueneurol@gmail.com (A.L. Guerrero).
} 


\section{KEYWORDS}

Anxiety;

Depression;

Plutchik scale,

Impulsivity;

Chronic migraine;

Medication overuse

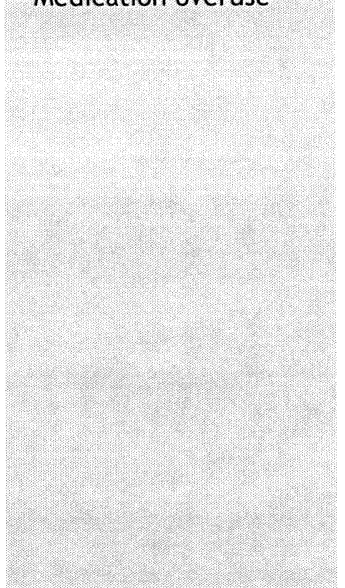

Impulsivity among migraine patients: Study in a series of 155 cases

\section{Abstract}

Introduction: Impulsivity is a psychological phenomenon that has not been extensively studied in headache patients. We aim to assess the presence of impulsivity in patients with chronic migraine $(C M)$ and medication overuse $(M O)$.

Patients: All patients examined in an outpatient headache clinic between January 2013 and March 2014 were included. Episodic migraine, CM, and MO were diagnosed according to ICHD-III beta criteria. We prospectively gathered demographic and clinical characteristics. Mood disorders were evaluated using the Hospital Anxiety and Depression Scale (HADS) and impulsiveness was assessed with the Plutchik impulsivity scale.

Results: A total of 155 patients were included ( 22 men, 133 women). The mean age (SD) was 38.2 (11.7) years (range, 18-70); 104 patients $(67.1 \%)$ presented CM and, among them, $74(71.1 \%)$ had MO. Of the patient total, $28.4 \%$ met criteria for anxiety, $7.1 \%$ for depression and $16.1 \%$ for impulsivity. The CM group showed higher scores for HADS-anxiety (8.5 [SD 4.5] vs. 6.4 [SD 3.6], $\mathrm{p}=0.003$ ) and HADS-depression (4.4 [4.3] vs. 1.9 [2.3], $\mathrm{p}<0.001)$. Among CM cases only, scores for HADS-anxiety (9.3 [4.4] vs. 6.8 [4.3], $p=0.01$ ) and HADS-Depression (5.1 [4.6] vs. 2.7 [2.9], $p=0.002$ ) were higher in patients who also had $M O$. We found no associations between Plutchik scale scores or presence of impulsivity with either CM or MO.

Conclusion: Impulsivity is a common trait in our population of migraine patients, but unlike mood disorders, it is not correlated with either CM or MO.

(c) 2014 Sociedad Española de Neurología. Published by Elsevier España, S.L.U. All rights reserved.

\section{Introducción}

La comorbilidad psiquiátrica en migraña es frecuente $e^{1,2}$. Se encuentra cada vez mejor documentada, especialmente en lo que se refiere al trastorno de depresión mayor y al espectro de los trastornos de ansiedad ${ }^{3,4}$. Se ha relacionado con una peor respuesta al tratamiento, uso excesivo de medicación y cronificación de la migraña ${ }^{5 \cdots 7}$. Asimismo, existen perfiles de personalidad que se han vinculado con patrones de afrontamiento al dolor que complican el manejo de la migraña ${ }^{8,9}$.

Uno de los principales factores de riesgo en la aparición de una migraña crónica (MC) es el uso excesivo de medicación (UEM) ${ }^{10,11}$. Este comportamiento puede responder a dos causas principales; por un lado, el simple aumento de la dosis de medicación sintomática como consecuencia del incremento de los días con dolor. Pero, y eso es especialmente interesante para el planteamiento de este trabajo, este uso excesivo se ha relacionado con ciertos rasgos de personalidad que se traducen en la tendencia de estos pacientes a tomar medicación por el miedo a sufrir nuevos episodios dolorosos, especialmente aquellos intensos que interfieren con sus actividades habituales ${ }^{12}$.

Hasta ahora han sido escasos los estudios que han analizado aspectos de la personalidad en los pacientes migrañosos y su influencia en el UEM y la $M C^{13 \cdots 16}$. Por ejemplo, la tendencia al aumento de consumo de medicación analgésica de forma rápida y escalonada, que en último término conlleva un UEM, puede estar asociado a un perfil de personalidad impulsivo. La personalidad impulsiva se expresa en forma de conductas rápidas provocadas por un bajo umbral de paso a la acción donde se subestiman las consecuencias. En este tipo de pacientes esto se traduce en la pérdida de control sobre el consumo de analgésicos, aspecto que queda fuera del alcance de gran parte de la medicación preventiva utilizada en estos pacientes, con la correspondiente mayor dificultad de manejo de su migraña; por ello, el despistaje de rasgos impulsivos puede proporcionar al clínico información que le permita ajustar el pronóstico o diferentes opciones de tratamiento en cada uno de sus pacientes ${ }^{12}$.

Pretendemos en este trabajo evaluar la impulsividad en diferentes situaciones clínicas de migraña y determinar si existe relación entre la presencia de esta dimensión de la personalidad y una mayor tendencia al uso excesivo de medicación sintomática o la evolución a una migraña crónica.

\section{Material y métodos}

Incluimos pacientes atendidos consecutivamente por primera vez en una Unidad de Cefalea de un hospital terciario entre enero de 2013 y marzo de 2014. Los diagnósticos de ME, MC, O UEM se llevaron a cabo de acuerdo con la III edición, versión beta de la Clasificación Internacional de Cefaleas (CIC-1II) $)^{17}$. Ninguno de los pacientes fue evaluado durante un episodio de migraña agudo. Fueron excluidos aquellos casos con algún trastorno médico o psiquiátrico no incluido dentro de los trastornos del estado de ánimo o de ansiedad, o bien un déficit intelectual que pudiera limitar su capacidad para entender o contestar a las preguntas de los cuestionarios. Se recogieron prospectivamente las características sociodemográficas de los pacientes, si se trataba de una ME o MC, y el tiempo transcurrido en años desde el inicio de su migraña. Registramos el número de días de 


\begin{tabular}{l} 
Tabla 1 Escala de impulsividad de Plutchik \\
\hline 1. ¿Le resulta difícil esperar una cola? \\
2. ¿Hace cosas impulsivamente? \\
3. ¿Gasta dinero impulsivamente? \\
4. ¿Planea cosas con anticipación? \\
5. ¿Pierde la paciencia a menudo? \\
6. ¿Le resulta fácil concentrarse? \\
7. iLe resulta difícil controlar los impulsos sexuales? \\
8. ¿Dice usted lo primero que le viene a la cabeza? \\
9. ¿Acostumbra a comer aun cuando no tenga hambre? \\
10. ¿Es usted impulsivo/a? \\
11. ¿Termina las cosas que empieza? \\
12. ¿Le resulta difícil controlar las emociones? \\
13. ¿Se distrae fácilmente? \\
14. ¿Le resulta difícil quedarse quieto? \\
15. ¿Es usted cuidadoso o cauteloso? \\
Las respuestas se recogen en una escala de frecuencia puntuada de 0 a 3 . Los items $4,6,11$ y 15 se puntúan en sentido inverso. \\
Fuente: Garcia-Portilla et al. ${ }^{33}$.
\end{tabular}

cefalea durante el mes previo. Excluimos del análisis a los pacientes con migraña episódica de alta frecuencia (entre 10 y 15 días de dolor al mes), al considerar que, pese a tratarse de acuerdo con $\mathrm{Ia} \mathrm{CIC}$-III de una ME, existe un solapamiento con lo que consideramos una MC. Tuvimos en cuenta el uso excesivo de medicación, los antecedentes psiquiátricos, los hábitos tóxicos y el uso durante los meses previos de medicación psiquiátrica o profilaxis antimigrañosa.

Evaluamos el impacto de la migraña con el Headache Impact Test-6 (HIT-6); este test establece mediante 6 preguntas de elección múltiple, cuatro categorías de discapacidad en función de la puntuación: Severa $(\geq 60)$, moderada (56-59), leve (50-55) y ausente $(\leq 49)^{18}$.

En cuanto a la detección de los trastornos del estado de ánimo y los trastornos de ansiedad utilizamos la Escala de Ansiedad y Depresión Hospitalaria (HADS) ${ }^{19}$. Se trata de un instrumento de cribado que permite la detección de trastornos depresivos y ansiosos. Es un test autoaplicado con un marco de referencia temporal en la semana previa. Adaptada y validada al español, consta de 14 ítems agrupados en 2 subescalas; ansiedad y depresión. Ninguno de esos ítems hace referencia a síntomas somáticos, lo cual resulta útil en los pacientes migrañosos para evitar la sobrestimación de psicopatología que podría producirse al interpretar síntomas físicos relacionados con la migraña como síntomas somáticos secundarios a ansiedad o depresión. El punto de corte establecido para cada una de las subescalas es de 10.

Para medir la impulsividad usamos la Escala de Impulsividad de Plutchik ${ }^{20}$. Se trata de un test autoaplicado, diseñado para evaluar conductas impulsivas. Es una herramienta de cribado validada al español, de fácil interpretación y corta duración (se aplica en entre 2 y 5 minutos). Consta de 15 ítems que se refieren a la tendencia del paciente a «hacer cosas sin pensar» o de forma impulsiva. Todos ellos se relacionan con una posible falta de control sobre determinadas conductas englobadas en la capacidad para planificar ( 3 ítems), control de los estados emocionales (3 ítems), control de las conductas de comer, gastar dinero o mantener relaciones sexuales ( 3 ítems) y control de otras conductas
(6 ítems). (tabla 1). Las respuestas se recogen en una escala de frecuencia que se puntúa de 0 a 3 (nunca, a veces, a menudo, casi siempre). Los ítems 4, 6, 11 y 15 se puntúan en sentido inverso. La puntación total se obtiene sumando todos los ítems y oscila entre 0 y 45 . En la versión española los autores proponen un punto de corte de 20 , con una sensibilidad del $60 \%$ y una especificidad del $74 \%$. La consistencia interna de la escala de acuerdo al coeficiente de fiabilidad alfa de Cronbach fue 0,9 y la fiabilidad test-retest por el coeficiente de correlación de Pearson 0,91.

Se compararon las características demográficas y clínicas así como los valores de las diferentes escalas, o la existencia según ellas de ansiedad, depresión o impulsividad entre los grupos de migraña episódica y migraña crónica y, posteriormente dentro de los pacientes con diagnóstico de $M C$, entre aquellos con y $\sin$ UEM. Utilizamos la t de Student o el test de la Chi cuadrado según conveniencia y empleamos para todo ello el software SPSS 22.0.

\section{Resultados}

Se incluyeron en el estudio 155 pacientes (22 varones, 133 mujeres). La edad en el momento de su inclusión en el estudio era de $38,2 \pm 11,7$ años (rango: 18-70) y el tiempo en años desde el inicio de la migraña de 19,2 $\pm 13,3$ (0-54). El número de días de dolor durante el mes previo fue de $17,9 \pm 10,4(1-30)$.

Cincuenta y un casos $(32,9 \%)$ padecían una migraña episódica y $104(67,1 \%)$ migraña crónica; dentro de estos últimos en $74(71,1 \%)$ pacientes había uso excesivo de medicación.

En 22 casos $(14,2 \%)$ se recogía como antecedente ansiedad y/o depresión, pero solo $12(7,7 \%)$ estaban tomando algún psicofármaco en el momento de la inclusión. En cuanto a los hábitos tóxicos 47 pacientes $(30,3 \%)$ fumaban y 25 $(16,1 \%)$ lo habían hecho con anterioridad. Treinta y cuatro $(21,9 \%)$ estaban recibiendo algún fármaco preventivo antimigrañoso. 
Tabla 2 Comparación entre el grupo de migraña episódica y migraña crónica

\begin{tabular}{|c|c|c|c|}
\hline & $M C(n=104)$ & $M E(n=51)$ & P \\
\hline Edad (años) & $39,8 \pm 12,3$ & $34,9 \pm 10,1$ & 0,009 \\
\hline Tiempo de evolución (años) & $21,6 \pm 13$ & $14,4 \pm 12,9$ & 0,002 \\
\hline Puntuación HIT 6 & $61,7 \pm 6,2$ & $60,6 \pm 6,9$ & Ns \\
\hline HIT- 6 mayor de 55 & $83,1 \%$ & $79,5 \%$ & Ns \\
\hline Puntuación HADS-ansiedad & $8,5 \pm 4,5$ & $6,4 \pm 3,6$ & 0,003 \\
\hline Puntuación HADS-depresión & $4,4 \pm 4,3$ & $1,9 \pm 2,3$ & $<0,001$ \\
\hline Criterios de ansiedad & $33,7 \%$ & $17,6 \%$ & 0,038 \\
\hline Criterios de depresión & $10,6 \%$ & $0 \%$ & 0,017 \\
\hline Puntuación Plutchik & $14,5 \pm 6,6$ & $13,1 \pm 6,8$ & Ns \\
\hline Criterios de impulsividad & $16,3 \%$ & $15,7 \%$ & Ns \\
\hline
\end{tabular}

MC: migraña crónica; ME: migraña episódica; ns: no significativa.

La severidad de la migraña medida por la escala HIT6 fue de $61,3 \pm 6,5(42-78)$ y en el $82,8 \%$ de los casos la discapacidad era al menos moderada (HIT-6 > 55).

Las puntuaciones en los 155 pacientes en las escalas administradas fue de 7,9 $\pm 4,3(0-17)$ en la subescala HADSansiedad, 3,6 $\pm 3,, 9(0-18)$ en HADS-depresión y 14,1 $\pm 6,7$ $(1-32)$ en la escala de Plutchik. Aplicando los correspondientes puntos de corte, el $28,4 \%$ de los pacientes cumplía criterios de ansiedad, el 7,1\% de depresión, y el $16,1 \%$ de impulsividad.

Al comparar las poblaciones de migraña crónica y migraña episódica, las puntuaciones en las subescalas HADSansiedad y HADS-depresión, así como el porcentaje de pacientes que cumplian criterios de ansiedad y de depresión eran significativamente mayores en el grupo de $M C$ (tabla 2).

Dentro de los casos con MC, las puntuaciones en HADSansiedad y HADS-depresión y el porcentaje de pacientes con ansiedad eran significativamente mayores en el grupo de uso excesivo de medicación (tabla 3 ).

No encontramos relación alguna entre la puntuación en la escala de Plutchik o el superar el punto de corte para impulsividad, y la presencia de MC o UEM.

\section{Discusión}

La impulsividad es una de las dimensiones más básicas y relevantes de la personalidad. Se trata de un concepto ampliamente utilizado. Debe ser correctamente explicitado cuando se utiliza ya que existen diferentes concepciones acerca de lo que es la impulsividad. A pesar de la heterogeneidad de las diferentes teorías existen importantes coincidencias entre los autores. Un comportamiento impulsivo responde casi siempre a tres mecanismos subyacentes: la alta sensibilidad a las recompensas, la actuación inmediata sin planificación, y el comportamiento compulsivo en búsqueda de alivio ante la tensión o estrés ${ }^{21}$.

Si nos centramos en la migraña, la impulsividad puede ser el origen de una anticipación ansiosa del dolor en sí mismo que puede suponer una pérdida de control sobre el consumo de fármacos sintomáticos. Se trata de un fenómeno neurocomportamental que puede representar un riesgo de consumo rápido y aumentado de analgésicos y una consecuente tendencia al uso excesivo de medicación sintomática, que, como ya se ha descrito, es uno de los factores de riesgo más importantes para la cronificación de la migraña ${ }^{10,11,22}$. Por ello consideramos relevante estudiar esta dimensión psicopatológica en pacientes migrañosos episódicos y crónicos para así evaluar su relación con la presencia de UEM.

Decidimos que el cuestionario de Plutchik constituía una buena opción para el cribado de esta dimensión. Evalúa conductas impulsivas mediante ítems relacionados con una posible falta de control sobre determinadas conductas distintas entre $\mathrm{si}^{20}$ : capacidad para planificar, control de los estados emocionales, control de conductas básicas y otras conductas.

Tabla 3 Comparación entre pacientes con y sin UEM dentro de la población de MC

\begin{tabular}{llll}
\hline & UEM $(n=74)$ & No UEM $(n=30)$ & $p$ \\
\hline Edad (años) & $42,4 \pm 11,4$ & $33,5 \pm 11,9$ & 0,001 \\
Tiempo de evolución (años) & $24 \pm 12,3$ & $15,6 \pm 13,1$ & 0,004 \\
Puntuación HIT 6 & $62,2 \pm 6,5$ & $60,5 \pm 5,6$ & Ns \\
HIT-6 mayor de 55 & $82,3 \%$ & $85,2 \%$ & Ns \\
Puntuación HADS-ansiedad & $9,3 \pm 4,4$ & $6,8 \pm 4,3$ & 0,01 \\
Puntuación HADS-depresión & $5,1 \pm 4,6$ & $2,7 \pm 2,9$ & 0,002 \\
Criterios de ansiedad & $41,9 \%$ & $13,3 \%$ & 0,006 \\
Criterios de depresión & $12,2 \%$ & $6,7 \%$ & Ns \\
Puntuación Plutchik & $14,8 \pm 6,3$ & $13,8 \pm 7,3$ & Ns \\
Criterios de impulsividad & $17,6 \%$ & $13,3 \%$ & Ns \\
\hline
\end{tabular}

MC: migraña crónica; ns: no significativo; UEM: uso excesivo de medicación.

Cómo citar este artículo: Muñoz I, et al. Impulsividad en pacientes migrañosos: estudio en una serie de 155 casos. Neurología. 2014. http://dx. doi.org/10.1016/j.nrl. 2014.10.006 
Dependiendo de que el uso excesivo de medicación sintomática por parte del paciente migrañoso responda a la necesidad del alivio de un dolor progresivamente creciente, o a acompañantes comportamentales, como la impulsividad cognitiva, el tratamiento sería diferente ${ }^{23}$. Así, en el primer caso valdría con la búsqueda del fármaco preventivo más eficaz para cada paciente, mientras que la eficacia de estos fármacos probablemente sería menor en el segundo grupo, haciéndose necesario un abordaje multidisciplinar incluyendo la actuación psicológica sobre estos determinantes; así, esta distinción permitiría un triage de estos pacientes y el desarrollo de estrategias de tratamiento más efectivas.

Debemos recordar aquí la decisión que tomamos en el diseño del estudio por la que no incluimos a pacientes con migraña episódica de alta frecuencia (entre 10 y 15 días de cefalea al mes). Es cierto que su inclusión no hubiese ido en contra de los criterios de la $\mathrm{CIC}-3$ y asumimos ese sesgo de selección. Sin embargo, coincidimos con otros autores ${ }^{24}$ en la arbitrariedad de los 15 días de dolor como punto de corte entre ME y MC; dado que, en nuestra opinión, el paciente con migraña episódica de alta frecuencia se parece más al que padece MC que al migrañoso episódico, estamos utilizando este criterio en este y otros trabajos en marcha en nuestro grupo.

Un dato a considerar en este estudio es la escasa diferencia entre la edad y discapacidad entre las poblaciones de ME y MC. En cuanto a lo primero ya hemos observado que el migrañoso crónico acude de una forma precoz a nuestra Unidad de Cefaleas ${ }^{25}$ y es posible que esto se deba al esfuerzo que estamos realizando para que todos los facultativos que remiten pacientes a la misma conozcan la MC. Además, es de destacar la alta severidad medida con la escala HIT-6 en nuestros migrañosos episódicos; es probable que aquí actúe un sesgo de selección al tratarse de casos de ME derivados a una unidad de referencia.

En nuestra serie destaca una fuerte asociación entre la presencia de trastornos del ánimo y la existencia de $M C$ o UEM. Esta mayor frecuencia de trastornos afectivos en estos pacientes ya ha sido recogida en la literatura ${ }^{14}$. Así, Curone afirma que el $44 \%$ de los migrañosos crónicos con UEM presentan trastornos del ánimo ${ }^{12}$; Raggi comparó estado de ánimo y discapacidad en pacientes con ME y MC con y sin UEM, y señaló que las puntuaciones del inventario de depresión de Beck eran significativamente más altas en los pacientes con MC y UEM ${ }^{26}$. Sin embargo, no puede afirmarse si la alteración afectiva de este tipo de pacientes se relaciona más con la cronicidad de la migraña o con el uso excesivo de medicación sintomática.

El término «pain panic» 0 «cefalgiafobia» ${ }^{27}$ fue acuñado por primera vez por Harvey Featherstone. Con esta palabra se recoge el miedo significativo y descontrolado de los pacientes a volver a presentar una nueva crisis de migraña, y su consecuente necesidad imperante de búsqueda de medicación de forma compulsiva y con escasa conciencia de posibles consecuencias. Se trata de una conducta que suele desembocar en un sobreuso de medicación y que puede estar presente en pacientes migrañosos con dolor de características crónicas y difícil manejo. Si nos remitimos al primer párrafo de esta discusión, existe cierta correspondencia con lo que representa una conducta impulsiva.
De acuerdo con el Cuestionario de Plutchik, en nuestra población a estudio la dimensión psicopatológica de impulsividad es frecuente, aunque, evidentemente, la ausencia de un grupo control no nos permite afirmarlo categóricamente. Sin embargo, no hemos encontrado correlación entre la existencia de MC o el UEM y la presencia de impulsividad.

Hasta la fecha no existen estudios que hayan analizado la presencia de conductas impulsivas en migrañosos ni su relación con el UEM o la presencia de MC que nos permitan comparar nuestros resultados. Por el contrario, sí se han descrito otro tipo de perfiles psicológicos relacionados con patrones de afrontamiento al dolor que parecen complicar el tratamiento y el pronóstico de la migraña ${ }^{12}$. Así, por ejemplo, la tendencia a la toma compulsiva de medicación se ha puesto en relación con rasgos obsesivo-compulsivos de personalidad. Curone y Cupini han mostrado que el uso excesivo de medicación sintomática asociado a dichas características de la personalidad influye en la respuesta a los tratamientos preventivos y por ende, en el curso clínico de la migraña, desembocando en muchas ocasiones en la cronificación de la misma ${ }^{14,15}$. En los últimos años se ha avanzado en la descripción de la disfunción orbitofrontal tanto en su aspecto neuropsicológico ${ }^{28}$ como estructural ${ }^{29}$ en pacientes con uso excesivo de medicación.

Nuestros resultados negativos al encontrar una relación entre impulsividad y UEM pueden deberse a una elección errónea del instrumento de cribado, a un enfoque inadecuado de la impulsividad como rasgo de personalidad, evaluado de forma categorial no integrada en una personalidad global, o simplemente a que la impulsividad no se asocia al UEM en este tipo de pacientes.

Sin embargo el porcentaje de casos con criterios de impulsividad dentro de la totalidad de la muestra, en nuestra opinión no desdeñable, sugiere que no debemos descartar que la presencia de este rasgo de personalidad constituya un factor importante en la respuesta de estos pacientes al dolor, la medicación preventiva u otros tipos de terapias.

Centrándonos en los sustratos neurobiológicos de la impulsividad, los pacientes con impulsividad presentan una disfunción en los circuitos que median la generación y la regulación de las emociones (córtico-límbicos y córticoestriatales ${ }^{30}$. La disfunción de estos circuitos está mediada por alteraciones de los neurotransmisores modulares principales (serotonina, norepinefrina y noradrenalina), así como por alteraciones en las sustancias blanca y gris ${ }^{27}$. Los pacientes impulsivos presentan una alteración de la regulación emocional frente a estímulos externos-ambientales o internos ${ }^{31}$ y el dolor representa un estímulo externo o interno negativo. Podríamos sospechar una hipotética relación entre las bases neurobiológicas de la impulsividad y la base del dolor, sobre todo el dolor crónico. Sirva como apunte que la International Association for the Study of Pain subraya la subjetividad del dolor y sus aspectos pluridimensionales (componente sensorial y afectivo-motivacional.

El procesamiento anormal de información de estos pacientes podría alterar las estrategias de doping ${ }^{32}$ ya que representan precisamente los esfuerzos cognitivos y comportamentales del paciente destinados a manejar, reducir o tolerar los estímulos externos e internos que amenazan al individuo. ¿Puede influir la impulsividad en la aparición de patrones de afrontamiento disfuncionales al dolor, por 
ejemplo apareciendo el ya mencionado «pain-panic»? Por ello, actualmente trabajamos en la evaluación de la personalidad de una forma dimensional y, simultáneamente, en la evaluación de posibles diferencias en la respuesta a los tratamientos preventivos en función de la presencia o ausencia de impulsividad en estos sujetos.

\section{Conclusiones}

Los trastornos del estado de ánimo y sobre todo de ansiedad son frecuentes en pacientes con migraña. Existe una fuerte asociación entre los trastornos del estado de ánimo y de ansiedad y la MC y el UEM, por lo que sería aconsejable un despistaje sistemático de este tipo de trastornos psiquiátricos.

Los pacientes migrañosos presentan con frecuencia impulsividad. No hemos encontrado correlación entre impulsividad y MC o UEM. Sin embargo, esto no significa que su presencia no constituya un factor determinante en el afrontamiento del dolor y la respuesta de estos pacientes a la medicación preventiva.

Son necesarios nuevos estudios que profundicen acerca de la hipotética relación entre las bases neurobiológicas de la impulsividad y el dolor, en especial el de características crónicas, así como de su influencia en la aparición de patrones de afrontamiento al dolor disfuncionales. El perfil psicológico anormal de un paciente con migraña puede tener importantes implicaciones clínicas y terapéuticas. La evaluación psicopatológica es importante por su significado pronóstico ya que puede proporcionar información adicional de utilidad en la decisión entre diferentes opciones de tratamiento.

\section{Financiación}

Este trabajo no ha recibido financiación.

\section{Conflicto de intereses}

Los autores declaran no tener ningún conflicto de intereses.

\section{Bibliografía}

1. Jette N, Patten S, Williams J, Becker W, Wiebe S. Comorbidity of migraine and psychiatric disorders. A national population-based study. Headache. 2008;48:501-16.

2. Antonaci F, Nappi G, Galli F, Manzoni GC, Calabresi P, Costa A. Migraine and psychiatric comorbidity: a review of clinical findings. J Head Pain. 2011;12:115 - 25.

3. Breslau N, Lipton RB, Stewart WF, Schultz LR, Welch KM. Comorbidity of migraine and depression: Investigating potential etiology and prognosis. Neurology. 2003;60:1308-12.

4. Merikangas KR, Stevens DE, Angst J. Headache and personality: results of a community sample of young adults. J Psychiatr Res. $1993 ; 27: 187-96$

5. Sheftell FD, Atlas SJ. Migraine and pshychiatric comorbidity: From theory and hypotheses to clinical application. Headache. $2002 ; 42: 934 \cdots \cdot 44$
6. Carod-Artal FJ, Irimia P, Ezpeleta D. Migraña crónica: definición, epidemiologia, factores de riesgo y tratamiento. JT Rev Neurol (Barc). 2012;54:629-37.

7. Bigal EM, Serrano D, Buse D, Scher A, Stewart WF, Lipton RB. Acute migraine medications and evolution from episodic to chronic migraine: a longitudinal population-based study. Headache. $2008 ; 48: 1157 \cdots 68$.

8. Bigal ME, Sheftell FD, Rapoport AM, Tepper SJ, Weeks R, Baskin SM. MMPI personality profiles in patients with primary chronic daily headache: a case-control study. Neurol Sci. 2003:24:103-10.

9. Mateos V, García-Moncó JC, Gómez-Beldarrain M, ArmengolBertolín S, Larios C. Factores de personalidad, grado de discapacidad y abordaje terapéutico de los pacientes con migraña atendidos en primera consulta en neurología (estudio PSICOMIG). Rev Neurol (Barc). 2011;52:131-..8.

10. Bigal ME, Lipton RB. What predicts the change from episodic to chronic migraine? Curr Opin Neurol. 2009;22:269-76.

11. Zwart JA, Dyb G, Hagen K, Svebak S, Stovner LJ, Holmen J. Analgesic overuse among subjects with headache, neck, and low-back pain. Neurology. 2004;62:1540-4.

12. Curone $M$, Tullo V, Mea $E$, Proietti-Cecchini A, Peccarisi $C$, Bussone G. Psychopathological profile of patients with chronic migraine and medication overuse: study and findings in 50 cases. Neurol Sci. 2011;32:5177-9.

13. Muñoz I, Toribio-Diaz ME, Carod-Artal FJ, Peñas-Martínez MJ, Ruiz L, Domínguez E. Rasgos de personalidad en pacientes migrañosos: estudio multicéntrico utilizando el cuestionario de cribado Salamanca. Rev Neurol (Barc). 2013;57:529-34.

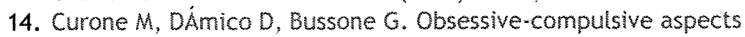
as predictors of poor response to treatments in patients with chronic migraine and medication overuse. Neurol Sci. 2012;33:5211-..-3.

15. Cupini LM, de Murtas $M$, Costa C, Mancini M, Eusebi $P$, Sarchielli $P$, et al. Obsessive-compulsive disorder and migraine with medication-overuse headache. Headache. 2009;49: $1005-13$.

16. Arena JG, Blanchard EB, Andrasik F, Applebaum K. Obsessions and compulsions in three kinds of headache sufferers: analy. sis of the Maudsley Questionnaire. Behav Res Ther. 1986;24: $127-32$.

17. Headache classification committee of the international headache society. The international classification of headache disorders, 3.rd edition (beta version). Cephalalgia. 2013;33:629-808.

18. Kosinski M, Bayliss MS, Bjorner JB, Ware JE Jr, Garber WH, Batenhorst $A$, et al. A six-item short-form survey for measuring headache impact: The HIT-6. Qual Life Res. 2003;12: $963-74$.

19. Zigmong AS, Snaith RP. The hospital anxiety and depression scale. Acta Psychiatr Scand. 1983;67:361-70.

20. Rubio G, Montero 1, Jáuregui J, Martínez ML, Álvarez S, Marín $\mathrm{JJ}$, et al. Validación de la escala de impulsividad de Plutchik en población española. Arch Neurobiol (Madr). 1998;61: $223-32$.

21. Lipton RB. Tracing transformation: Chronic migraine classification, progression and epidemiology. Neurology. 2009;72: $53-7$.

22. Bigal ME, Lipton RB. Modifiable risks factors for migraine progression (or for chronic daily headaches)-clinical lessons. Headache. 2006;46:5144-6.6.

23. Saper JR. "Are you talking to me?" Confronting behavioral disturbances in patients with headache. Headache. $2006 ; 46: 5151 \cdots 6$.

24. Pozo-Rosich P. Migraña crónica: epidemiología e impacto. Rev Neurol. 2012;54(Suppl 2):\$3-11.

25. Rojo E, Pedraza MI, Muñoz 1. Diferencias entre migraña crónica con y sin uso excesivo de medicación: Experiencia

Cómo citar este artículo: Muñoz l, et al. Impulsividad en pacientes migrañosos: estudio en una serie de 155 casos. Neurología. 2014. http://dx.doi.org/10.1016/j, nr1,2014, 10.006 
en una serie hospitalaria de 434 pacientes. Neurología. 2014. Epub Ahead.

26. Raggi A, Giovannetti AM, Leonardi $M$, Schiavolin S, DÁmico D, Curone $M$, et al. Disability and mood state in patients with episodic and chronic migraine associated to medication ove. ruse. Neurol Sci. 2012;33(Suppl 1):\$169-71.

27. Saper JR, Lake AE III. Borderline personality disorder and the chronic headache patient: review and management recommendations. Headache. 2002;42:663-74.

28. Gómez-Beldarrain $M$, Carrasco M, Bilbao A, García-Moncó JC. J Headache Pain. 2011;12:459-66.

29. Chanraud S, di Scala G, Ditharreguy B, Schoenen J, Allard M, Radat F. Cephalalgia. 2014;34:605 - 15 .
30. Hazlett EA, New AS, Newmark R, Haznedar MM, Lo JN, Speiser $L$, et al. Reduced anterior and posterior cingulate gray matter in borderline personality disorder. Biol Psychiatry. 2005; 58:614-23.

31. Orozco.Cabal L, Pollandt S, Liu J, Shinnick-Gallagher P, Gallagher JP. Regulation of synaptic transmission by CRF receptors. J Neurosci. 2006; 17:279-...307.

32. Lazarus RS, Folkman S. Stress appraisal and coping. New York: Springer PC; 1984.

33. Garcia-Portilla MP, Bascarán MT, Sáiz PA, Parellada M, Bousoño $M$, Bobes J. Banco de instrumentos básicos para la práctica de la psiquiatría clínica. 6. I ed. Barcelona: Ars Médica; 2011. p. 222. 


\section{RASGOS DE PERSONALIDAD EN MIGRAÑA CRÓNICA: ESTUDIO CATEGORIAL Y} DIMENSIONAL EN UNA SERIE DE 30 PACIENTES

\section{AUTORES}

I Muñoz, (1), E Domínguez (1), MS Hernández (1), M Ruiz (2), G Isidro (1), E Mayor (1), EM Sotelo (1), V Molina (1), F Uribe (1), AL Guerrero (2)

1. Servicio de Psiquiatría. Hospital Clínico Universitario de Valladolid.

2. Servicio de Neurología. Hospital Clínico Universitario de Valladolid

Este trabajo no ha recibido financiación

No existen conflictos de interés

\section{RESUMEN}

Introducción: El rol patogénico de la personalidad en la migraña no está definido. Para su estudio se pueden utilizar instrumentos de medida dimensional o categorial, sin que haya tampoco acuerdo acerca del abordaje más adecuado.

Objetivo: Analizar la personalidad de pacientes con migraña crónica (MC) desde el punto de vista dimensional y categorial.

Pacientes: Como test categorial utilizamos el cuestionario Salamanca y como dimensional el MMPI-2. Evaluamos trastornos del ánimo con la escala de Ansiedad y Depresión Hospitalaria (HADS) y el impacto de la migraña mediante el Headache Impact Test-6 (HIT-6).

Resultados. Incluimos 30 pacientes (26 mujeres, 4 varones), con edad media de 40,7 \pm 9,6 años (23-61). Un caso (3,3\%) presentaba criterios de depresión y 4 (13,3\%) de ansiedad. En el test Salamanca los rasgos de personalidad más frecuentes fueron los integrados en el cluster C: anancástico (28 casos, 93,3\%), ansioso (18, 60\%) y dependiente (7, 23,3\%). En el MMPI-2, 16 pacientes (53,3\%) cumplían criterios de hipocondría, 7 (23,3\%) de depresión y $10(33,3 \%)$ de histeria, rasgos integrados en la triada neurótica. Se objetivó una configuración denominada "conversiva V". No hallamos correlación entre los rasgos de personalidad y tiempo de migraña crónica, la severidad medida por HIT-6, o el uso excesivo de medicación sintomática.

Conclusiones. En el análisis de la personalidad en MC destaca desde el punto de vista dimensional el neuroticismo, y respecto al categorial el rasgo obsesivo-compulsivo o anancástico. Es necesario el estudio de series más extensas y la comparación con pacientes con migraña episódica y población control

Palabras clave. Cuestionario Salamanca; Migraña; Migraña crónica; MMPI-2; Rasgos de Personalidad; Tríada Neurótica.

Palabras de cabecera: Estudio dimensional y categorial de personalidad en Migraña Crónica 


\section{INTRODUCCIÓN}

La relación entre personalidad y migraña es una de las líneas de investigación más transitadas desde que Harold G. Wolff acuñara el término de personalidad migrañosa, refiriéndose al perfil obsesivo y rígido encontrado repetidamente en pacientes con migraña (1).

Durante años un buen número de estudios han buscado definir perfiles de personalidad comunes en pacientes migrañosos que pudieran diferenciarse de los de la población general (2-4) o de otras entidades clínicas $(5,6)$. El rasgo de la personalidad que se encontró más consistentemente asociado a la migraña fue el neuroticismo. Este rasgo psicológico viene definido por una importante inestabilidad emocional que conlleva susceptibilidad a la hora de experimentar afectos negativos y altos niveles de ansiedad y preocupación (7-10). La mayor parte de las investigaciones utilizaron instrumentos psicométricos como el Eysenk Personality Questionnaire (EPQ) y el Minnesota Multiphasic Personality Inventory (MMPI-2). Sin embargo, una de las carencias de estos estudios fue que se centraban en recoger características de personalidad utilizando instrumentos de medida dimensionales que no se corresponden con los rasgos específicos de personalidad, tal y como se recogen en los manuales de diagnóstico DSM-IV y CIE-10. Por otro lado, en muchos casos estos trabajos no tenían en cuenta la comorbilidad psiquiátrica, lo que impedía discriminar en qué medida el neuroticismo estaba asociado a psicopatología, en particular al trastorno de depresión mayor o de ansiedad, ambos muy prevalentes entre migrañosos (11).

En este sentido uno de los primeros objetivos de nuestro grupo de estudio fue definir la personalidad en términos operativos. Este enfoque categorial nos permitió registrar perfiles anormales en un gran número de pacientes migrañosos. Consideramos relevante desde un punto de vista clínico detectar rasgos de personalidad recogidos en los manuales DSM-IV y CIE-10 sin detenernos en descripciones largas y detalladas de la personalidad. Utilizamos para ello el cuestionario de cribado Salamanca (12).

Pretendemos con este nuevo trabajo evaluar la personalidad de pacientes con Migraña Crónica (MC) mediante dos test diferentes. Uno de tipo categorial, de nuevo el test de cribado Salamanca, y otro de tipo dimensional, el MMPI-2. 


\section{PACIENTES Y MÉTODOS}

Se trata de un estudio transversal en el que incluimos pacientes con Migraña Crónica atendidos consecutivamente en una consulta monográfica de cefaleas en un hospital terciario. El diagnóstico de MC se realizó de acuerdo con la III Edición, versión beta, de la Clasificación Internacional de Cefaleas (CIC-III) (13).

Seleccionamos pacientes con edades comprendidas entre 19 y 65 años, excluyendo aquellos con algún trastorno médico o psiquiátrico, o bien un déficit intelectual que pudiera limitar su capacidad para entender o contestar a las preguntas de los cuestionarios. Se obtuvo consentimiento informado previo a la inclusión de los pacientes en el estudio. La investigación fue aprobada por el Comité Ético de Investigación Clínica de nuestro centro. Ninguno de los pacientes fue evaluado durante un episodio de migraña agudo.

Se recogieron prospectivamente sus características demográficas, el tiempo en años desde el inicio de la migraña, los meses transcurridos desde el inicio de la Migraña Crónica, y el número de días con cefalea durante el mes previo a su evaluación. Se consideró si el paciente presentaba uso excesivo de medicación sintomática de acuerdo con los criterios de la CIC-III

Evaluamos el impacto de la migraña en cada paciente mediante el Headache Impact Test-6 (HIT-6) que establece, mediante 6 preguntas de elección múltiple, cuatro categorías de discapacidad en función de la puntuación: Severa $(\geq 60)$, moderada (56-59), leve (50-55) y ausente $(\leq 49)(14)$

Realizamos una detección de la comorbilidad psiquiátrica utilizando la escala de Ansiedad y Depresión Hospitalaria (HADS) (15). Se trata de un instrumento de cribado que permite la detección de trastornos depresivos y ansiosos. Es un test autoaplicado con un marco de referencia temporal en la semana previa. Adaptada y validada al español, consta de 14 ítems agrupados en 2 subescalas: ansiedad y depresión. El punto de corte establecido para cada una de las subescalas es de 10. E1 HADS es especialmente útil para pacientes migrañosos ya que ninguno de los 14 ítems hace referencia a síntomas somáticos, lo que elimina el riesgo de realizar una sobreestimación de psicopatología derivada de la interpretación de síntomas físicos relacionados con la migraña como secundarios a ansiedad o depresión.

El análisis de la personalidad lo llevamos a cabo mediante 2 test. En primer lugar utilizamos el Minnesota Multiphasic Personality Inventory (MMPI-2) que permite una evaluación psicológica multidimensional $(16,17)$. Hemos empleado la versión de la escala validada al español, concretamente la adaptación de Ávila-Espada y Jiménez-Gómez (18). Se trata de un test autoaplicado que tarda en realizarse entre 60 y 90 minutos. Está compuesto por 567 ítems. Dependiendo de las respuestas (verdadero-falso) la puntuación se reparte en 3 escalas de validez (L: Mentira, F: Incoherencia o validez, K: Corrección o defensa) y 10 escalas clínicas (Hs: Hipocondría, D: Depression, Hy: Histeria de conversión, Pd: Desviación psicopática, Mf: Masculinidad-Feminidad, Ps: Paranoia, Pt: Psicastenia, Sc: Esquizofrenia, Ma: Hipomanía y Si: Introversión social). Existen además otras 15 escalas de contenido que no utilizaremos, con la excepción de aquella que mide las preocupaciones por la salud de cada paciente y que es denominada bajo este mismo nombre. Las escalas se encuentran debidamente diferenciadas por sexos y baremadas mediante unas tablas de puntuaciones típicas normalizadas. Las puntuaciones brutas o puntuaciones directas son transformadas en una medida estandarizada conocida como puntuaciones $\mathrm{T}$ (media 50 , desviación típica 10), haciendo su interpretación más sencilla. En cada una de las escalas una puntuación T de 65 
indica que se ha alcanzado un nivel de significancia clínica correspondiente al percentil 95. E1 MMPI-2 posee una estabilidad temporal (fiabilidad test-retest) entre 0,58 y 0,92 en las escalas clínicas, entre 0,78 y 0,91 en las escalas de contenido y entre 0,34 y 0,91 en las suplementarias. La fiabilidad de la consistencia interna (coeficiente alfa) en los mismos grupos de escalas anteriormente mencionados, va respectivamente de 0,33 a 0,84 , de 0,68 a 0,86 y de 0,24 a 0,91 .

En cuanto al Cuestionario Salamanca, es un test de cribado autoaplicado menos utilizado que el MMPI-2. Como ventajas tiene que su aplicación lleva poco tiempo (menos de 10 minutos) y es de fácil interpretación. Fue validado en 2007 y se correlacionó con el International Personality Disorder Examination, considerándose un adecuado test de cribado, con una sensibilidad del 100\% y una especificidad del 76,3\% (19). Clasifica los rasgos de personalidad desde un punto de vista categorial y los define según la nomenclatura del DSM-IV, texto revisado (20) (paranoide, esquizoide, esquizotípico, histriónico, antisocial, narcisista y dependiente) o según la nomenclatura de la Clasificación Internacional de Enfermedades, décima revisión (CIE-10) (21) (inestabilidad emocional subtipo impulsivo, inestabilidad emocional subtipo límite, anancástico y ansioso). Los 11 rasgos son evaluados mediante 22 preguntas ( 2 preguntas por rasgo de personalidad). Cada pregunta tiene 4 posibilidades puntuadas 0 a 3 . La puntuación de corte para cada rasgo de personalidad se estableció en 3 (12). Los 11 rasgos se agrupan en tres grupos diferentes:

A. Extraños o extravagantes: paranoide, esquizoide y esquizotípico.

B. Inmaduros: histriónico, antisocial, narcisista y trastorno de la inestabilidad emocional, con sus dos subtipos (límite e impulsivo).

C. Temerosos: anancástico, ansioso y dependiente.

Se compararon las características demográficas y clínicas de cada paciente con las puntuaciones de todos los test utilizados, así como con la presencia de cada uno de los rasgos de personalidad de acuerdo con los puntos de corte mencionados. Utilizamos la $t$ de Student o el test de la Chi cuadrado según conveniencia y empleamos para todo ello el software SPSS 20.0 


\section{RESULTADOS}

Se incluyeron 30 pacientes (26 mujeres, 4 varones). La edad en el momento de la inclusión era de 40,7 \pm 9,6 años (rango: 23-61). La edad al inicio de la migraña fue de 16,1 \pm 7,7 años (rango 4-41) y el tiempo en meses desde el inicio de la migraña crónica de 37,6 $\pm 43,5$ (3-180). Durante el mes previo a la valoración estos pacientes habían sufrido 23,8 \pm 5,5 días de dolor (15-30) y 13,8 $\pm 3,2$ (8-20) días de dolor migrañoso. La puntuación en la escala HIT-6 fue de 62,7 $\pm 6,8$ (46-76), presentando 24 pacientes ( $80 \%$ ) una discapacidad severa (HIT-6 $\geq 60$ ).

Las puntuaciones en las subescalas ansiedad y depresión de la HADS fueron respectivamente 7,1 $\pm 3,9(0-16)$ y 2,4 $\pm 2,9$ (0-12). Un paciente (3,3\%) sobrepasaba el punto de corte para depresión y $4(13,3 \%)$ para ansiedad.

En el test de Salamanca los rasgos de personalidad más frecuentes fueron aquellos incluidos dentro del grupo C (temerosos); así, el rasgo anancástico aparecía en 28 casos (93,3\%), el ansioso en 18 (60\%) y el dependiente en 7 (23,3\%). Dentro del grupo B destaca la presencia del rasgo histriónico (10 pacientes, 33,3\%). Ningún migrañoso presentaba rasgos de personalidad antisocial ni narcisista. La frecuencia de los 11 rasgos de personalidad evaluados en el Test de Salamanca se muestra en la FIGURA 1.

En cuanto a los resultados obtenidos mediante el MMPI-2, los 30 pacientes mostraron perfiles válidos, es decir presentaban puntuaciones dentro de los límites normales en las tres escalas de validez. Los tres factores de personalidad medidos en el test que reflejan neuroticismo, también denominada tríada neurótica, fueron los más frecuentemente encontrados en nuestra serie. Así 16 casos (53,3\%) cumplían criterios de hipocondría, 7 (23,3\%) de depresión y $10(33,3 \%)$ de histeria. Se objetivó una mayor presencia de hipocondría e histeria, unida a una menor frecuencia en la tríada de la depresión, lo que corresponde a la configuración denominada "conversiva V". En 20 pacientes $(66,7 \%)$ había al menos un factor de la triada positivo y en $11(36,7 \%)$ se objetivaron dos o más escalas positivas de esta tríada. En 15 casos (50\%) se observaron puntuaciones elevadas en una de las subescalas que indica el grado de preocupación de cada paciente en relación con su salud. La frecuencia de positividades en cada una de las escalas del MMPI-2 se muestra en la FIGURA 2.

Existe una correspondencia entre el neuroticismo medido por estos tres factores y los rasgos de personalidad incluidos en el grupo $\mathrm{C}$ del Test de Salamanca, y en particular con el rasgo anancástico de la personalidad.

No hallamos correlación entre las puntuaciones de las escalas de personalidad o la presencia de cada uno de los rasgos evaluados en los dos test aplicados, con el tiempo de migraña crónica, la discapacidad medida por HIT-6 o el uso excesivo de medicación sintomática. 


\section{DISCUSIÓN}

El modelo único de "personalidad migrañosa" que propuso Harold G. Wolff (1) no pudo ser demostrado de forma empírica. No obstante, este esfuerzo inicial sirvió para impulsar conceptualizaciones de tipo psicosomático en el campo de las cefaleas (22).

Las teorías contemporáneas sobre la personalidad hablan de un continuum psicopatológico entre "normalidad" y rasgos de personalidad dentro del cual pueden ordenarse los individuos. De acuerdo con esta teoría los rasgos de personalidad representarían las variantes de personalidad que se sitúan en el extremo opuesto a las dimensiones "normales" de personalidad (23). Esta teoría se enmarca dentro de un modelo dimensional (24).

Desde mediados del siglo XX los estudios persiguen definir perfiles de personalidad de los pacientes migrañosos mediante una evaluación dimensional que no sólo les caracterice sino que les diferencie de otros individuos que no tengan dolor o presenten otro tipo de cefalea (25).

Las características de personalidad pueden ser evaluadas con sistemas de medida tanto dimensionales como categoriales. De forma general, las escalas dimensionales son las preferidas a la hora de detectar diferencias estadísticamente significativas entre grupos. Sin embargo, los sistemas diagnósticos para psicopatología, DSM-IV (21) y CIE-10 (21) usan sistemas categoriales, de manera que existen dificultades a la hora de correlacionar los resultados hallados de dichas escalas dimensionales con los rasgos específicos de personalidad tal y como se recogen en los manuales DSM-IV (21) y CIE-10 (21). Por otro lado los análisis dimensionales de la personalidad consumen una gran cantidad de tiempo y son difíciles de interpretar sin entrenamiento previo, lo que no ocurre con los instrumentos de medida categoriales (26).

En este sentido, nuestro grupo de investigación presentó los resultados de un estudio de personalidad en pacientes migrañosos con un enfoque categorial (12). Es decir que consideramos 11 rasgos de personalidad cualitativamente distintos de acuerdo con los manuales DSM-IV y CIE-10; en él, y comparando población con migraña crónica y migraña episódica vimos que el rasgo anancástico estaba significativamente más representado en los pacientes con MC (12).

De dichos resultados y apoyándonos en la literatura, inferimos que los rasgos de personalidad del grupo C podrían correlacionarse con las dimensiones clásicas de introversión y neuroticismo, comparables a otros estudios que utilizaron como herramienta el MMPI. De ahí este nuevo paso en el que hemos considerado en una población de pacientes con Migraña Crónica la personalidad tanto de forma categorial (utilizando de nuevo el test Salamanca), como dimensional (mediante el mencionado MMPI-2), comparando ambos resultados..

E1 MMPI-2 es una herramienta de análisis dimensional de la personalidad que, aunque no ha sido diseñada específicamente para el estudio de pacientes con dolor, ha sido bastante utilizada en este campo (7,8,27-31). La mayor parte de los estudios que han utilizado cuestionarios de análisis dimensional de la personalidad ampliamente aceptados como el "Eysenck Personality Questionnaire" (EPQ) $(2,9,10)$ o el "Temperament and Character Inventory" (TCI), que hace referencia al modelo desarrollado por Cloninger, han señalado un alto grado de neuroticismo en los pacientes migrañosos así como una mayor tendencia a la evitación de daños (32). De manera similar, las investigaciones que utilizaron el MMPI-2 como instrumento de medida demostraron que los pacientes con migraña presentaban un perfil de personalidad caracterizado por puntuaciones elevadas en las tres primeras 
escalas (Hs: Hipocondría, D: Depression, Hy: Histeria de conversión) que conforman la triada neurótica $(4,7,8$, $29,31,33,34)$.

Si consideramos estudios en los que la MC se diagnostica de acuerdo con los criterios de la CIC y la personalidad se evalúa con el MMPI-2 (TABLA 1), se aprecia una configuración típica "conversiva V" (con elevación en las puntuaciones de las escalas hipocondría e histeria, siendo inferior la puntuación de la escala depresión) en las mujeres con migraña crónica, equiparable a la que hemos observado en nuestra serie (35). Mayores puntuaciones en las escalas que forman la triada neurótica al inicio de un registro prospectivo se asocian a un pronóstico desfavorable de la MC independientemente del grado de discapacidad presentado, la severidad, frecuencia o la duración de la migraña. Nuestros resultados, dentro de una población homogénea de pacientes con MC, no han mostrado tampoco que las alteraciones de la personalidad dependan de la severidad de la migraña recogida en la escala HIT-6 ni del tiempo transcurrido desde el inicio de la migraña o de su forma crónica.

Cuando analizamos los trabajos que incluyen pacientes con Migraña Crónica diagnosticada con la CIC y que miden la personalidad de una forma categorial (TABLA 2), en ellos se señala el rasgo obsesivo-compulsivo como más prevalente en pacientes con uso excesivo de medicación, migraña crónica y depresión comórbida, lo que puede actuar como factor predictivo de una pobre respuesta al tratamiento (36). Se ha puesto de manifiesto que el rasgo obsesivo-compulsivo de personalidad representa un posible factor de refractariedad al tratamiento preventivo en la MC, así como un riesgo de mantenimiento del uso excesivo de medicación sintomática (37-39). En nuestra serie observamos que los resultados obtenidos mediante el test de cribado Salamanca indican una frecuencia notablemente superior de los rasgos que componen el grupo $\mathrm{C}$ en los pacientes con MC. Dentro de los tres rasgos que componen el grupo $\mathrm{C}$ destaca el rasgo anancástico u obsesivo-compulsivo de personalidad lo que sería coherente con los hallazgos de los estudios previos comentados.

El rasgo anancástico de personalidad evaluado con el Cuestionario Salamanca viene determinado por las preocupaciones, las obsesiones que pueden desencadenar en compulsión, la rigidez y los miedos irracionales. Estas características de personalidad podrían corresponderse con la escala clínica Psicastenia en el MMPI-2. Por ello sería esperable que existiera un elevado porcentaje de pacientes de la muestra que presenten una elevación de dicha escala. Si analizamos los resultados obtenidos en esta muestra no se recoge una frecuencia equivalente en la escala Psicastenia del MMPI-2 a la hallada en el rasgo anancástico de la personalidad del Cuestionario Salamanca. Es decir, que según los resultados obtenidos en esta muestra el rasgo anancástico de la personalidad y la psicastenia no se correlacionan. Una posible explicación sería que los pacientes con rasgo anancástico de la personalidad presentan psicastenia sólo en un determinado porcentaje de casos, puntuando también en otras escalas del MMPI-2 como por ejemplo la hipocondría.

El perfil de personalidad de los pacientes con MC analizado en nuestra serie es consistente con el descrito en estudios previos. Si observamos los resultados hallados mediante evaluación dimensional con el MMPI-2 existe una prevalencia mayor de los rasgos que conforman el neuroticismo. Se objetiva una elevación de las características de personalidad de la triada neurótica y existe una configuración típica "conversiva V". Si lo enfocamos desde el punto de vista categórico existe una clara elevación de los rasgos que forman el grupo C, en particular el rasgo anancástico u obsesivo-compulsivo tal y como señalaron investigaciones previas. Las escalas de 
personalidad que analizan el neuroticismo en el MMPI-2 se corresponderían con los rasgos de personalidad del grupo $\mathrm{C}$ evaluados en el Test de Salamanca. Tampoco se correlacionó la presencia de estos rasgos de personalidad con la duración o el grado de severidad relacionado con la migraña. Esto apoyaría la teoría según la cual los rasgos de personalidad no son factores derivados de la severidad de la migraña sino componentes propios de la misma, recordando las propuestas de Wolff.

Si bien es cierto que el rol patogénico de la personalidad no está totalmente claro (5), cada vez son más los estudios que han demostrado que un perfil psicológico anormal puede tener importantes implicaciones clínicas y terapéuticas. Existen ciertos rasgos de personalidad relacionados con patrones de afrontamiento al dolor que parecen complicar el manejo de la migraña $(3,40,41)$. En aquellos pacientes que los presentan puede aparecer una mayor susceptibilidad al estrés resultando infructuoso el tratamiento preventivo de la migraña, y favoreciéndose la cronificación de la misma. Una evaluación psicológica en los pacientes migrañosos puede, por tanto, proporcionar información que guíe al clínico en el tratamiento (42); lo óptimo sería, por ello, realizarla en todos los migrañosos en los que sea posible.

En la literatura no se recoge ningún estudio que haya analizado y comparado en una misma muestra de pacientes con MC sus características de personalidad a la vez de forma dimensional y categorial. Uno de los puntos fuertes de nuestro estudio es que utiliza instrumentos de medida de ambos abordajes. Objetiva a la vez un alto grado de neuroticismo en el MMPI-2 y una mayor frecuencia de los rasgos de personalidad recogidos en el grupo $\mathrm{C}$ en el cuestionario Salamanca. Esto indica la existencia de una relación entre el grupo C del test de Salamanca, sistema de medida categórico, y la triada neurótica del MMPI-2, sistema de medida dimensional. La dimensión clásica de neuroticismo estaría expresada por los rasgos de personalidad del grupo C, pero sobre todo por el rasgo anancástico u obsesivo-compulsivo de personalidad (12). Los rasgos anormales de uno y otro test aparecen de forma paralela en ambos de modo que el cuestionario Salamanca podría ser un buen instrumento de medida en una primera consulta de neurología, facilitando el trabajo del neurólogo y asegurando que la detección de rasgos anormales de la personalidad sea llevada a cabo. Como ya hemos explicado, estos rasgos anormales pueden representar dificultades a la hora del tratamiento y suponer un riesgo para la refractariedad de los tratamientos y la cronicidad de la enfermedad.

Este estudio presenta ciertas limitaciones. Se trata, en primer lugar, de una muestra pequeña de pacientes. En segundo lugar, no hemos comparado los resultados obtenidos con un grupo control. No obstante, el MMPI-2, como ya se mencionó previamente está formado por 10 escalas clínicas que se encuentran debidamente diferenciadas por sexos y baremadas mediante unas tablas de puntuaciones típicas normalizadas lo que obvia al menos en parte la referencia a un grupo control. Por último, se trata de un estudio transversal que no permite establecer una posible influencia de los perfiles de personalidad en el desarrollo de la migraña, respuesta a medicación y pronóstico de la misma.

Pretendemos continuar profundizando, siguiendo esta línea de investigación, en el estudio de la personalidad analizando la posible relación entre los perfiles de personalidad de pacientes migrañosos y los diferentes patrones de afrontamiento al dolor. 
En conclusión, los pacientes con migraña crónica presentan rasgos de personalidad bien definidos en base a los resultados obtenidos en esta muestra, para cuya valoración es razonable utilizar cuestionarios categoriales de cribado como el Cuestionario Salamanca.

\section{BIBLIOGRAFÍA}

1. Wolff HG. Personality features and reactions of subjects with migraine. Arch Neurol Psychiatry 1937; 37: 895921.

2. Merikangas KR, Stevens DE, Angst J. Headache and personality: results of a community sample of young adults. J Psychiatr Res 1993; 27: 187-96.

3. Sánchez-Román S, Téllez-Zenteno JF, Zermeño-Phols F, García-Ramos G, Velázquez A, Derry $P$ et al. Personality in patients witn migraine evaluated with the "Temperament and Character Inventory". J Headache Pain 2007; 8: 94-104.

4. Mongini F, Keller R, Deregibus A, Raviola F, Mongini T, Sancarlo M. Personality traits, depression and migraine in women: a longitudinal study. Cephalalgia 2003; 23: 186-92.

5. Cao M, Zhang S, Wang K, Wang Y, Wang W. Personality traits in migraine and tension-type headaches: a fivefactor model study. Psychopathology 2002; 35: 254-258.

6. Mongini F,Rota E, Deregibus A, Mura F, Francia Germani A, Mongini T. A comparative analysis of personality profile and muscle tenderness between chronic migraine and chronic-type headache. Neurol Sci 2005, 26: 203-207.

7. Mongini F, Ibertis F, Barbalonga E, Raviola F. MMPI-2 profiles in chronic daily headache and their relationship to anxiety levels and accompanying symptoms. Headache 2000; 40: 466-472.

8. Bigal ME, Sheftell FD, Rapaport AM, Tepper SJ, Weeks R, Baskin SM. MMPI personality profiles in patients with primary chronic headache: A case-control study. Neurol Sci 2003; 24: 103-110.

9. Breslau N, Andreski P. Migraine, personality and psychiatric comorbidity. Headache, 1995; 53: 382-386.

10. Hedborg K, Anderberg U, Muhr C. Stress in migraine: personality-dependent vulnerability, life events and gender are of significance. Ups J Med Sci 2011; 116: 187-199.

11. Silberstein SD, Lipton RB, Breslau N. Migraine: association with personality characteristics and psychopathology. Cephalalgia 1995; 15: 358-69.

12. Muñoz I, Toribio-Diaz ME, Carod-Artal FJ, Peñas-Martínez MJ, Ruiz L, Dominguez E et al. Rasgos de personalidad en pacientes migrañosos: estudio multicéntrico utilizando el cuestionario de cribado Salamanca. Rev Neurol (Barc) 2013; 57: 529-34.

13. Headache classification committee of the International Headache Society. The International Classification of Headache Disorders, 3rd edition (beta version). Cephalalgia 2013; 33: 629-808.

14. Kosinski M, Bayliss MS, Bjorner JB, Ware JE Jr, Garber WH, Batenhorst A et al. A six-item short-form survey for measuring headache impact: The HIT-6. Qual Life Res 2003; 12: 963-74.

15. Zigmong AS, Snaith RP. The hospital anxiety and depression scale. Acta Psychiatr Scand 1983; 67: 361-70. 
16. Hathaway SR, McKinley JC. Manual of the Minnesota Multiphasic Personality Inventory. University of Minnesota Press, Minneapolis. 1943.

17. Butcher JN, Dahlstrom WG, Graham JR, Tellengen A, Kaemmer B. MMPI-2 (Minnesota Multiphasic Personality Inventory-2): Manual for Administration and Scoring (Rev. ed.). Minneapolis, MN: University of Minnesota Press; 2001.

18. Avila-Espada A, Jiménez-Gómez F. The castilian version of the MMPI-2 in Spain: development, adaptation, and psychometric properties. International adaptations of the MMPI-2: research and clinical applications, Universidad de Salamanca; 1996, p. 305-328.

19. Caldero-Alonso A. Estudio de los resultados obtenidos en el cuestionario Salamanca en población normal. Salamanca: Universidad de Salamanca; 2009.

20. López-Ibor Aliño JJ, Valdés-Miyar M. Manual diagnóstico y estadístico de los trastornos mentales. Barcelona: Masson; 2002.

21. CIE 10. Trastornos mentales y del comportamiento. Madrid: Meditor; 1994.

22. Davis RE, Smithermann, TA. Personality traits, personality disorders, and migraine: a review. Neurol Sci 2013; 34:(Supp1 1): S7-S10.

23. Parker G, Barrett. Personality and personality disorder: Current issues and directions. Psychol Med 2000; 30: 1-9.

24. Livesley WJ. Commentary on reconceptualizating personality disorder categories using trait dimensions. J Pers 2001; 69: 277-286.

25. Rasmussen, BK. Migraine and tension-type headache in a general population: psychosocial factors. Int J Epidemiol 1992; 21: 1138-1143.

26. Maizels MM, Smitherman TA, Penzien DB. A review of screening tools for psychiatric comorbidity in headache patients. Headache 2006; 46 (Supp1 3): S98-S109.

27. Huber D, Henrich G. Personality traits and stress sensitivity in migraine patients. Behav Med 2003; 29: 4-13.

28. Lake AE III, Rains JC, Penzien DB, Lipchik GL. Headache and psychiatric comorbidity: Historical context, clinical implications and research relevance. Headache 2005; 45: 493-506.

29. Ellertsen B. Personality factors in recurring and chronic. Cephalalgia 1992; 12: 129-132.

30. Mongini F, Ibertis F, Ferla E. Personality characteristics before and after treatment of different head pain syndromes. Cephalalgia 1994; 14: 368-373.

31. Inan L, Soykan C, Tulunay FC. MMPI profiles of turkish headache sufferers. Headache, 1994; 34: 152-4.

32. Mongini F, Fassino S, Rota E, Deregibus A, Levi M, Monticone D et al. The temperament and character inventory in women with migraine. J Headache Pain 2005; 6: 247-249.

33. De Fidio D, Sciruicchio V, Pastore B. Chronic daily headache: personality study by means of computerized MMPI-2. J Headache Pain 2000; (Suppl 1): S67-S70.

34. Mongini F, Defilippi N, Negro C. Chronic daily headache. A clinical and psychological profile before and after treatment. Headache 1997; 37: 83-87. 
35. Mongini F, Rota E, Evangelista A, Ciccone G, Milani C, Ugolini A et al. Personality profiles and subjective perception of pain in head pain patients. Pain. 2009; 144: 125-129.

36. Curone M, Tullo V, Savino M, Proietti-Cecchini A, Bussone G, D'Amico D. Outcome of patients with chronic migraine with medication overuse and depression after duloxetine: influence of coexisting obsessive compulsive disorder. Neurol Sci 2013; 34 (Suppl 1): S175-S177.

37. Curone M, D'Amico D, Bussone G. Obsessive-compulsive aspects as predictors of poor response to treatments in patients with chronic migraine and medication overuse. Neurol Sci 2012; 33 (Supp11): S211-S213.

38. Curone M, Tullo V, Mea E, Proietti-Cecchini A, Peccarisi C, Bussone G. Psychopathological profile of patients with chronic migraine and medication overuse: study and findings in 50 cases. Neurol Sci $2011 ; 32$ (suppl 1): S177- S179.

39. Cupini LM, De Murtas M, Costa C, Mancini M, Eusebi P, Sarchielli P et al. Obsessive-compulsive disorder and migraine with medication-overuse headache. Headache 2009; 49: 1005-1013.

40. Mateos V, García-Moncó JC, Gómez-Beldarrain M, Armengol-Bertolín S, Larios C. Factores de personalidad, grado de discapacidad y abordaje terapéutico de los pacientes con migraña atendidos en primera consulta en neurología (estudio PSICOMIG). Rev Neurol (Barc) 2011; 52: 131-138.

41. Abbate-Daga G, Fassino S, Lo Giudice R, Rainero I, Gramaglia C, Marech L et al. Anger, depression and personality dimensions in patients with migraine without aura. Psychoterapy and psychosomatics, 2007; 76:122-8. 42. Luconi R, Bartolina M, Taffi R, Vignin A, Mazzanti L, Provinciali L et al. Prognostic Significance of personality profiles in patients with chronic migraine. Headache 2007 ; $47: 1118-1124$. 


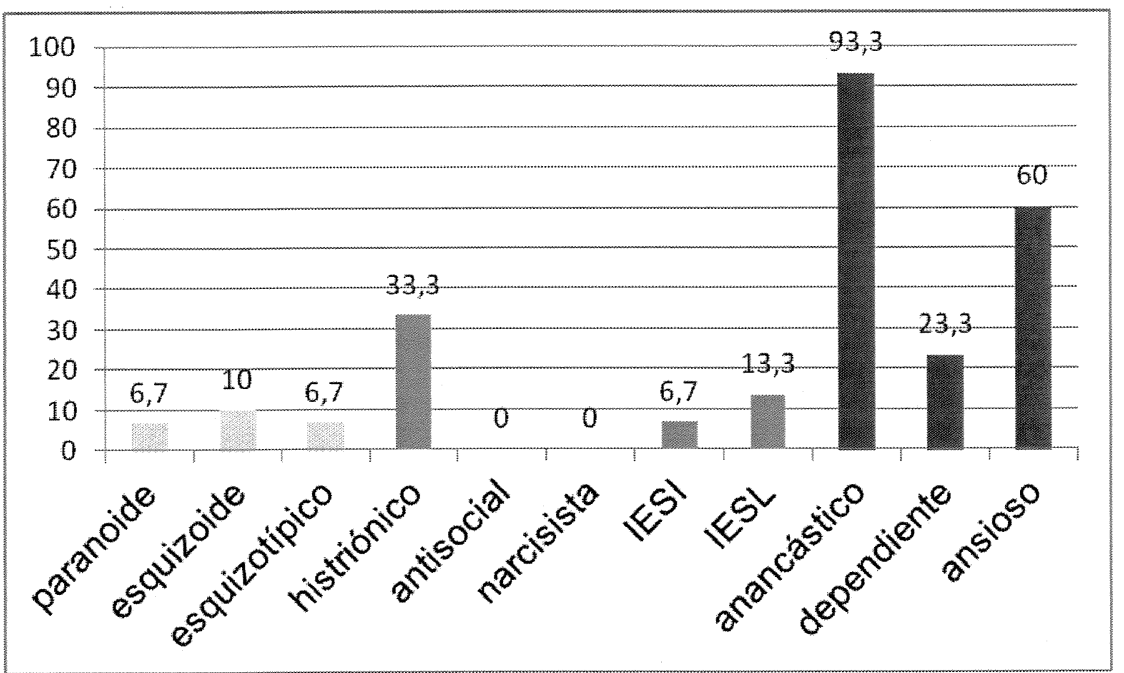

Figura 2. Frecuencia de escalas positivas en el MMPI-2 dentro de nuestra muestra.

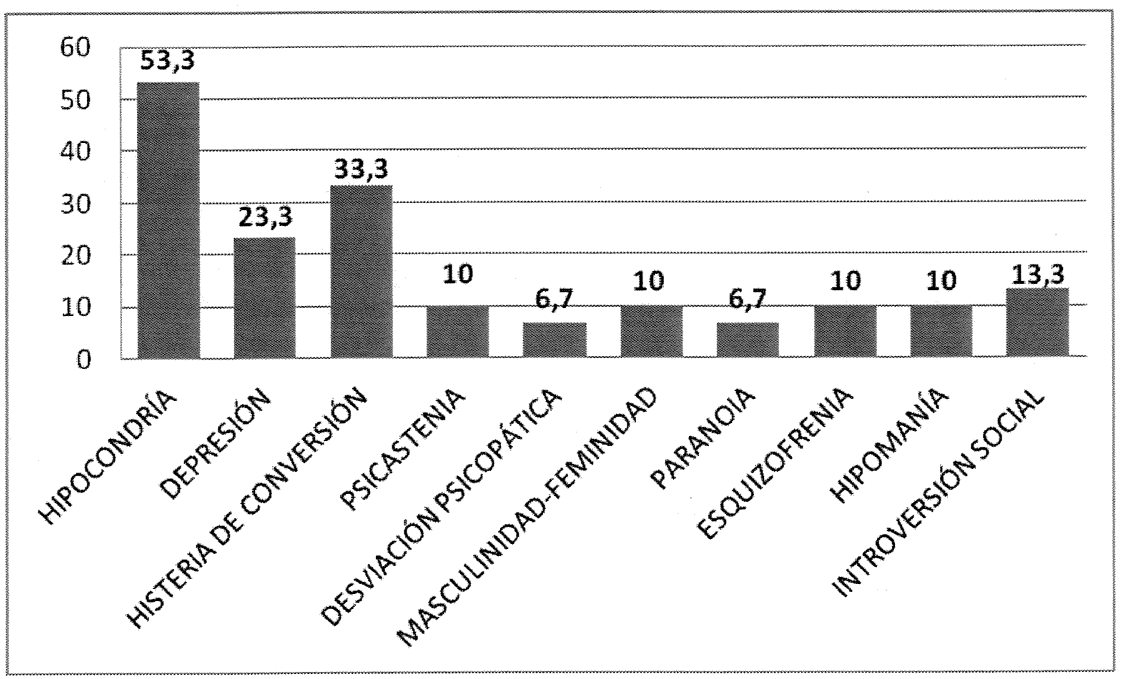




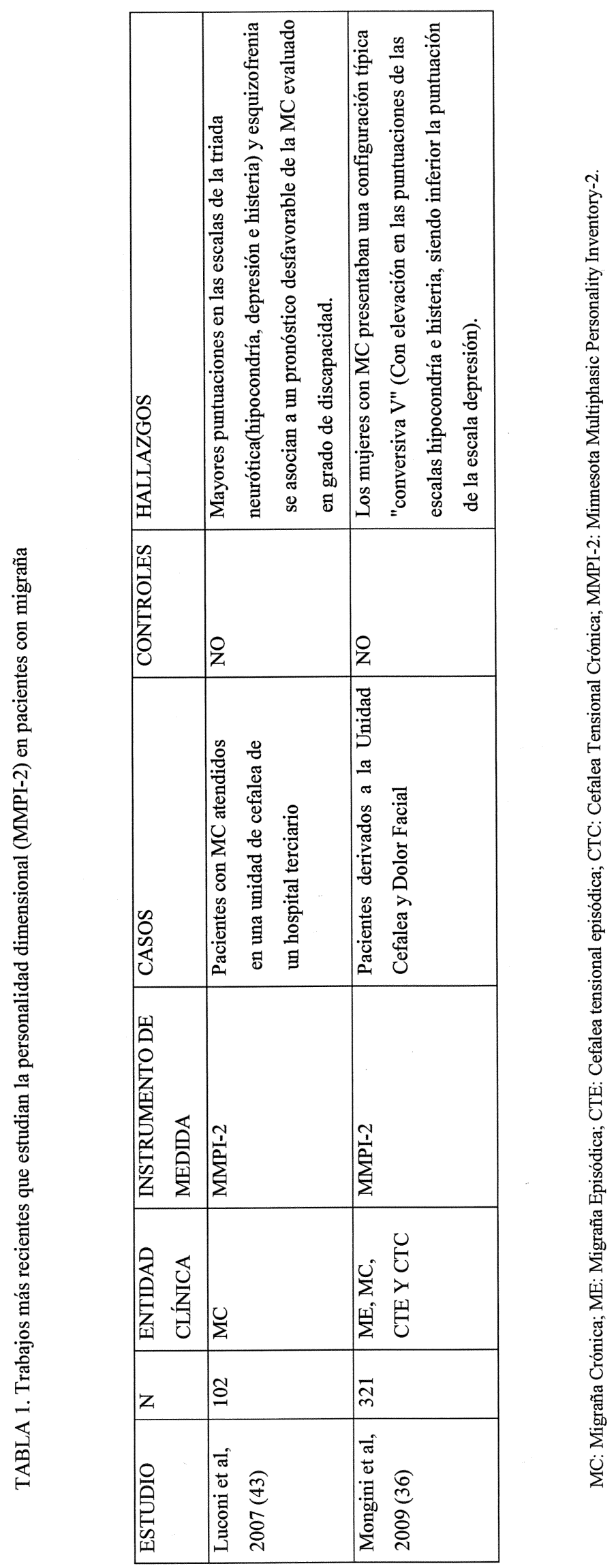




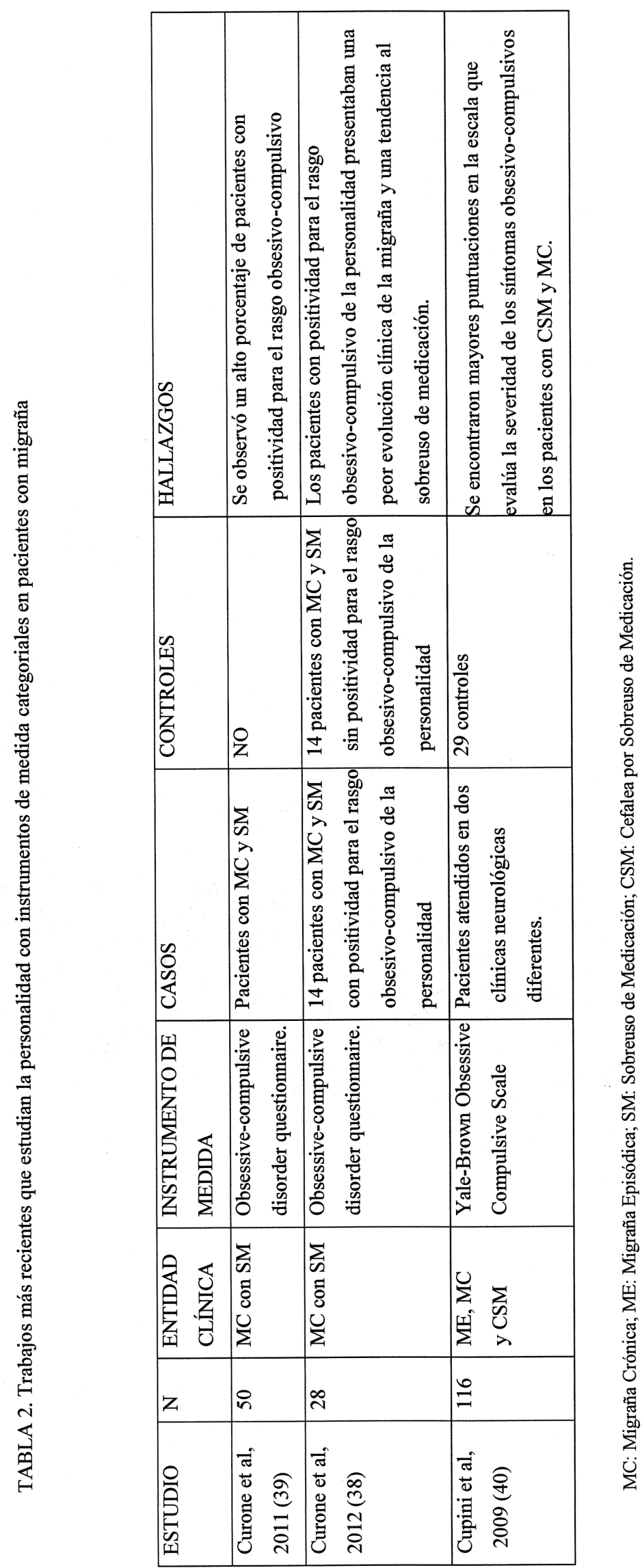


